\title{
Gage.
}

The Coccidae of lllinors 



\section{THE COCCIDAE OF ILLINOIS}

BY

JOHN HOWARD GAGE

\section{THESIS}

FOR THE

\section{DEGREE OF BACHELOR OF ARTS}

IN

ENTOMOLOGY

COLLEGE OF LIBERAL ARTS AND SCIENCES

UNIVERSITY OF ILLINOIS

1916 



\section{UNIVERSITY OF ILLINOIS}

May 25,

THIS IS TO CERTIFY THAT THE THESIS PREPARED UNDER MY SUPERVISION BY John.. Howard Gage

ENTITLED The coccidae of IIlinols

IS APPROVED BY ME AS FULFILLING THIS PART OF THE REQUIREMENTS FOR THE

DEGREE OF Bachelor of Arts

\section{Aleret. Nacyillivay}

APPROVED: Stghem a. fordar HEAD OF DEPARTMENT OF........ En tomology 



\section{Historical.}

The first systematic subdivision of the Coccidae was attempted by signoret in 1868. He divided the group into four subfamilies; the Diaspidae, Brachyscelidae, Iecanidae, and the Coccidae. During the same year Targioni-Tozzetti published his work, the stidii sulle Cocciniglie", in this publication four subfamilies are also described, however, the work of this writer differs from that of signoret $s$ in that he has divided the family into the Ortheziniae, Coccinae, Iecaninae, and the Diespinae.

Iittle was done towards arranging tables for the classification of the family after this time until Maskell published in the "Transactions of the New Zealand Institute", Vol. 28, 1895 , the results of his study of the family. In this work he divides the Cocciaae into the following subfamilies: the Diaspidiniae, Lecaninae, Eemicoccinae, Acanthococcinae, Dactylopinae, Idiococcinae, Monophlebinae, and Brachyscelinae.

In August, 1896, Professor T. J. A. Cockerell published a check list of the Coccidae, in the Bulletin of the Illinois state Laboratory of Natural History, Vol. 6. In this work he divides the family into ten subfamilies; the Honophlebinae, Porphyrophinae, Coccinae, Femicoccinae, Ortheziinae, Asterolecaniinae, Brachyscelinae, Idiococciinae, Lecaniinae, and Diaspinae. Three years later the same author published in the Canadian Intomologist, Vol. 31, "Tables for the Determination of the Genera of the Cocciale". In the later work this writer has included his former subfamilies Hemicoccinae, Idiococcinae, and Asterolecaniinae in the Coccinae: the Brachyscelinae are included in the Tachardinae, 



\section{CONTEITS .}

\section{THE COCCIDAE CE IHIIITOIS.}

I. INTPODUCTINI -

page.

Families of the Enmoptera li cadidae_... ...............................

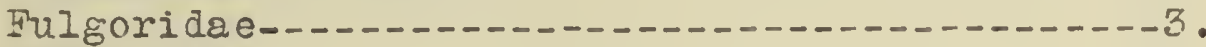

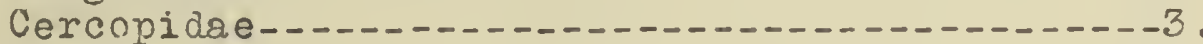
Jassidae Hembracidae_.........

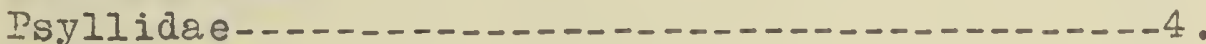

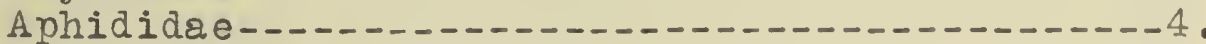

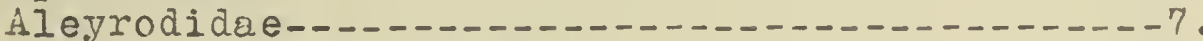

First Nymoiral itage

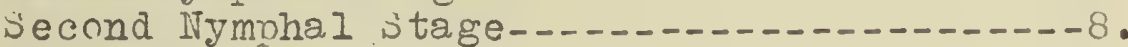

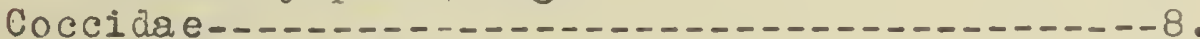

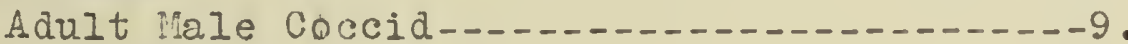

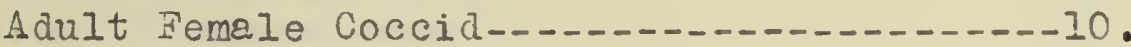
First Jymphal Stage second Nymphal stage....................

Historical ..........

II. OBJECT $\ldots \ldots \ldots$

III. MIATRIAIS-.......

IV. IIETHODS AIN TECHIIOUE-_.

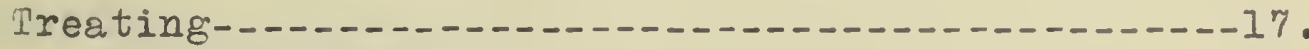

Chloroform ifethod............................

Glycerin-Jelly iethod_....................

Caustic Potash ilethod_..................... 19.

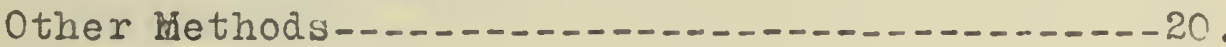

staining-...................

Dehydration_............

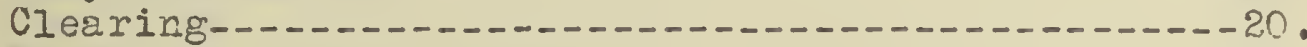

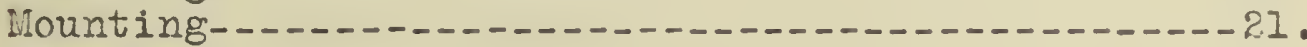

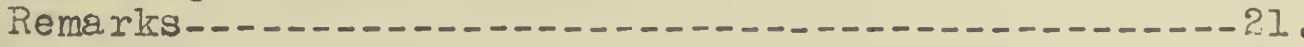

V. \TAIIIIIG -

tains-_.

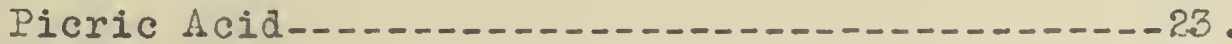

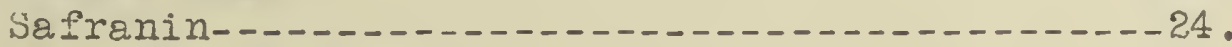

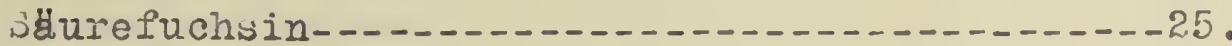

Defination of Terms-..........

Tabulation of Experiments With stains._.......-2.9.

Results of the Btaining Experiments............39.

Chemistry of staining 
Digitized by the Internet Archive in 2013

http://archive.org/details/coccidaeofillino00gage 
VI. EXPIANATION CF THRMSVII. CHASSIFICATION OE IHE COUCIDAE CF IIIIIOIS-...-.-.48. Pseudococcus Iongispinus-

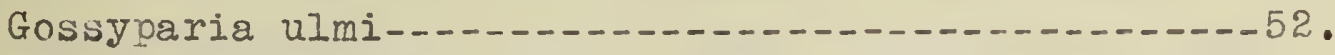
Parlatoria perigandii_... Aulacaspis rosae_....... Chionaspis americana Chionaspis corni-_. Chionaspis fiurfura

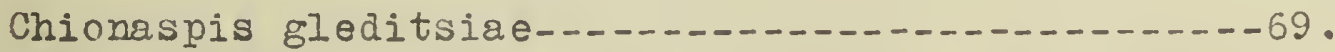
Chionaspis pinifolia Chionaspis salicis-nigrae

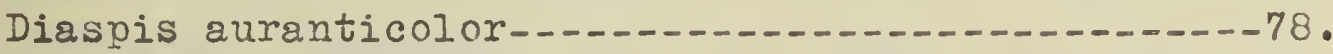
Iepidosaphes uImi-_... Aspidiotus ancylus... Aspidintus forbesi-_... Aspiảiotus fernaldi_..... Aspidintus hederae-1. Aspidintus juglans-regine_....................

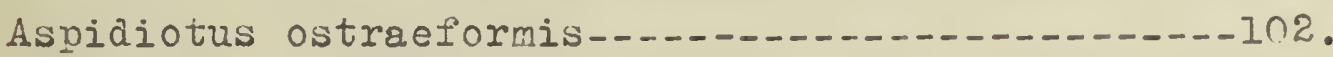
Aspidintus pernicosust_... Aspidiotus UImi-n... Chrysomphalus obscurus......................... VIII. ACRIOITLDGEMENTD_. PIATES - _.

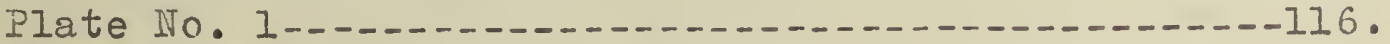

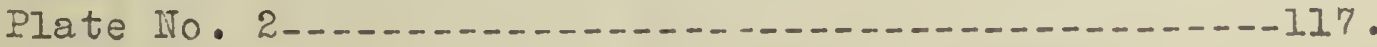





\section{IHTRODUCTICH.}

scale insects, mealy bugs, and bark lice, as they are commonly called, belong to the family Coccidae of the order Hemiptera. This order includes three suborders; the Heteroptera or true bugs; the Parasitica or lice; and the Homoptera or plant lice, leaf-hoppers, and scale-bugs. This latter suborder contains forms that show a very wide departure from the true honopterous type; the Coccidae are perhaps the most highly specialized family of the suborder. The Hemiptera have an incomplete metamorphosis, that is, after leaving the egg they do not undergo a complete change of form. Yet one finds in the Coccidse a very wide divergence from this type of transformation. In fact, entomologists are not agreed upon the type of metamorphosis of the male coccid. About ten per cent of the writers of this subject say that the male coccid has a complete metamorphosis, or undergoes a complete change of form after hatching; while on the other hand, the remaining students of the family contend that the transformation is incomplete and that the males have an incomplete metamorphosis. Since there is a complete change in the body form of the insect and since the wings are developed from wing-pads, one might have reasons for thinking that the metamorphosis is complete. The ejes of the adult male coccid also show a distinct change of form from the nymphal ejes; this characteristic might also be taken by some students of this family as being an indication of complete metamorphosis. However,there are exceptions to these typos in other species of the family, and one would have reasons equally as good for 


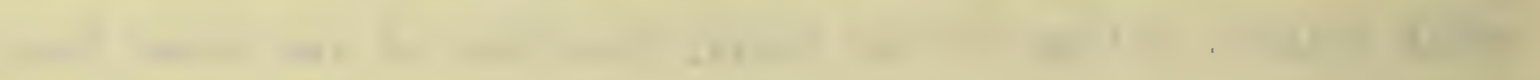

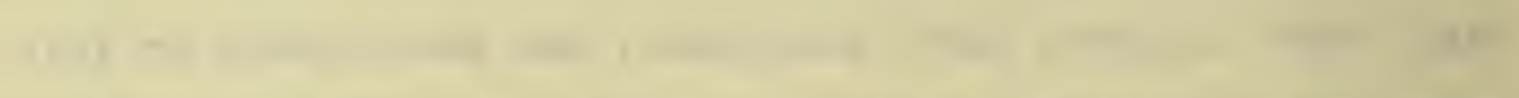

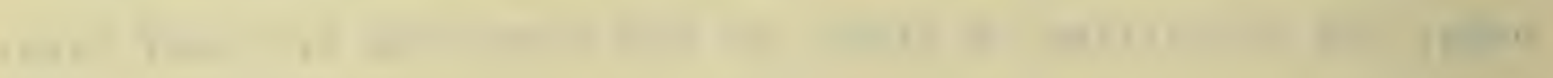

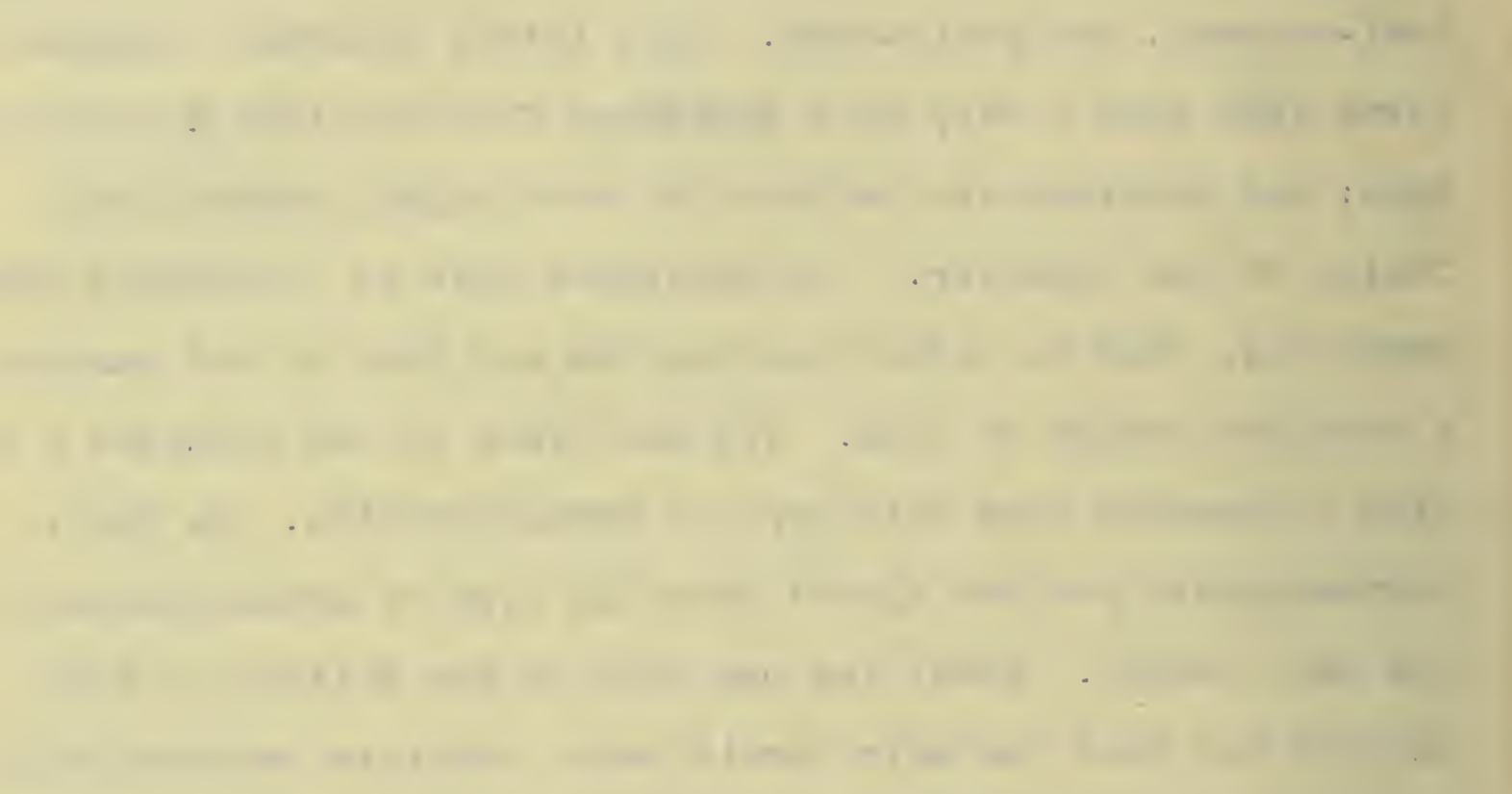

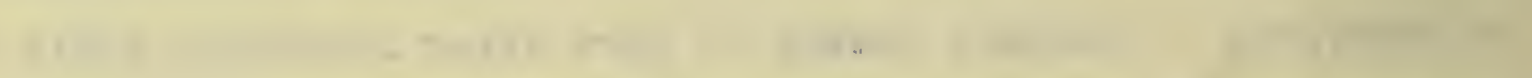

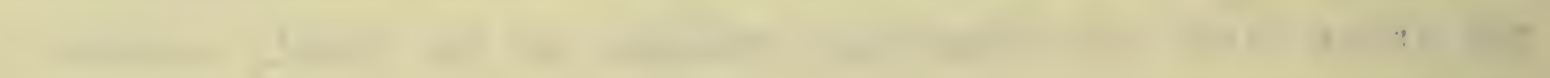

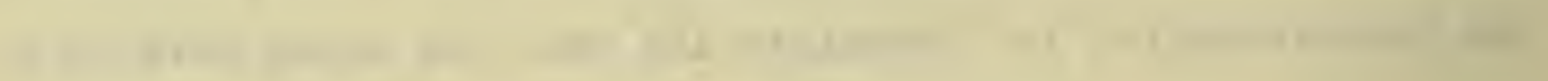

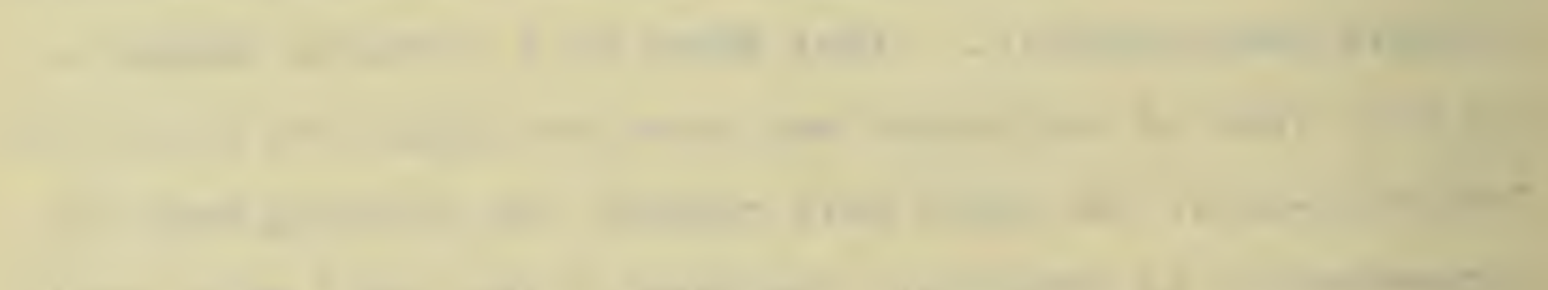

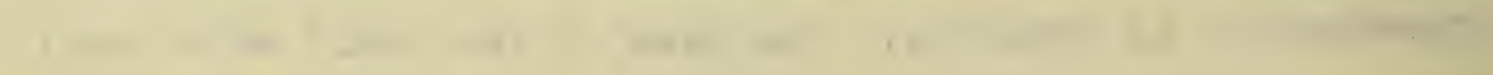

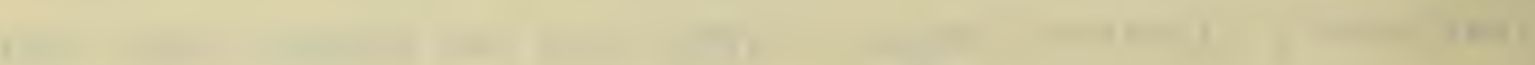
.

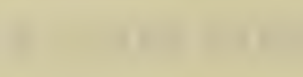

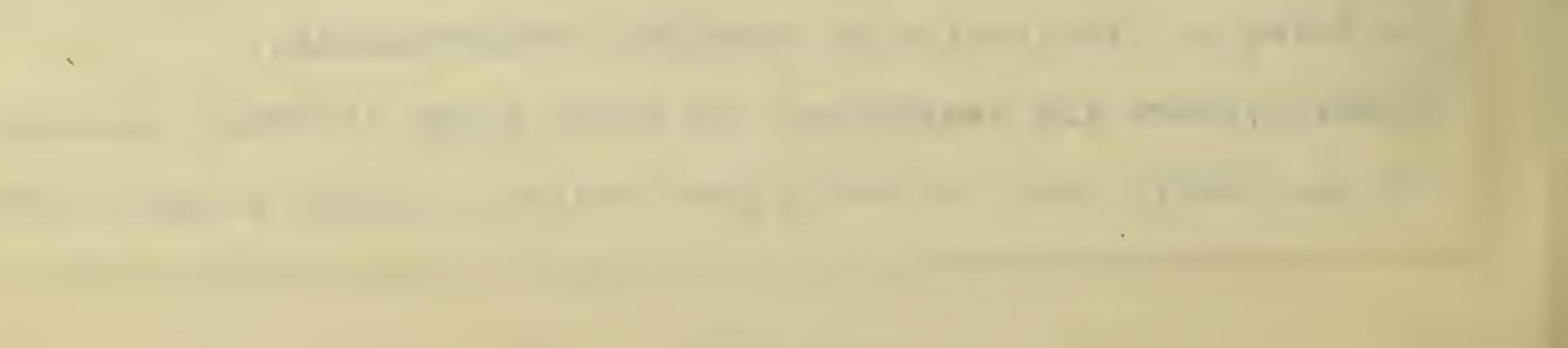


saying that the transformation is incomplete. Whether scientists wish to accept the incomplete type of metamorphosis for the group as a whole and consider those forms which have an apparent complete transformation as more highly specialized, or vice-versa, is not the purpose of this study. But for the sake of clearness we shall in this paper consider the metamorphosis of both male and female of this family as being incomplete.

Before going further into this study, let us take a brie? resume' of the suborder Homoptera. The suborder includes insects that have a somerhat triangular head and a rostrum which arises Irom the hinder part of the lower surface. The mouth-parts are formed for piercing and sucking, and are attached adjacent the first pair of legs. They usually appear as a slender pointed rostrum arising at the base of a shorter pointed upper ip or labrum. This rostrum consists of a Pleshy, jointed sheath which encloses four bristles. Two of the bristles represent the mandibles and two the maxillae. The rostrum oroper is formed by a modification of the Inwer lip or labium. The antennae are awIshaped and consist of only a few segments, the eyes are usually compound, and ocelli are frequently present. There is usually a distinct constriction between the head and the thorax: The thorax bears five pairs of appendages; three pairs of legs which have tarsl consisting of three segments, two pairs of wings which are usually membranous. The name of the suborder is derived from two Greek worảs: homos, same; pteron, a wing. That is the wings are of the same thickness throughout. 

Families of the Homoptera.

The Homoptera is usually divided into nine families as follows:

Cicadidae.- Insects with three ocelli, and the males usually possesilng musical organs. The members of this family are usually large and possess wings that are entirely membranous.

Fulgoridae.- Insects in which only two ocelli are present, the males are without musical organs, and the antennae are inserted on the sides of the cheeks and below the eyes. This family contains the lantern Plies.

Cercopidae.- The members of this family have two ocelli, the males are without musical organs, and the antennae are inserted in Iront of and between the eyes. The prothorax is not prolonged above the abdomen. The hind tibia is armed with one or two stout teetin and the tip is crowned with short spines. This family includes the sittle-insects or frog-hoppers.

Jassidae.- In this family the members also have two ocelli present, the males are vithout musical organs, and the antennae are inserted in front of and between the ejes. The prothorax is not prolonged above the abdomen. Whe hind tibia have a row of spines below, but are without teeth. These insects always have a rather slender body. The family includes the leaf-hoppers.

Membracidae.- The ocelli in tinis family may or may not be present, but when present are always two in number, the males are without musical organs, and the antennae are inserted in front of and between the eyes. The prothorax is prolonged into a point or horn above the abdomen. The family includes the tree-noppers. 

Pspllidae.- The psgllids usually have three ocelli present, the compound eyes are prominent and globular. The antennae are present, they are usually very prominent and thread-like and consist of nine or ten segments. The rostrum arises between the prothoracic legs, and is borne on the ventral surface of a somewhat triangular-shaped hoad. These insects have three pairs of legs, the tarsi of which have two segments. The metathoracic legs are fitted for jumping. The psyllids have two pairs of rather delicate and transparent wings. The members of this family are commonly known as jumping plant-lice, and resemble a very small cicada.

Aphididae.- The members of this family usually possess three ocelli, and compound ejes which are prominent and globular. The antennae are attached on the front of the head and consist of from three to seven segments. The rostrum arises between the first pair of legs, it varies greatly in length, but is alwags composed of three segments. The wings may or may not be present, but when present always consist of two pairs and are very delicate, transparent, and contain a few simple veins. The first pair of wings is always larger than the second pair; the two wings of each side are usually connected by a compound hook which is a part of the hind wing and fits into a pocket on the caudal margin of the fore wing. The legs are long and slender and are not fitted for jumping. The tarsi consist of two or three segments. On the dorsal surface of the sixth abdominal segment, in many species, there is a pair of tubes through which a wax-like 

material is excreted. These tubes mag be entirely absent in some genera, while in others they may be very highly specialized. The members of this family are commonly known as aphids or plant1ice. These insects are quite well known and may be found on nearly all kinds of vegetation in all parts of the country. Perhaps the most common form we are acquainted with is the green aphid. These are minate, soft, green bodied insects having long legs and antionne. As a rule, these aphids may be found in abundance on nearly all of our house and field plants. Among our common species are found both winged and wingless forms. Aphids excrete a substance commonly lnown as honez-dew. This substance is excreted from the posterior end of the alimentary canal. Where plant-lice are numerous the honey-dew is sometimes produced in such great quantities that it forms a glistening coat on the leaves and branches of the host plant. Honey-dew is eaten by ants, bees, and wasps; hence one generally finds great numbers of ants near an aphid colony. In addition to the honey-dew some species of aphids secrete a white waxy substance which is usually scattered over the body; in some genera, however, this powder may be collected so that it forms large flocculent and dormy masses.

Most plant-lice exhibit a very remerkable mode of development, and the species vary widely in the details of their transformations, however, the following generalizations may be made.

There are several distinct forms in each species, each one of these forms plays a peculiar part in the life history. If one should examine a colong of plant-lice during the summer 


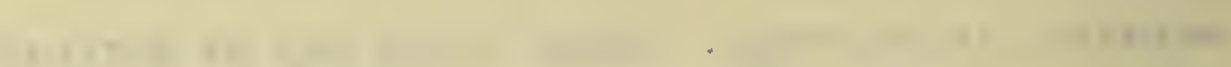

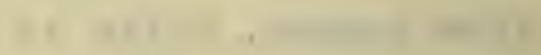

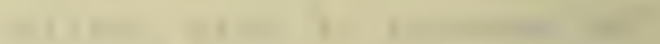

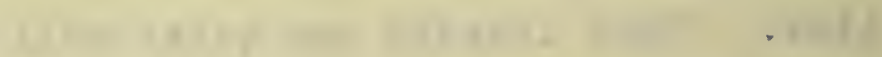

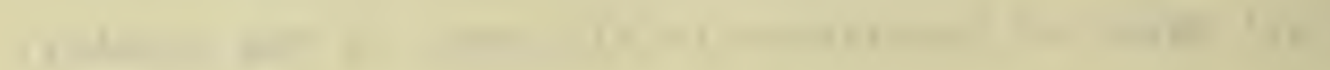
(1) , $\quad$. (2)
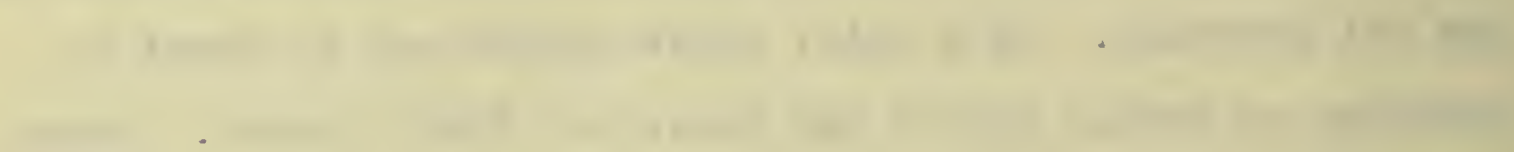
. . , en (1) $+7$

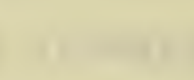
10

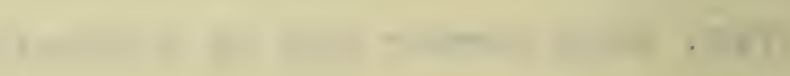
$\therefore$

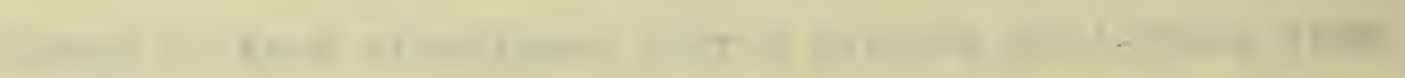

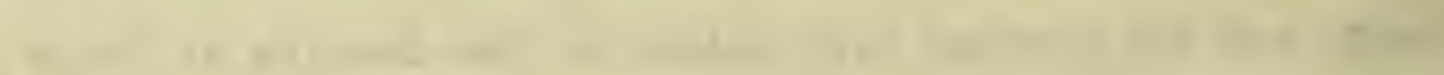

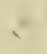

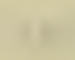


months, there would usually be found a very large number of wingless individuals, these are the female aphids, which reproduce without the intervention of the males. Entomologists call this stage of the insect the wingless agamic form. Upon a study of these forms it will be found that in many cases the females give birth to living young, instead of laying eggs. Since this is true, the process of reproduction becomes so rapid that it would be disasterous to the life of the colony; for the host plant would be destroyed and the individuals starve if another form of the species did not arise: But at various intervals joung are produced which are winged, thereby providing for the spread of the species. This winged form consists of females, and is known as the winged agamic form. These migrate to a new locality and in turn produce females of the wingless agamic form, hence, we have a new colony of aphids formed. When the supply of food becomes low or cold weather sets in, there is produced a generation of males and females known as the sexual forms. The males may or may not be winged but the females are never winged. These sexual forms pair and the female produces one or two eggs which are known as the winter eggs. In the spring an agamic female hatches Prom these winter eggs and this female is termed the stem mother since she is the stock from which the summer generation springs. This peculiar method of the reproduction of wingless agamic forms is often called buding. Not only do plant-lice vary in their methods of reproduction, but they alse/ their maner of living and in their habits. Certain species burrow in the ground and Iive on the roots of plants, while other forms live exposed on 


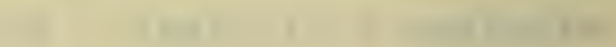

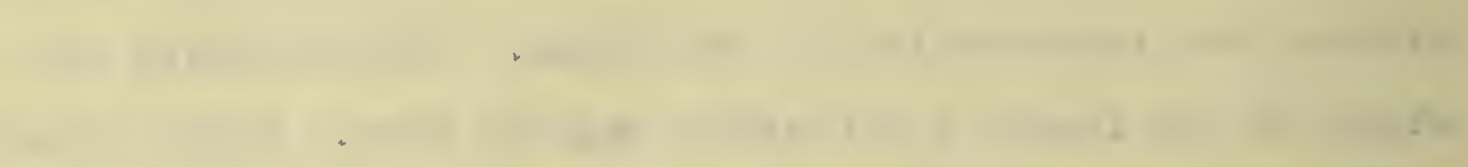

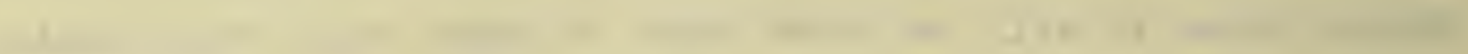

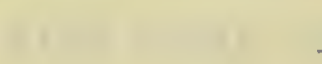

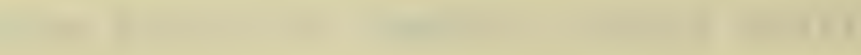

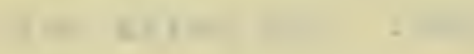

-

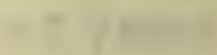

-

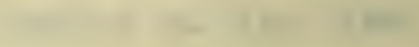

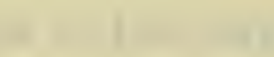

,
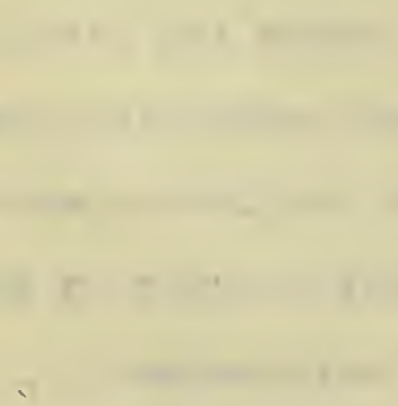

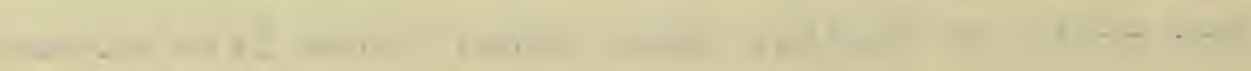


the tender shoots and leaves of their host.

Aleyrodidae.- The members of this family have compound eyes, which are oval in form and are located on the sides of the head. The antennae are present, they consist of seren segments, and are inserted in front of and between the eyes. The rostrum arises between the prothoracic legs, it is short and consiets of three very distinct segments. The head is triangular in form and is bent downard so that it appears to be on the ventral surface of the body. There is a distinct constriction betrecn the head and thorax. The thorax bears five pairs of appendages; two pairs of wings, and three pairs of legs. The wings are alvays present in both male and female, they are long, slender, and membranous; both of their surfaces,as well as the body itself is covered with a wax-like powder which renders them noaque. The wings are carried horizonally when at rest and their inner margino never overlap. The legs are always present, and they bear tarsi consisting of two segments. The wax cornicles are wanting.

The young aleyrodids show two very distinct nymphal stages.

The First Nymphal stage.- The insect has a greenish glossy appearance. Neither the eyes nor the ocelli are present. The antennae are wanting. The rostrum is present and is very distinctly segmented. There is no indication of a head, consequently, the constriction between the head and the thorax is wanting. The wings and legs are also absent. The body is oval in form. There is no wax-like secretion present at this stage. On the caudal portion of the insect there is a distinct opening known as 

the vasiform orifice. This orifice is alwags present and. characteristio of the family.

Siscond IJymotel Stage.- During this stage of development the I and the antennae are absent. The mouth-parts are the same in this stage as in the first nymphal stage. There is no indication of a head and the thorax is also wanting. The wings and legs are wanting, however, one finds indications of the developing appendages of the adult. "The body form is plump and is some larger than in the preceeding stage. The wax secretion is present and comes from a series of pores arranged around the margin of the body in the form of plates which tend to fasten the insect to the host plant. The vasiform orifice is always present in this stage. The members of this fomily show a very great resemblence to the Coccidee and until recently were classified as such. In their immature stages they resemble a species of the genus Lecanium, but in their mature stagea they exhibit such a great difference from the coccids, that the group has been seperated as a distinct family. The adults are insect-like in form; having three main body divisions; head, thorax, and abdomen.

Cocciare. This family shows the most remarkable variation from the true hompterous type. The wings of the typical Homoptera are carried roof-like, that is, they slope upward and inward and their inner margins meet above the midale of the back and do not overlap. In the Coccidae, however, we can judge this character only in the winged males, and in these the wings are carried horizonally above the back of the insect. when they are at rest. Furthermore, the wings are not only carried horizonally, but they 


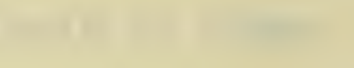

i

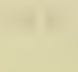

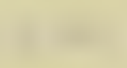


frequently overlap each other. This is a very distinctive character of the Heteroptera, or true bugs; and is found in no other Iamily of the Homoptera.

Adult male coccid.- The ejes of the adult male coccid have undergone a remarisable change. The true eyes have apparently disintegrated and formed a series of simple eyes ranging in number from two to sixteen. These small eyes resemble ocelli, and might easily be mistalien for them; hovever, upon a detailed study they are found. not to be ocelli, but single simple eyes. Their position on the head varies among the subfamilies. In some cases where they are very few in number they may all be located on the dorsal sarface of the head; in other cases they may be distributed upon the dorsal, ventral, and lateral surfaces. The antennae ate present and consist of seven to ten segments, and are inserted upon the cephalic aspect of the head. The rostrum is very small, and the mandibles and maxillae are wanting. There is a distinct constriction between the head and the thorax. The thorax bears five pairs of appendeges; three pairs of legs, one pair of wings, and a pair of club-shaped organs wam as halteres; these are probably derived from the second pair of wings. These halteres are provided with small hook-like bristles which fasten into a pocket on the caudal margin of the front wings. The front wings are very delicate, membranous, and contain a very fev simple veins. While the above generalizations as a rule are true, nevertheless a few apterous male forms have been found and described. ITowstead lists the male of Ponscolombia fraxinit in Vol. II, of his work," The Monograph of The British Coccidae", while in 

Vo1. 23, "Transactions of The New Zealand Institute", pages 8,9 Maskell gives the following list of apterous male coccids:

"Aspidiotus (?t sabalis, Comst., Necond Cornell Uni. Rep. 67. Chionaspis salicis, Iinn., Bouche stett. Ent. Zeit., 1884,294. Chionaspis fraxinus, sig., Newstead.

Chinnaspis alni, Sig., Newstead.

Chionaspis dysoxli, Mask.,New Zealand Trans., Vol.22, 163. Leucaspis pusella, Ibr Wiener Bnt. Zeit., Vol.2, 1893. Ericoccus (Acantbococcus) aceris, $58 \%$. Wiener Ent. Zeit.,

$$
\text { Vol. 2, } 1883 .
$$

Iecanium hesperidum, Moniez Comptes de l'Academy des sciences, Feb., 1887 .

Ericoccus hoheriae, Mask., New Zealand Trans., Vol. 23. Sometimes only rudimentary wings are found in the following forms:

Gossyparia ulmi, S1g., Essa1 sur le Cocc., 320.

Iechia zelandica, Mask., Ner Zealand Trans., Vol. 23."

The legs are always present, the metathoracic legs are not modified and the tarsi always consist of ne segment and a single claw. However, an exception occurs to this in the genus ollifiella described by Professor Cockerell, and in the genus Exaereptopus; in these two cases the tarsi have two segments. The cornicles are always wanting.

Adult female coccid.- In the female coccid the eyes may or may not be present, but when present they are always simple and two in number. The antennae may or may not be present, but when present they always consist of a very small number of segments, or they are represented by a small tubercule. The rostrum arises 

between the prothoracic legs; the mandibles and the maxillae are very well developed. There is no constriction between the head and the thorax. The wings are never present; the legs may or may not be present, when present, they rarely project beyond the margin of the body. The tarsi always consist of a single segment armed with a single claw. The body-form varies in the different subfamilies from a globular to a very thin plate-like structure. The females are usually provided with a series of wax glands and it is from these that the waxy substance is secreted. The plan or the arrangement of the gland orifices, and their secretions varies among the subfamilies. The females in some species are active throughout life; while in others they become fixed to the surface of the host and do not move after the first nymphal stages. The vasiform orifice is always wanting.

First, Nymphal stage.- In this stage of the development the eyes may or may not be present, but when present the $y$ are always simple. The rostrum arises between the prothoracic legs and bears the well developed mouth-parts. The antennae are always present and are provided with rather long, stiff setae. The head is present but there is no constriction between the head and the thorax. The wings are never present; while the nymph almays has three pairs of long legs which are provided with long setae. The body form is cenerally oval, and in comparison to the length of the legs is very small. The abdomen at this stage is distinctly segmented.

second Hyphal stage.- During this stage in the development of the female the eyes are present as in the first nymphal 


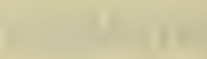

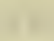
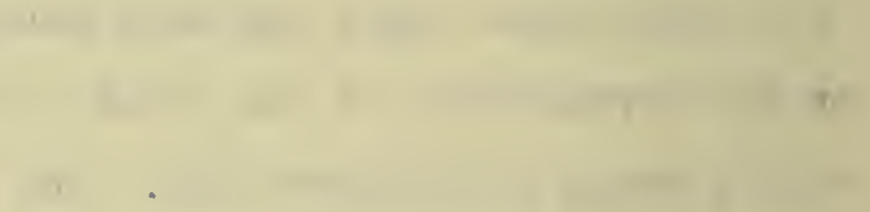

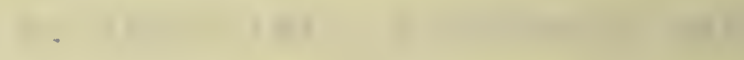
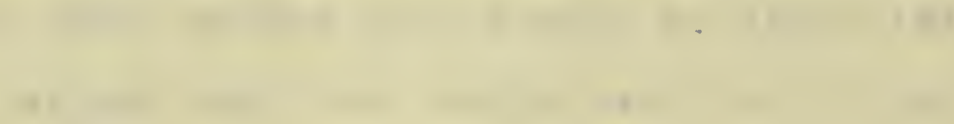
stage. The antennae are wanting or are reprosented by a tubercule. The rostrum and the mouth-parti remain as in the first nymphal stage. There is no further modification of the head. The wings are not present, and the legs have become very much shorter, in comparison with the size of the body. The segmentation of the abdomen is much less distinct.

The number of moults ana nymphal stages varies among the subfamilies. In the subfamily Diaspinae the males become quiescent at the end of the second nymphal stage, while in the Erriococcinae they do not become quiescent until the third nymphal stage, and in the Monophlebinae quiescence begins during the I0nurth nymphal stage. The period between the nymphal stages is spoken of as the period of moulting. About the time the male nymph goes into the quiescent stage it spins a coconn of wax filiaments about itself and then moults or casts its skin, after this the nymph becomes quiescent. During the period of quiescence there appears a great transformation in the insect, it looses its mouth-parts, its legs and antennae are develojed externally, wing-pads also begin to appear externally and gradually the quiescent/ takes the form of an insect pupa. In a short time it emerges from the quiescent as stage/ an adult coccid. The life history and the degrees of specialization of certain parts are quite noticable between various groups of the family, thereby afiording a systematist a good basis for dividing the family into subfamilies. 

and the Porphyrophorinae are included in the Margarodinae. Wile it will be noticed that Professor Cockerell has combined some of his former subfamilies, he has nevertheless, presented three aditional subfamilies, the Conchaspinae, Tachardiinae, and the Margarodinae. The subfamilies, then, that he describes are: Ortheziinae, Monophlebinae, Margarodinae; Conchaspinae, Diaspinae, Tachardinae, Lecaniinae, and Coccinae. Hence, it will be seen that in this later work Professor cockerell has decreased the number of the subfamilies by two.

During the same year that Professor Cockerell published his "Check Iist of the Coccidae", Mr. 3. . Green published his work "The Coccidae of Ceylon". In this work Mr. Green divides the family into the following subfamilies: Conchaspinae, Iecaniinae, Lemicoccinae, Dactylopiina, Tachardinae, Coccinae, Idiococcinae, Brachyscelinae, Orthezinae, Monophlebinae, and later in the fifth volume of this work he divides the Dactylopiinae into the Dactylopiina and the Astreolecaniinae.

In 1900 Newstead published his work, "A Monograph of the British Coccidae". In this work Mr. Mewstead bases the division of the family on the characters of the adult male insect, and describes twelve subfamilies, namely; Diaspina, Conchaspinae, Lecaniinae, Brachyscelinae, Ortheziinae, Largarodinae, Hemicoccinae, Dactylopiinae, Tachardinae, Idiococcine, Coccina, and Monophlebinae. In the same Jear Kuwana published tables for the identification of the Coccidae in his work on"the Coceidae of Japan". Kurana des. oribes five subfamilies, however, he divides these subfamilies into tribes. It is evident from his work that this writer did not think 

the characters used by some of the previous writers were of sufficlent importance to warrant their separation as subfamilies. This writer describes the following subfamilies: Monophlebinae; Margarodiinae which he divides into two tribes, the Margarodini and Xylococcini; Coccinae which he divides into four tribes, the Asterolecanini, Kermesin1, Eriococcini, and Dactylopini; the Lecaniinar, and Diaspinae.

In 1903 irs. M. S. Fernald published the first catalog of the family, "The Coccidae of the Forld", and in this work she divides the family into nine subfamilies. In her woris she also bases the distinctive characters on the adult male insect. The subfamilles she describes are ilonophlebinae, Margarodiinae, Orthezinae, Phenacoleachiinae, Conchaspiinae, Dactylopiina, Tachardina , Coccina, and Diaspinae.

From the foregoing résumë of the aivision of the family one can easily see that entomologists are not at all agreed upon the number, and the characters for dividing the family into subfamilies. It is beyond all doubt that a more detailed study of specimens that heve been prepared in a more modern way, I refer to the use of stains), will disclose a number of characteristics that will tena to clear away some of the doubt that is in the minds of the students of the family. In this paper, however, the writer will follow the subdivisions as proposed by Irs. Fernald. 



\section{OBJECT.}

The original object of this study was to identify the Coccidae of Illinois, and as far as possible, to determine the number of species and their distribution tnroughout the state, also to identify the host plants upon which each species occurred. But owing to the fact that nearly all of the specimens collected were members of the subfamily Diaspinae, the study has been confined almost wholly to this subfamily. It was not the original intention of the mriter to include in this study any of the green-house species, but owing to the rather common occurrence of some species, a few of the more common forms have been studied. In adition to the above stated object, the writer had in mind to devise some means, it poisible, to make the study of the members of this family less difficult and more accurate.

\section{MATERIAIS.}

Collecting and preserving the specimens.- Specimens of scale insects were collected at large over the state during the summer months of 1913, 1914, 1915, and in the early part of 1916 at which time the writer was engaged in nursery inspection for the office of the State Entomologist. It would seem, therefore, that practically all of the species of coccids, at least those that are of economic importance, would be contained in such a collection. The specimens were removed from the host plant and sealed in small spocimen envelopes. On these envelopes the locality, owner of the host, the host plant, the extent of the infestation, the date of collection, and the collector were written. The specimens were 

then packed in empty cigar boxes. Then these boxes were full, three of four napthaline balls were placed in each box and the covers were then firmly fastened. The napthaline balls were used to insure the specimens against the destructive work of museum pests. The specimens were then stored avay until a further study could be made.

Cther materials.- One who wishes to make a detailed study of this family must have a complete laboratory equipment, includreagents and microscopes. A leitz binocular was used in preparing the mounts studied in this work, while for a more detailed study of the insect, a Ieitz compound microscope with three objectives and a complete set of oculars was used.

In adition to the above stated materials, a student of this family must have an unlimited reserve of patience and perserverance, for the classification of the coccida 1s/a small problem and requires the most accurate observation of minute details.

\section{METHODS AID TECHIRUE.}

Treating.- Before a detailed study, that is a microscopic study, of any coccid can be made it is necessary to clean them. During this process all of the solt parts of the body, together with any waxy or greasy secretions that may be present, must be removed. This leaves only the chitin which is more or less transparent. Specimens may be treated in the following manners:

Choloform method.- This method does not destroy the soft parts of the body, for the choloform only dissolves the wax that may be present on the external surface, clears the tissues of the 

body and also the thinner parts sufficiently to ake them transparent. The method has the disadvantage in that it leaves the thicker parts opaque; moreover, specimens that are dry and shmiken cannot be successfully treated because tine choloform does not cause any swelling of the specimen. However, this method has the advantage of requiring a very small amount of handind the specimens, for they are simply placed in the choloform and alloned to remain there until they are sufficiently clear and then mounted in balsam. Since choloform is missible in balsam, the specimens can be mounted at once.

Glycerin-Jily method.- This method is of little or no practical use in the laboratory: however, it is useful when one desires to make mounts in the field, for, it admits of a quick preparation. The method can be used to best advantage only with live specimens; however, dryed specimens may be treated if they are boiled in water a few moments to soften them. Specimens to be mounted in this manner are placed on a microscope slide and near them is also placed a small particle of glycerin-jelly, the slide is then gently heated over an alcohol lamp allowing the jelly to surround and completely penetrate the specimens, then a cover-glass is pushed down upon them. The cover-glass should be pushed down as firmly as possible, for in doing so the specimens are flattened out and made more nearly transparent. The method has the advantage of being easily used in the field, and of requiring that the insects be handled but \& very little for one does not need to use alcohol, xylol, or balsam. But on the other hand, it is of little or no use with any of the coccids except the members of the sub- 

family Diaspinae.

Caustic potash method.- This method admits of two modes of procedure, the fast and the slow.

specimens that are to be prepared by the fast method are placed in a cold ten per-cent solution of potassium hydroxide. This solution is then heated gently, or it may even be boiled. The heating tends to hasten the process of cleaning; however, there is a great possibility of the specimens being distorted, some of the minute hairs of the pygidial fringe may be broken off, consequently, the preparation will be of no taxonomic value. In using this method, one needs to treat the specimen for only a fer moments in the in the potassium solution; however, it seems that the disadvantages of this method are so much greater than ito one advantace, the economy of time, that it shoula not be used unless one is in great haste and does not care for a carefully preserved specimen. After the insects have become sufficiently clear, they should be thoroughIy washed in two or three changes of distilled water, after which they are ready to be dehyarrated.

If one chooses to prepare the specimens by the slow method, a few cubic centimeters of cold ten percent potassium hydroxide are pored into a watch-glass, the specimens are placed in this solution and allowed to remain there until they are sufficiently cleared for study. This process may require only a few minutes in some sases, while in others it may require two or three weeks. After the specimens are sufficiently clear they should be removed from the potassium hydroxide and washed in distilled water as in the fast method. The specimens are now ready for dehydration. 

The potassium hydroxide destroys all the parts of the body except the cuticular covering; hence, when one studies a specimen prepared in this manner, he is in truth studying only the skeleton of the insect.

Other methods.- There are several other methods of cleaning insects, however, I shall only mention them. They are the beechwond-creosote method, the sulfuric-ether method, the alcoinl method, and the acetic-acid method. These are only short cuts and should not be used if one wishes to make a close and detailed study of the specimens.

Staining.- If one wishes to stain the specimens, it can be done, to the greatest advantage, at this point of the preparation. The process of staining will be treated at length later in this pa per.

Dehydration.- After the specimens have been thoroughly washed and stained, they should be dehydrated. This is best accomplished by allowing them to remain in a ninety-five per cent, or, still better, absolute alcohol for an hour or so. This process removes all of the water that may be present in the specimen.

Clearing.- After the orocess of dehydration is complete, it is necessary to treat the specimens with a solution that is missible in both alcohol and balsam, since the specimen is to be mounted in balsam. Many substances may be used as clearers, but in my experiments and work, carbol-xylene has given the best results. This clearer is prepared in the following manner:

Carbolic acid crystals......... I part.

Xylene..................... 3 narts. 

This preparation was then set aside to be used as the occasion demanded. Carbol-turpentine, oil of cloves, and oil of wintergreen may also be used as clearers; but they have not given as good results as the carbol-xylene. In order to clear the specimen most successfully, the dehydrated insect should be put in a watchglass containing carbol-xylene and allowed to remain there at least an hour. There is little danger of leaving the specimen in the clearer too long. After this process is completed the specimen is ready to be mounted.

Nounting.- In this process the specimen is removed from the watch-glass containing the carbol-xylene and placed on a microscope slide which has been moistened with a few droos of the clearing solution. Then without allowing the specimen to become dry a cover-giass which has been moistened with xylene-balsam should be dropped upon the insect, this cover-glass must then be pressed down firmly. The prepared mount is now ready to be set aside to dry. The slides wore then lablod and numbered, and the data on the specimen envelope wa carefully recorded under a number corresponding to that on the slide and specimen envelope. The slides were then stored in a regular microscope slide case, containing one hundred preparations, to await further study and to be identified.

Remarks.- Nounts of scale insects, no difference by what method they are prepared, should always be made as thin as possible, inasmuch as they admit of greater ease of study and the use of high power microscopldobjectives. In transferring the specimen from one solution to another or placing them on a silde, a par of 

forceps having a fine curved point/ has been found to be the best instrument to use. With these forceps the specimen may be removed with a small portion of the fluid between their points. In specimens that have been handled in this manner there is the minimum danger of their being mutilated.

\section{STAINIIGG.}

Up to the present time the practice of staining Coccidre in toto as an aid to taxanomic study has not been adopted in this country; nor, has it been practiced to any great extent in Iuropean countries. Iewstead mentions the use of stains in his "Monograph of the Coccidae of the British Isles", and in the preparation of his specimens he used a stain whenever it was possible. Mr. E. E. Green, another English student of this family, also mentions the use of stains in his work " The Coccidae of Ceglon". He says, " I would strongly recommend the staining of all the more delicate objects. Unexpected characters will often be revealed by this means and it will help to clear up many doubtful points. If there is any question about the number of joints in the antennae, or the hairs on the anal ring, the adition of a stain will usually make them perfectly distinct."

Both Green and Newstead were pioneers in the use of stains so far as the writer has been able to ascertain and their woris shows that they were not able to get the heavier parts to take the stain: especially is this true in the case of the pygidial fringe. In their work they used an alcoholic solutinn of Gratshers Hagenta; however, Green recommends the use of any of the 

aniline dyes or even red ink. It will be seen that both of these writers have divided the family into more permanent subfamilies than any worker who: studied the family before them, their contemporaries, or with one or two ezceptions, those who have studied the family since the publication of the above named works. This of course may be due to many causes, but it would not be out of place to account for part of their success, at least, to their use of stains.

Host attempts to stain the chitinous covering of insects, as a whole or in part, have given but very little permanent success. Chitin is a very difficult substance to color and in fact only a few of the ordinary stains will effect it. In most cases where the chitin does take the stain there is a general complaint that the color fades, or, on the other hand, that it is not bright, clear, and definite.

Stains.- In his work with the Cocciale the writer has experimented with three staining substances, picric acid, safranin, and sthurefuchsin. All of these materials gave a fair degree of color, however, it was not permanent.

Picric acid.- A stock solution of this stain was prepared as follons:

Picric acid crystals........... 2n grams. Absolute alcohol.............. Ino ce. This solution was then set aside to be used as the occasion demanded. In using this stain the process of dehydration and staining were combined and equal amounts of the solution and alcohol were used. The specimens were allowed to remain in this solution 

two or three hours, then they were transferred to the carbolxylene clearer. Picric acid gives the specimens a light yellowish green color: however, it produces a rough ground stain and affords but little contrast. It does not color the marginal spines or plates, hence, its chief value is only that of a ground stain. Safranin.- A stock solution of this substance was made as follows:

Safranin ................... 5 grams.

In using this stain dehydration and staining were likewise combined; one part of the solution and five parts of absolute alcohol were used. The specimens pere left in the solution at least two hours and then removed and the excess of the stain was washed off in absolute alcohol. Safranin is very soluble in alcohol and also in carbol-xylene, hence, it is necessary to remove the specimens from the wash alcohol as quiclrly as posiible and the process of clearing in carbol-xylene must be reduced to the minimum length of time, which is about fifteen minutes, or otherwise all of the stain would be washed out of the specimen. This stain colors the chitin a bright carmine red, it also colors the marginal spines and plates. The gland orifices become quite clear and distinct, while on the other hand the small tubularia are not distinctly colored. My experience with specimens stained with/ has been, that they fade out very quickly and the minute details become very indistinct. In Preshly stained specimens practically all of the details are well enough colored to make a detailed study of the specimen quite easy and accurate, but, a great deal 

of reliance cannot be placed upon the stain as it becomes aged. Skurefuchsin (Acid magenta).. In preparing a stock solution of this stain the following formula was used:

säurefuchsin............. 5 grams.

Ten per sent hydrochloric acid,5 parts.

Distilled water............ Ino cc.

Lee in his "Vade Mecum" says of this stain, "This dye is an 'acid' colour, and it is the soda salt of the di- or tri-sulphoconjugated rosanilin which exists as an acid in the compound, and not to the soda". It is then very evident that the presence of an alkali, even in minute quantities, will impair the working of this stain, and it is very important that all traces of the potash should be removed. This requires that the specimens be washed in three or four baths of distilled water. As a further precaution to insure against the presence of an alkali, the hydrocholoric acid was added. This acid will neutralize any of the potash that may be present and throw it down as a potassium salt. sarefuchsin is not highly soluble in either alcohol or aarbolxylene, therefore, the specimens can be left in these solutions a sufficient length of time to insure complete dehydration and clearing.

The time required to stain the specimens varies: however, thirty minutes are usually surficient to give the proper degree of color to most coccids. The ordinary acid-magenta or sdurfuchsin that can be obtained on the market ${ }^{2}$ color that has the same difficulty as has the other substances referred to above in this paper, namely, that of fading. It gives a very distinct ground stain, but the coloring in the structures of the pygidium 

of the subfamily Diaspinae faded out as the specimen became older. This left the structures almost invisible, as they have approximateIy the same refractive index as the balsam in which they vere mounted. This stain is very advantageous when one wishes to make a study ol the specimens soon after they are mounted.

In order to overcome this apparent aifficulty of the stain fading, the writer carried on a series of experiments, the object being to find, if possible, some stain that would give a aistinct, permanent color and at the same time as much contrast as possible. In carrying out this experiment,all of the insects that were placed In the same series received the same treatment in the same dishes and at the same time, the only point of difference in the process of preparation was that of staining.

The staining materials, used .. were picric acia, magenta or salurefuchsin, and safranin, out the results obtained from the use of picric acid and from safranin were in no way as good as those obtained from the use of sulurefuchsin. As a result of this both the picric acid and satranin were discerded and practically all of the experiments were made with the latter.

Before giving the results of the experiment, it will be nec essary to define the following terms that are to be used in tho tabulation of the work:-

Color.- This refers to the uniform ground color of the specimen.

Marginal contrast.- This refers to the contrast of the merein of the insect with the balsam in whicis it was mounted. 

Degrees of marginal contrast.

Weak.- The contrast is weak when the fringe of the insects did not take enough of the stain to color them.

Muddy.- The contrast is spoken of as being muddy when the stain did not color the fringe distinctly, that is, the color washed out leaving the balsam also colored.

Strong.- The contrast is strong when the fringe took enough of the stain to make it distinct and contrasty.

Internal contrast.- This refers to the contrast of the internal characters with the surrounding parts of the insect.

Degrees of internal contrast.-

Weak.- When the internal characters did not take enough of the stain to make them clearly defined, the stain is designated as being weak.

Distinct.- When the internal characters tool enough of the stain to make them clear and distinct, the contrast is designated as boing distinct.

Overstained.- When the specimen took so much of the stain that the internal characters were rendered opaque, the specimen is said to be overstained. 

Understained.- When the specimen did not take enough of the stain in oxder to show clear If and distinctly the internal characters, the specimen is said to be understained.

Tabulation of the experiment with stains.

\section{Experiment No. 1 .}

The specimens were put into the following staining solutions.

Distilled water.............60 parts.

Shureluchsin stock solution...... I part.

Time.................... 15 minutes.

Results.

Color.........................Good.

Harginel contrast............. Strong.

Internal contrast............. Teak.

Experiment Ho. 1a.

The same staining solution as No. 1 .

Time................. 60 minutes.

Results.

Color.......................Good.

Marginal contrast.............. Strong.

Internal contrast............ Distinct.

Experiment No. 2.

Distilled water...........6 60 parts.

Sturefuchsin stocis solution.... 2 parts.

Time................... 15 minutes

Results.

Color................... Excellent.

Warginal contrast............ strong.

Internal contrast........... Distinct. 

Expe riment ijo. 2a.

Staining solution the same as in No. 2 .

Time................... 45 minutes

Results.

Color........................ Excellent.

Marginal contrast.............. strong.

Internal contrast............. Distinct.

Experiment No. 3.

Dlstilled water ............. 60 parts.

Sulurefuchsin stock solution....... 4 parts.

Time.................... 15 minutes.

Results.

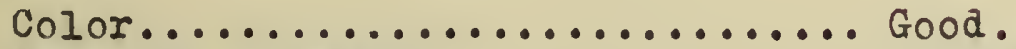

Marginal contrast............... Strong.

Internal contrast.............. Poor.

The specimen was decidedly overstained.

Exper iment No. $3 a$.

Staining solution the same as in No. 3 .

Time.................... 35 minutes.

Results.

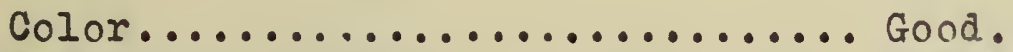

Narginal contrast.............. Strong.

Internal contrast.............. Poor.

The specimen was overstained.

Experiment No. 4.

Distilled water.............6 60 parts.

Sturefuchsin stock solution....... 1 part.

Ten per cent hydrochloric acid.... I part.

Timo.....................20 minutes. 

Results.

Color......................... Poor

Marginal contrast................ Weak.

Internal contrast................ Teak.

This specimen was understained.

Experiment No. 4a.

Staining solution the same as in No. 4 .

Time..................... 50 minutes.

Results.

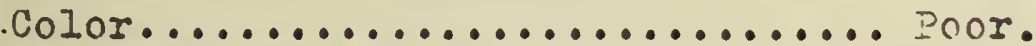

Marginal contrast................ Strong.

Internal contrast.............. Overstained.

The specimen was decidedly overstained.

Experiment No. 5 .

Distilled mater..............6 60 parts.

Skurefuchsin stock solution....... I part.

Ton per cent hyarochloric acid.... 3 perts.

Time....................20 minutes.

Results.

Color........................ Excellent.

Marginal contrast............... Strong.

Internal contrast............. Jistinct.

Results in this specimen were not uniform.

Experiment $\mathbb{N o} 5 \mathrm{a}$.

staining solution.the same as in.\$0 .5.

Time....................4 45 minutes.

Results.

Color ..................... Excellent.

Marginal contrast............... strong.

Internal contrast............... nverstained.

specimen was decidedly nverstained. 

Experiment No. 6.

Distilled water.............. 6n parts. Sturefuchsin stock solution........ 2 parts. Ten per cent hydrochloric acid..... 5 varts. Time............................. minutes.

\section{Results.}

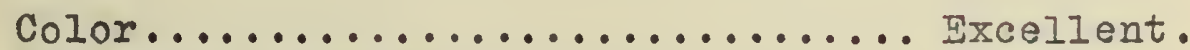

Marginal contrast............... strong.

Internal contrast............. Jistinct.

\section{Experiment No. 6a.}

staining solution the same as No. 6 .

Time..................40 minutes. Results.

Color........................ Excellent. Marginal contrast.............. Very strong. Internal contrast.............. Very distinct.

The staining in this specimen is perfect.

$$
\text { Experiment No. } 7 .
$$

Distilled water...............60 parts. Forty per cent formalin.......... 2 parts. surefuchsin stock solution........2 2 parts. Time........................ 15 minutes.

Results.

Color........................ Poor.

Marginal contrast............... Very reak. Internal contrast.............. Very veak.

The specimen is decidedly understained.

$$
\text { Experiment No. } 7 a \text {. }
$$

Staining solution the same as No.7.

Time..................4 45 minutes. 

Results.

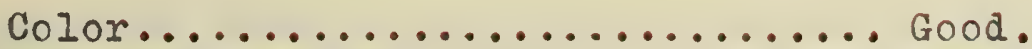

Marginal contrast.............. strong.

Internal contrast............. Distinct.

\section{Experiment Ho. 8.}

Distilled water.............6 60 parts. Forty per cent formalin.......... 4 parts. Sturefuchsin stock solution........ 2 parts. Time...................... 25 minutes.

Results.

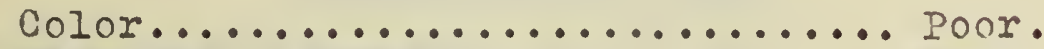

Narginal contrast............... Weak.

Internal contrast.............. Weak.

The specimen appeared muddy and not clear.

Experiment No. 8a.

Staining solution the same as No. 8.

Time..................40 minutes. Results.

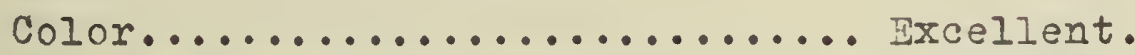

Marginal contrast................. strong.

Internal contrast............. Distinct.

In the above series of experiments the specimens treated with the stain were Chionaspis gleditsiae. This species has a very thin body-wall and represents one of the most easily stained diasids. The specimens treated were fresh; therefore, there was no possibility of theifpeing damaged by fungus or museum pests. 

Experiment No. 10.

Distilled water...............6 60 parts.

Sururefuchsin stock solution.......... I part.

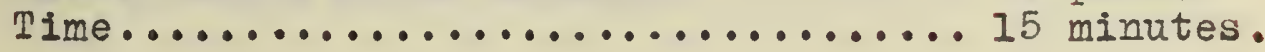

Results.

Color......................... Weak.

Marginal contrast................ Teak.

Internal contrast................ Teak.

This specimen was not stained at all.

Experiment No. 108 .

Staining solution the same as No. 10.

Time........................ 4 b minutes.

Results.

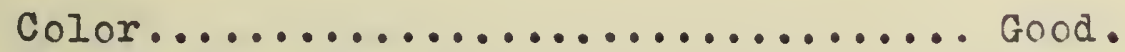

Marginal contrast................. Strong.

Internal contrast............... Distinct.

Experiment No. II.

Distilled water...............60 parts. Skurefuchsin stock solution.........2 2 parts. Time........................ 15 minutes.

Results.

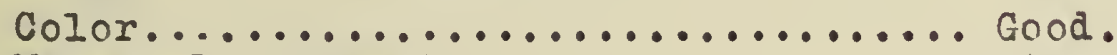

Narginal contrast .................. strong.

Internal contrast............... Distinct.

Experiment No. 11a.

Staining solution the same as Ho. II.

Time.....................4 minutes. Results.

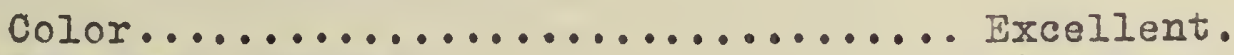

Marginal contrast................. strong.

Internal contrast............... Distinct. 

Experiment No. 12.

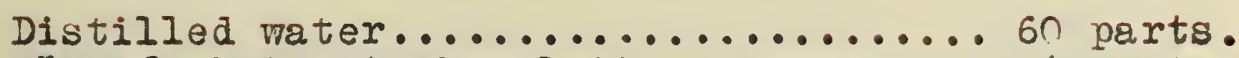

Stlurefuchsin stock solution.......... 4 parts.

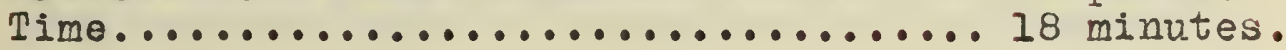

Results.

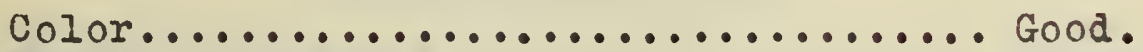

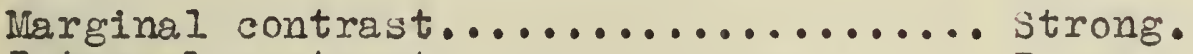

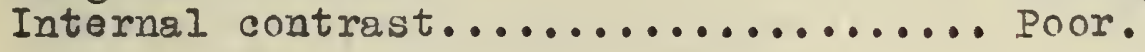

The specimen was decicediy overstained.

Experiment No. 128 .

Staining solution the same as No. 12.

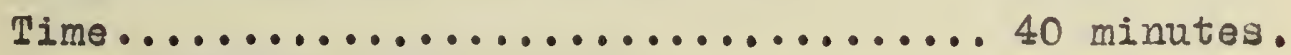

Results.

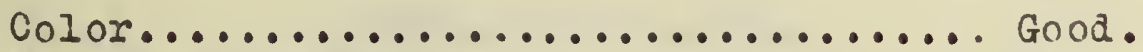

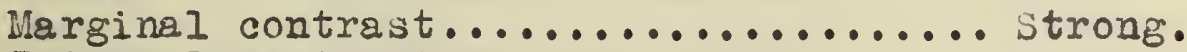

Internal contrast.................. Poor.

Specimen overstained.

Experiment No. 13 .

Distilled wator.................. 60 parts.

Shurefuchsin stock solution........... 1 part.

Ten per. cent hydrochloric acid........ I part.

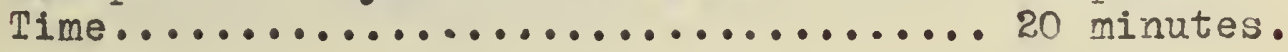

Results.

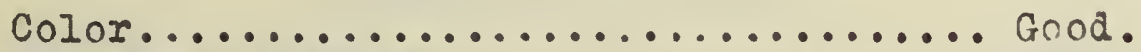

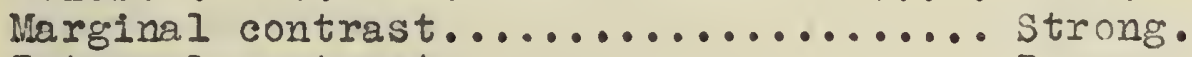

Internal contrast.................. Ponr.

The specimen appeared to be mudiy.

Experiment No. $13 a$.

Staining solution the same as in No. 13.

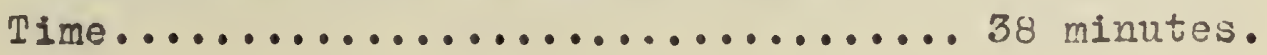



Results.

Color............................Good.

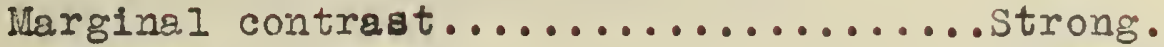

Internal contrast................ Distinct.

Experiment No. I4.

Distilled water................66 parts. SHurefuchsin stock solution.......... 2 parts. Ten per: sent hydrochloric acid....... 2 parts. Time....................... 20 minutes.

Results.

Color.......................... Excellent.

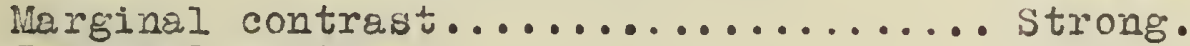

Internal contrast.................. Poor.

specimen overstained.

Experiment ITo. $14 a$.

staining solution the samo as Io. 14.

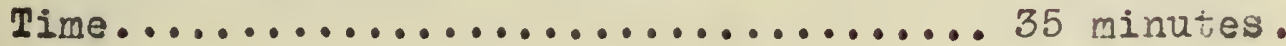

Results.

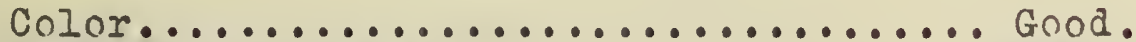

Marginal contrast................. Strong.

Internel contrast.................. Poor.

Specimen overstained.

Experiment No. 15.

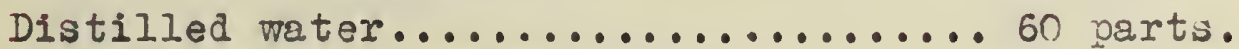
Skurefuchsin stock solution........... 2, parts. Ten per cent hydrochloric acid....... 5 varts.

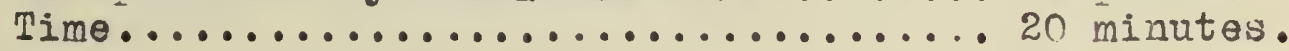

Results.

Color...........................Excellent.

Marginal contrast.................. Strong.

Internal contrast............... Very distinct. 



\section{Experiment No. $15 \varepsilon$.}

Staining solution the same as No. 15.

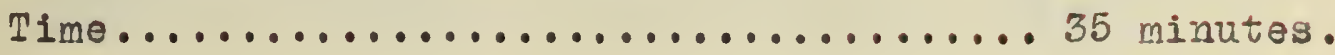
Results.

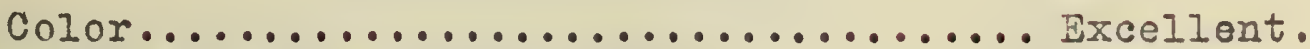

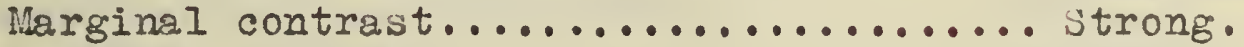

Internal contrast................... Donr.

specimen overstained.

Experiment No. 16.

. Distilled weter................60 parts. SHurefuchsin stock solution.......... 4 parts. Ten per cent hydrochloric acid........ 2 parts. Time........................ 20 minutes.

Results.

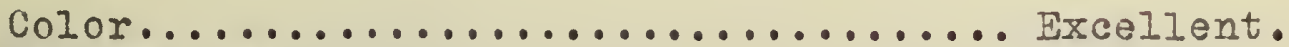

Marginal contrast.................. Strong.

Internal contrast................. Distinct.

\section{Experiment $\mathbb{N o} 16 a$.}

Staining solution the same as No. 16.

Time 45 minutes.

Results.

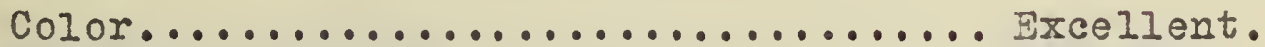
Marginal contrast....................... Internal contrast................. Poor.

Specimen overstained.

Experiment No. 17.

Distilled water................60 parts. Ten per cent potassium hydroxile..... 4 parts. Säuretuchsin stock solution......... 3 parts. Time........................ 2n minutes. 

Results.

Color......................... Very poor.

liarginal contrast................. Teak.

Internal contrast................... Heak.

\section{Experimant 1ro. 17 a.}

Staining solution the same as $\mathbb{N o}$. 17 .

Time.....................45 minutes.

Results.

Color........................ None.

Warginal contrast................. None.

Internal contrast................ None.

The specimen did not show any color whatever.

The specimens used in this series of experiment; were

Chionaspis salicis-nigrae. This species has a very thick and

heavy body $=\mathbb{}$ all and repregents one of the most difficult coccids to stain. The results of this series of experiments were impaired beouse the specimens were damaged by the presence of a parasitic fungus.

Experiment ITo. 20.

Distilled water...............6 60 parts.

Slurefuchsin stock solution........... 2 parts.

Ten per-cent hydrochloric acid....... 4 parts.

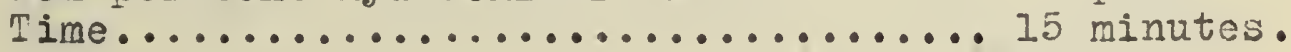

Results.

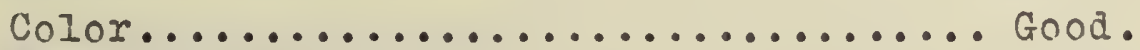

Marginal contrast................... Strong.

Internal contrast................ Distinct.

Experiment ITo. 2ra.

staining solution the same as 10.20 .

Time.............................. minutes. 

Results.

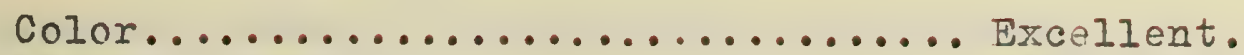

Hargingl contrast................. Very strong.

Internal contrast................. Very distinct.

\section{Experiment No. $20 \mathrm{~b}$.}

staining solution the same as No. 2r.

Time .......................45 minutes.

Results.

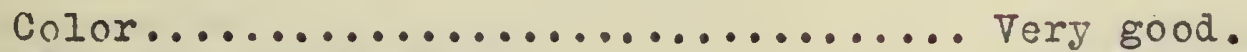

lilarginal contrast.................. Very strong.

Internal contrast................ Very distinct.

Staining perfect.

Experiment No. 21.

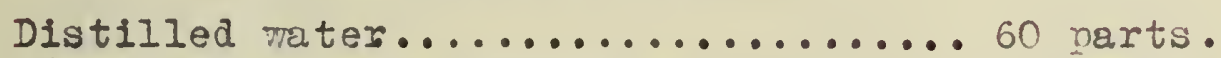

Shurefuchsin stock solution.......... 3 parts.

Ten per cent hyarochloric acie....... 5 parts.

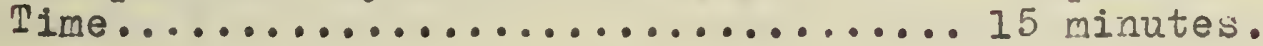

$\underline{\text { Results. }}$

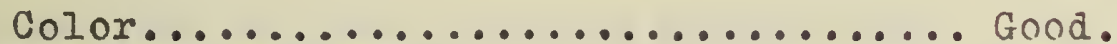

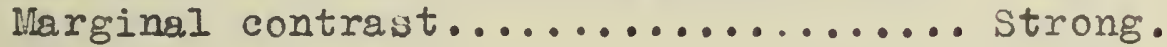

Internal contrast................ Distinct.

Experiment No. 21e.

staining solution the same as No. 21.

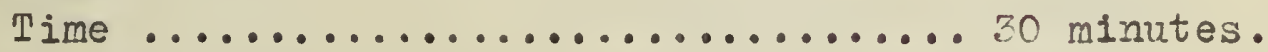

Results.

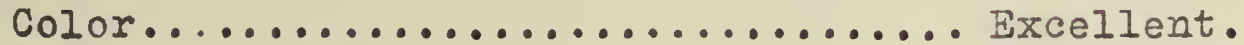

Marginal contrait................. Very strong.

Internal contrast................. Very distinct.

staining perfect.

The insects stained in this series of experiments were the Pseudococcus longispinus. These insects are soft bodied and belong to that group of scale bugs commonly lnomb as the unarmored 

scales. The body wall of this species is very thin and delicate and when properly cleaned becomes nearly transparent, this makes a study of the subfamily difficult. These insects were treated with the same stain and in the same manner as were the menbers of the genus Chionaspis. Owing to the character of the bodyz wall of this species, it is one of the easiest coccids to stain. In this experiment only those formulae were used that gave a favorable result in the previous experiments.

\section{Results of the staining Experiments.}

The specimens used in these experiments were taken from the potassium hydroxide and washed in three changes of distillea water, then they were treated with the stain. It will be seen from the above results that in series $\mathbb{N o}$. I in which Chinnaspis gleditsiae, a very thin walled coccid, was used the best color was obtained in experiment No. $6 a$, ani the staining formula was:

Distilled water................... gn parts.

SAlurefuchsin stock solution........... 2 parts.

Ten per cent nydrochloric acid........ 5 parts.

Time........................ 4n minutes.

In series No. II in which Chionaspis salicis-nigrae, a very thick walled heavily chitinized insect, was used, the best results were abtained from experiments To. 15 and 16. The formulae for these solutions were,

Iio. 15

Distilled water..............

Skurefuchsin stock soluticn....

Time.....................
Ten per cent hydrochloric acid.

60 parts.......60 parts.

2. parts.......4 4 parts.

5 parts........2 parts. 20 minutes......20 minutes.

This might lead one to believe that the amount of staining solution used was not of importance; but! in experiment $\mathbb{N o}$. 16 the 

results obtained were not all uniform, some of the specimens were decidedy overstained and none of them nere understained; while, in experiment Fo. I5 none of the specinens were overstained or seriousIy understained. The results in this series were not as good as they might have been because the specimens vere damaged by the presence of a fungus.

In series No. III in which Pseudococcus Iongispinus, a very thin walled unarmored scale. was usea only those formulae vere tried that gave the best results in the preceeding experiments. In this series all of the specimens were vell colored, but, INos. 2Ca and 2la gave decidedly the best results. The formulae used in these experiments were,

No. 2Ca. No. 21a. Distilled water..............60 parts....... 6r varts. sturefuchsin stock solution...... 2 perts........ 3 parts. Ten per cent hydrochloric acid... 5 parts....... 2 parts. Time..................... 30 minutes..... 30 minutes.

In this experiment it will be seen that the only difference in the staining solutions was one part of saurefuchsin. The specimens in 21 were all coloreà a deeper carmine than those in 2Ca: honever, specimens stained by both of the solutions show distinctly all the characters used in the identification and classification of the insect.

A little study of these formulae will show that the relative tiniclmess of chitinization of the body wall has but little to do with the amount of the stain required, for in the case of one of the most heavily chitinized and the least chitinized of the coccids the same strength of the staining solution gave equally as good results, and the sixty parts of water, two parts of saure- 

fuchsin stock solution, and five parts of ten per-cent hydrochloric acid is strongly recommended for use in staining the members of this family. The time limit should be a fer minutes longer in staining a heavily chitinized insect than one less heavily chitinized. The results of the experiments show that twenty to forty minutes are required to get a well stained specimen.

In experiments $\mathbb{N o} .17$ and $17 \%$ in which the staining solution was made strongly alkaline, it will be observed that the results are porthless. This is due to the prosence of the alkali which caused the color to fade; in fact, when the specimens vere removed from the staining solution all the color had faded from the solution in the watch-glasses.

Chemistry of staining.- IInst of the fading. if not all of it, is caused by the presence of minute particles of alkali in the specimen. To remove the alkali sufficiently that the working of the stain will be unimpaired will require much more than the customary three washings. The presence of an alkali was first detected by finding small crystals of some substance, presumably potassium chloride, in the specimens that had been treated with hydrochloric acid. Then a test was made in which a specimen was taken from the potaswium hydroxide and, without washing, was treated with hydrochloric/ This specimen, after being mounted, appeared to be stuffed with small crystals, evidently of potassium chloride: furthermore the specimen was rendered worthless for study. If one removes the larger part of the potassium hydroxide by washing the specimen, the small amount of crystals present do not at all im- 

pair its study. By using a distinctly acid staining solution the presence of these minute particles of alkali is insured against, for: hydrochloric acid neutralizes the alikil and forms a salt and water with it thus:

\section{$\mathrm{HCl}$ in excess $+\mathrm{KOH} \rightleftarrows \mathrm{KCI}+\mathrm{HOH}+\mathrm{HCl}$.}

Potassium chloride is highly soluble in nater, but, since all of the water is removed during the process of dehydration there remains nothing but the small amount of potassium chloride and the hydrochloric acid. since there is an excess of the acid in the specimen, it is then mounted as an "acid" specimen and sealed in with balsam as an "acian specimen; therefore; the possibility of its fading has been eliminated. This fact was proven by a study of slides wich were prepared early in the autumn of 1915. The specimens that were stained in a noutral solution have become almost colorless. while others prepared soon afterwards and stained in a strongly acid solution have retained their color and are now as bright carmine-red as when freshly removed from the staining bath.

Characters Revealed By stains.- All of the characters that are visible in an unstained specimen and many characters that are not at all plain or visible become very distinct in specimens that have been properly stained. In the more generalized coccids the anal ring, its setae, and the rows of cell=zike structures around it, the number of joints in the antennae, the antennal setae, the abdominal labiae, and the numerous wax pores, are made very aistinct and plain. In the more specialized coccids the segmentetion of the body is distinctly shom. But most of all, the internal 

characters of the pygidium are colored so that they are the most conspicuous objects on the specimens. The tubularia of the dorsal pores and of the micropores are made visible, and it is possible that this character may be of considerable taxonomic valus. The structure of the circumgenital gland orifices as compared with that of the dorsal glands is clearly shown. In unstained specimens the basal thickenings in most cases cannot be seen, yet; in a stained specimen they are shown with a wonderful degree of clearness. The shape and arrangement of these thickenings may be of considerable taxonomic importance in the genus Aspidiotus in which they occur. The molifications of the pygiaid fringe are so clearly shown that there can be no doubt as to the relation of the various parts. 



\section{VI.EXPLANATION OF TERMS.}

In order to make the following descriptions clear, it will be necessary, before describing the Illinois Coccidae, to explain the terms that are to be usea in the descriptions. N'vo plates representing the typical form of the body in Aspidiotus and Chionaspis will shom the form of the pygidium, its parts,and their identity. It will be seen from an examination of the descriptions that the characters of the pygidium serve in a large way to determine the systematic position of the species.

The following technical terms have been used:-

Anus, Anal 6pening.- The terminal opening of the alimentary canal. More or lesis circular in form; located on the dorsal surfare of the body, Lovever, the location varies, and it is usually found on the fifth to the nineth segments.

Anal Lobes.- The anal lobes are projections of the body-wall and are found on either side of the anal opening in the coccinae and Eriococcinae.

Anal iing.- The anal ring is an oval or circular stmucture thich surrounds the anal opening in the more generalized subfamilies of the coccidae. It is usually composed of one or two rotrs of cell-like structures.

Anal Setae.- The setae borne on the anal ring are the anal setae. Basal Thickenings.- These are thickened places in the chitinous exoskeleton of the insect. They are located mesad of the anterior and posterior groups of circumgenital pores. Mhey have been found only in the genus Aspidiotus. 

Callus (pl. Calli).- These are chitinous thickenings, usually four in number, forming a transverse row across the pygidium cephalad of the anus.

Cerari.- The cerari are spine-like structures found along each lateral portion of the body in some subiamilies. They tend to hold the body amay from the host plant, tinus providing for an air. supply.

Circumgenital Gland Orifices.- These are the openjngs n\& the glands arranged around the vaginal opening. They are visually arranged in groups.

Dorsal Pores.- The dorsal pores are oval orifices, however, in some species the orifices may be round. They are Incated on the dorsal surface of the pygidium, usualiy arranged in more or less transverse rois, each row consisting of two groups, an anterior and a posterior one. The rovis are designated oy numvers beginning with the one nearest the
part of median lobes.L the secretions which form tine scales are discharged from these openings.

Exuvia.- Tilis is the dorsal integument of the early stages which has been cast off at moulting. The cast off integument is fastenel to the scale by wax threads. The uppermost exuria is called the first and the larger one underneath it is callei the second.

Gland Orifico.- The external opening through which a gland emits its secretion is called a gland orifice.

Incisinns.- These are the notchew along the margins of the pygidiun. They are considered, by some autinrs, as marking 

the position of the conjunctiva between the original segments of the pygidium. They are designated as follows; the ne between the median lobes is the first, the one between the melian and second pair of lobes is the second, the third eas is the ne between the second and the third loves, etc. Inbes.- The lobes are projections f the body-wall, they usually mark the diviaing line between the transformei segments of the pygidium. The lobes are designated as follows; the pair at the posterior extremity of the body is calle 3 the median par, and the pairs cephalo-laterad them are numbered second, thixd, and fourti, as they nccur.

Lobule.- nne of the lobe-like structures of a lobe formed when it is deeply incised.

Narginal Pores.- The openings $O f$ the marginal glands are called the marginal pores. They are arranged around the margin of the pygidium, fineir function is the same as that of the dorsal pores.

Median Lobes.- These are the Inbes located at the caudal extrenity of the body near the meson.

Wodian Incision.- This is the incision at the posterior extremity of the body between the median lobes. This incision is very distinct in Aulacaspis and Phenacaspis.

Wicropores.- These are the small round pores Ioeated on the posterinr part of the pygidium of the Diaspinse; they are much smaller tiran the anrsal pores.

Paraphyses.- The paraphyses are heavy chitinous thickening extending into the body-wall from the margin of the pygidium. 

Pectinae.- These are broad bifurcated, trifurcated, or polyfurcated plates.

Plates.- The plates are projections of the body-wall, they are considered by some writers as being developed from setae. There is usually a gland orifice at their tips. The plates are designated as the first or median; the secnnd pair, between the median and second nair nf lobes", the third, between the second and the third pairs of lobes, and so on. They are represented by the following formula;1-2; 1-2; 1-2; 1-2; $3-7$ :

Pygidial Fringe.- Mhis is a collective term and is applied to the entire outline of the pygidium.

Pygidial Margin.- The pygidial margin is that portion of the pygidium on each side cephalad the cephalic pair of lobes. Setae of the Pygidium.- These are small hair-like structures on the dorsal and ventral surfaces, those on the dorsal surface are called dorsal setae and those on the ventral surface are called the ventral setae.

Tuularia.- These are the chitinized ducts which lead from the glands that supply the dorsal, marginal, and micropores of the body. There are three distinct forms of tubularia as follows:

1. Those with long narrow ducts.

2. Those with long wide ducts.

3. Mnose with short and very wide ducts.

Vaginal Opening.- The vaginal openung is the terminal opening of the vagina, it is usually located cephalad of the anus on the sixth segrnent. 



\section{CIASSIFICATION OE THE COCCIDAE OE ILIIINOIS.}

This work is offered only as a partial list of the coccidae which occur within the state of Illinois. A large part of the work has been done in the tmo genera Aspidiotus and Chionaspis. Species of these two genera largely composed my collection of the coccidae, owing to the fact that most of the specimens were collected from growing nursery stock. Practically none of the species infesting our native trees and shrubs were collected. The species are arranged beginning with the most generalized and proceeding to the most specialized types.

Due to the remarlable success with stains and the revedlation of new characters by the process of staining, attention should be callea to the fact that several nev characters have been used in describing the suecies. These new characters nere constant to a remarkable degree in the same species and were very useful in differentiating the species studied.

The basal thickenings are thickened places in the chitinous exoskeleton of the insect, and have been found only in the genus Aspidiotus. They are faintly visible in unstained specimens, but they are very aistinct and clear in a stained specimen.

The dorsal pores that have not been considered as being important by most students of this amily, were found to be very useful in differentiating the species. The form, number, and arrangement of these pores are clearly show in a well stained specimen.

In the uhionaspis a weries of small round micropores mas discovered within the circumgenital gland ring. The arrangement of these pores and their relation to the anus is consant within a species. This character may be of considerable taxononic importance. 

The ducts or tubularia which extends from the glands to the orifices are invisible in a specimen that has not been strined; but in a specimen that has been stained tney are clearly visible, and the student is able to see considerable variation in their form, arrangement, and numbers in the different species. one thing that is especially noticable is that the more highly specialized a member of the family is the longer the tubularia be come. 



\section{Pseudococcus longispinus.}

Dactylopius longispinus, sig. Ann. Soc. Ent. Fr.(5)5,1875,306. Dactylopius longispinus, Ckell.., Ann. Mag. T.H. (6) 16.1895, 61. Dactylopius adoniaurn, Comst., Rept. U.S. Deot. Agri..1880, 34 I. Dactylopius longispinus, Hers., Jr. Roy. Hor. Soc., 23,19no, 29. Covering of Female.- Insect unarmored, body soit, covered with/wite fluffy secretion of wax.

Female.- Body color white or pinkish-yellow in living individuals; convex; elongated, 2.50 to $3.10 \mathrm{~mm}$ in length and 1.40 to 2.In mm in width; boly distinctly segmented; each segment with a series of wax filiqments, Ionger near posterior end of body; antennae with eight segments, eighth segment the longest and the seventh one the shortest; each segment with several short setae; legs long and slender; trochanter with a group of pores on either side, also with two stiff spine-like setae, one long bristle-like seta, and many smaller inconspicuous ones; the tibia about twice as long as the tarsi; lateral margin of the body with seventeen cerari; a oair of triangular lobes on the posterior end of the body; lobes with a long slender seta at the apex; inner margin of each lobe with a group of cerari, several short setae, and many wax pores; anal ring not projected from the body, large, egg-shaped, with six long slender setae; a single row of cells along the sides of the ring, roms of cells on either side of the ring not meeting at meson, setae outside of the ring of cells.

Hosts. This species is found on almost all of the common green house plants.

specimens collected at Uhampign and Blnomington were studied. It is found generally over the state in greenhouses. 



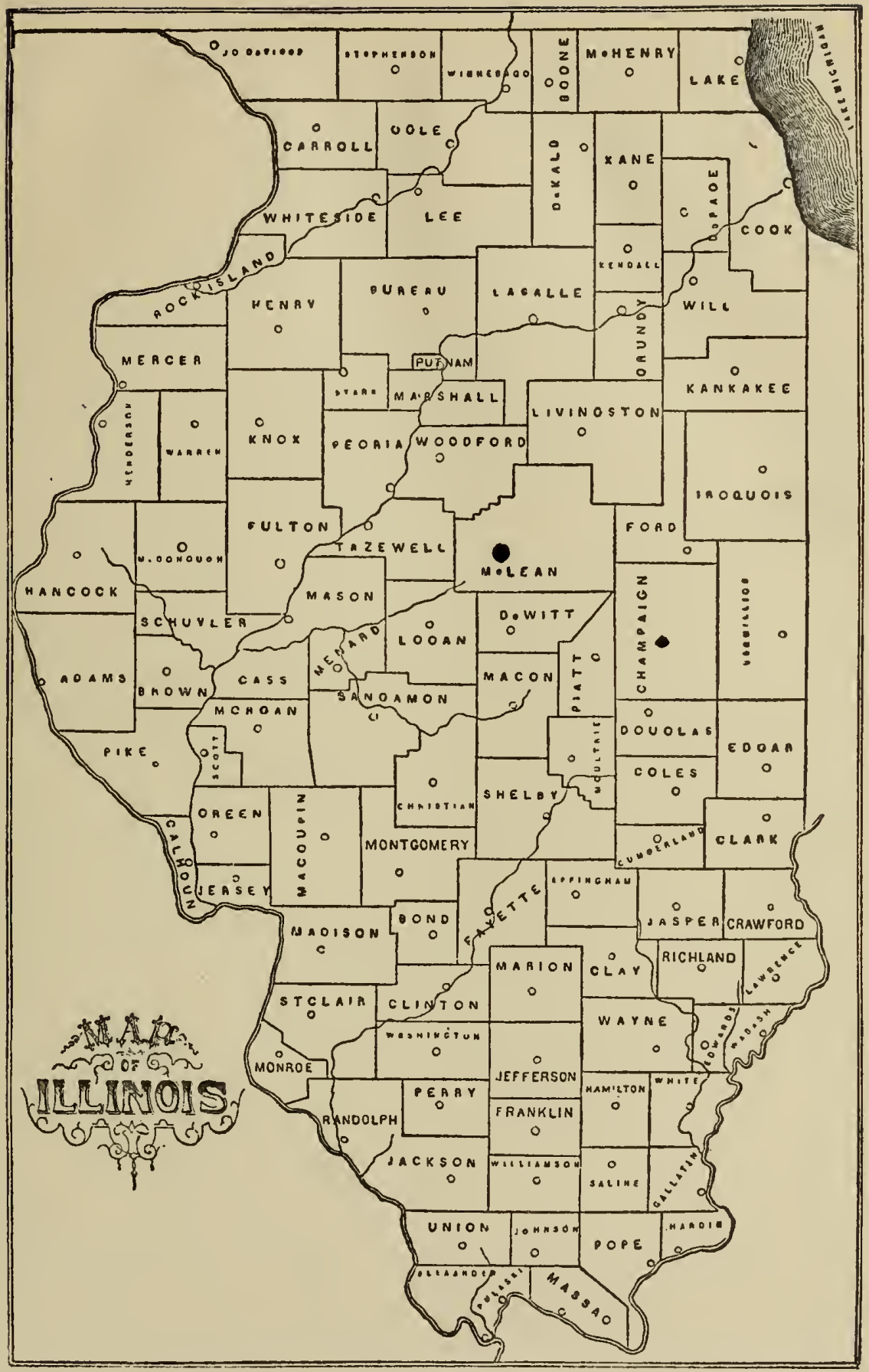

Locations where Pseudococcus longiopinus was collected. 

Gossyparia ulmi.

Gossyoaria ulmi, Howard, Insect Iife, 2, $1889,34$.

Gossyparia ulmi, sig., An. de la soc. Ent. Er. (5) 5, 1875, 21. Covering of Female.- Insect with scale covering absent; dorsal surface of the body covered with a thin wax-Iike seretion; oval; margin of insect completely surrounded with a border of white wax-like substance.

Female.- Body color dark orange to light red in living individuals; elongated, oval, narrower in the posterinr than in the anterior region, convex, and 8.50 to $4 . n 0 \mathrm{~mm}$ in diameter; distal margin of the body with a pair of terminal lobes, elongated, sharply rounded at apex, with a long seta at the distal extremities: and four shorter setae on the body of the lobes; anal ring cephalad of the lobes; with eight long, stiff setae; regmentation of body indistinct; body covered with wax pores with spine-like gland tubes; adult with three pairs of legs; short, slender, and small in comparision to the size of the body; tarsi longer than the tibia; antennae with six segments, the second the longest, and the fourti and fifth the shortest; each segment except the sixth with two or more setae, sixth segment with eight or ten long setae; a distinct protuberance of the body on either side of the antennae.

Host. Ulmus americana.

soecimens collected at Chicago and Bowmanville were studied. This species does not conmonly occur in Illinois, 



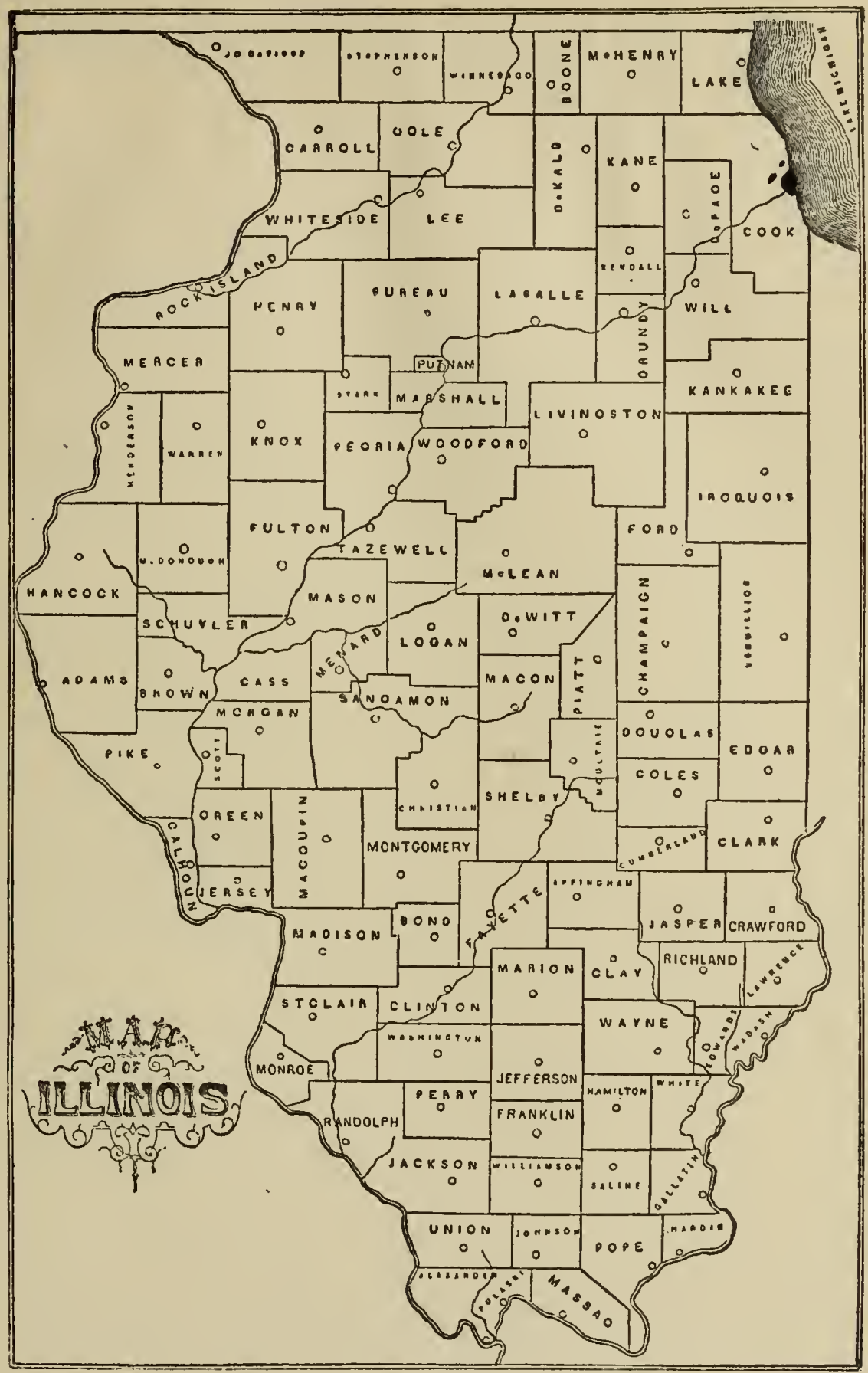

- Locations where Gossyparia uImi was collectea. 

Parlatoria perigandi.

perígandi, Comstock, Rep. U.S. Dept. Agri. , 1880-81, 327. perigandi1! liarlatt, Yearbook U.S. Dept. Agr1., 1900, 270. perigandi, Newstead, Mono. Br. Coccidae, 1, 1900, 143. perigandi, Kumana, Pr. Cal. Ac. Sci., (3) 3, 1902, 78. scale of Female.- scale circular to oval, convex, $1.5 n$ to 1.90 mm in dismeter; dirty-gray; exuvia located near tine margin, light yellow, naked; ventrel sule äelicate.

Female.- Body color light range to yellon in living individuals, circular to oval; pygidium broady rounded and with three pairs of Irbes; median, pair of lobes well developed, proximal ends narrower than the distal, distinctly notched on mesel and lateral margins, and converging near tise opex; second and third pairs of lobes slightly smaller than the median pair, proximal ends narrower than the distal, and with mesal and lateral margins distinctly notched; fourth lobe rudimentary, produced into a spine-like projection; a pair of pectinae between the median pair of lobes; two between the second and third; three between the third and the fourth pairs of 10 bes; and live laterad of the fourth pair of lobes; a dorsal seta. on the lateral base of each lobe; ventral setae on the ventral surface/ of the dorsal setae on the second, third, and rudimentary fourth pairs of lobes; four groups of circumgenital pores; anterior laterals six to nine pores, posterior laterals six to eight: two roms of d risal pores located on the antericr cart of the oygidium, tubularia shcrt and wide; a crescent-whaped marginal pore between the meaian pair of lobes, one between the median and second and one between the second and third nairs of lobes, two between the third and the rudimentary fourth loves, and two between ine fourth lobe and the cep- 
halic margin of the pygidium; tubularia of marginal pores located cephaln-mesad of their corresponding pores, ducts very short and as wide as the lobes; a rom of pores extends arcund the margin of the pygiảium cephaln-mesad of the tubularia of the marginal pores, oval, tubularia short and as viaje as the pores.

Hosts.- Citrus trees.

specimens collectod at Mount Roserood vere studied.

This species is a southern insect and is important in Illinois only as a greenhouse pest. 



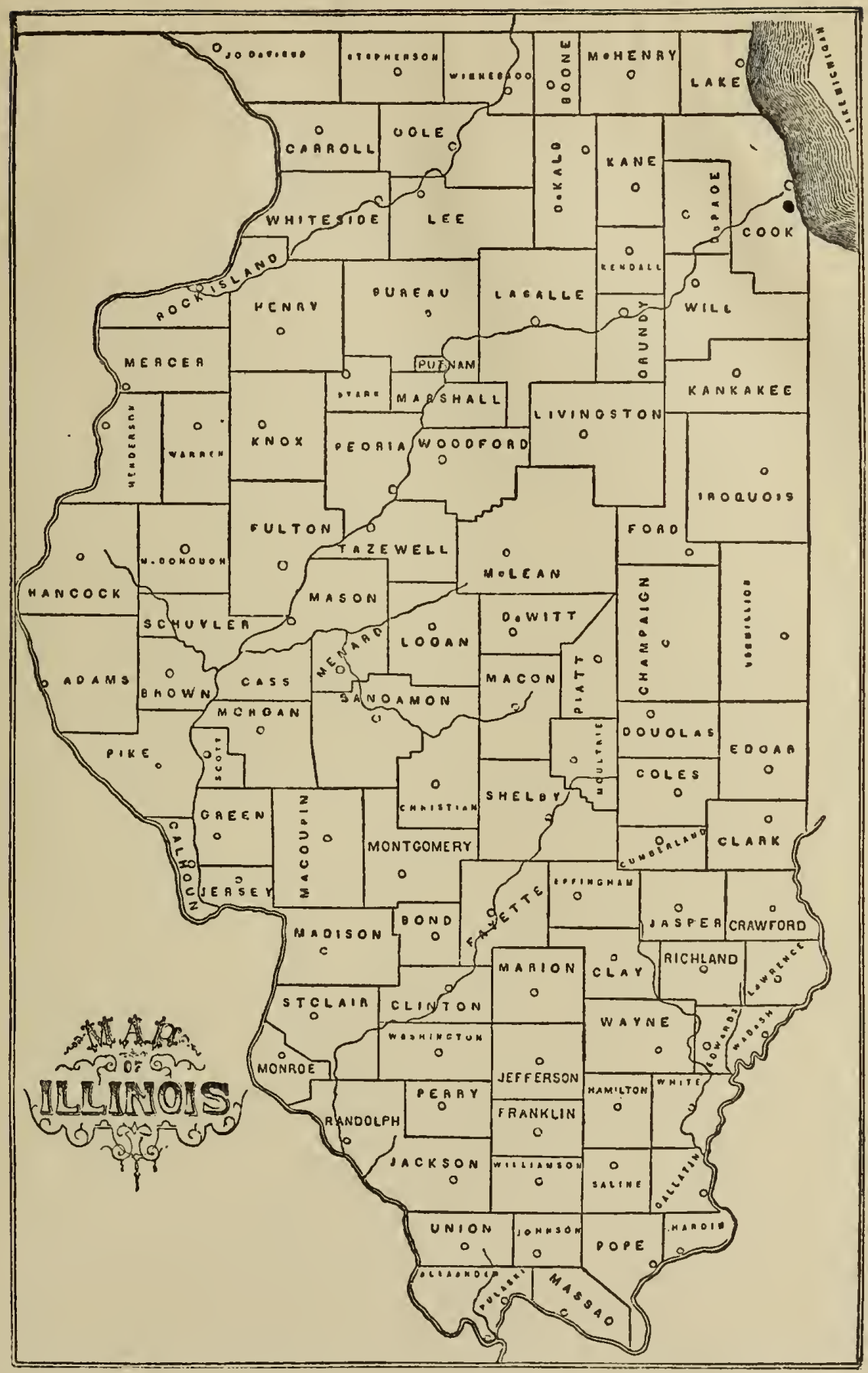



Aulacaspis rosae.

Diaspis rosae, Comst., Rept. U.J. Dept. Agri., 1880-81, 312. Diaspis rosae, smith, Bull. 159, N.J. Experiment st., 1902 . Diaspis rosae, Forbes, 22nd Rep. Ins. III., 19n3, 120. Aulacaspis rosae, Newstead, Nono. 3r. Coccidae, 1, 1901, 168. scale of Female.- Scale circular of nearly so, flat, 2.n to $2.80 \mathrm{~mm}$ in diameter, white to jellowish color; exuvia eccentric, light Jellow, first nymphal sinin exposed, second covered.

Female.- Body color muday orange to dull crimson in living individuals, pygidium a few shades darker; elongate, anterior portion wider than the broady rounded posterinr portion; pygidium broady hollowe out at its mesal extremity; pygidium with three pairs of lobes; median looes in the hollowed out portion of the pygidium, large, mesal margins close togetner, distinctly serrated, converging near the apex, distal margins bluntly rounded, Iateral margins attached throughout their lergth to the body; second pair of lobes incised; mesal lobule larger than the lateral one, distal margins of both lobules bluntly rounded; third nair of lobes incised; mesal lobule larger than the lateral one, distal margin bluntly rounded; lateral lobule small and pointed; chitinous thickenings wanting; incisions small and inconspicuous; one between the median and second pairs of lobes, one between the second and third, and one laterad of the third lobe; plates large and conspicuous; one between the median and second pairs of lobes, ne between the second and tinira, one laterad o the third pair of lobes, one one-third and two onehalf the distance to the cephalic margin of the pygidium; dorsal setae lncated on the lateral base of the median lobes, one on the outer looule of the second pair of loses, one on the third lobe, 

one one-fourth and one three-fourths the distance to the cephalic margin of the pygidium; ventral setae located on the ventral surface slightly mesad of their corresponaing dorwal ones; five groups of circumgenital pores; median with sirteen to nineteen orifices, anterior laterals twenty-five to thirty-three, posterior laterals twenty-iix to thirty-six; three rows of dorsal pores; first row wanting; second row located cepnalad of the second pair of lobes with two to four oores in the anterior group, posterior group wanting; third row located cephalo-laterad of the third pair of lobes with four or five pores in the anterior group. anil four to six in the posterior group; fourtin rom located cephalo-mesad of the last dorsal seta wlth four or five pores in the anterior and five to seven in the posterior group.; marginal pores present; one in the incision between the mejian and second pair of lobes; two in the incision between the second and the third pair of lobes; three rows of tubularia; a row for each row of dorial pores, tubules wide, snort, situated cephalad of their respective rovs of pores; tubules of the marginal pores wide, short, and situated cephalad of their corresponding pores; four small micropores mesad of the second dorsal seta on each side of the meson, tubularia long ani slender. Hosts.- Blackberry, red raspoerry, raspoerry, Rosa rugosa, Rosa $(\mathrm{sp}$.$) .$

jpecimens collected at Astoria, Chicago, Mount sterling, Onarga, and Mexico were studied.

This species is generally distributed throughout the state, but very seldom the infestation becomes bad enough to cause any serious damage to the host plants. 



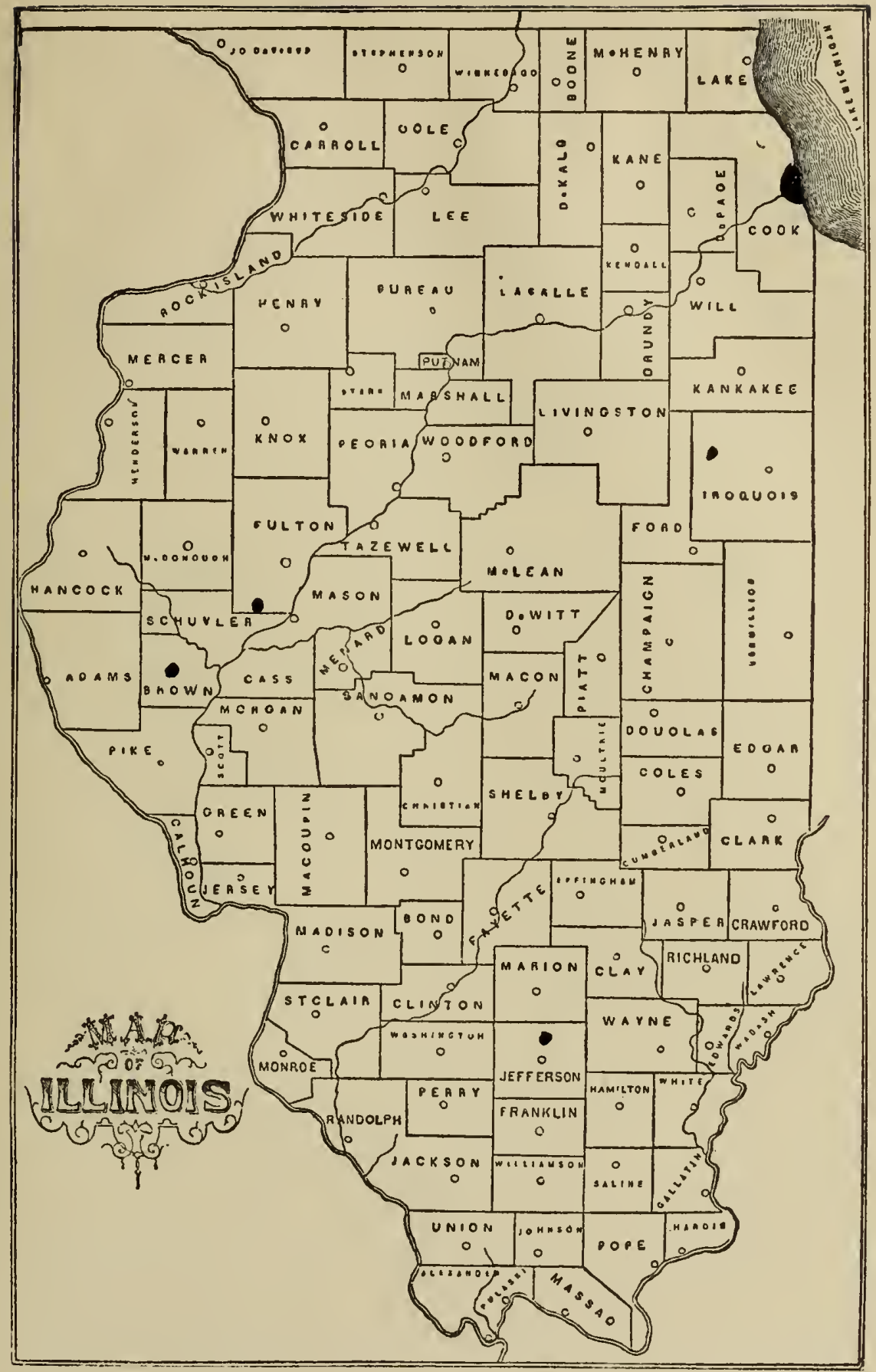





\section{Chionaspia americana.}

americana, Johnson, Entom. Nevs, 7, 1896, 150

americana, Bulletin IIl. state Iab. N.H., 4, 1896, 340 .

americana, Cooley, Special Bull. Mass. Exp. st., 1899, 41.

americana, King, Can. Entom., 34, 1902, 62.

scale of F'emale.- scale elongate, usually widest near the

midale portions, convez, heavily armored, snow-white to dirty gray; exuvia in the anterior part of the scale, sometimes hidden; ventral scale white, and unally adheres to bark after insect is removed.

Female.- Body color yellow or light brom in living individuals; widest slightly caudad of the middle; pygidium broady rounded, with two pairs of lobes; median lobes well developed, mesal margins fused, latero-distal margins distinctly notched; second pair of lobes smaller than median pair, incised, mesal lobule three times as large as the lateral, bluntly rounded at the apex, and distinctly notched on the oblique lateral margin; lateral lobule triangular, and pointed at its distal extremity; a pair of club-shaped chitinous thickenings between the median pair of lobes, a pair of smaller thickenings in the second incision, and another in the third incision; a small plate between the median and the second pair of lobes; two laterad of the second pair of lobes, mesal one simple, lateral one bifurcated or trifurcated, a pair of plates one-half the distance to, and another pair three-fourtis the distance to the cephalic margin of the pygidium, and a group of six or eight plates near the cephalo-lateral margin of the pygidium; dorsal setae short, spine-like, and inconspicuous; one on each lateral base of the median pair of lobes, one on the lat- 

eral margin of the mesal Inbule of the second peir of lobes, one cephalo-laterad of the lateral lobule, and one one-half the distance to the cephalic margin of the pygidium; the ventid/are on the ventral surface slightly laterad of the corresponding dorsal setae; five groups of circumgenital pores ; median group with twenty to thirty-six pores, anterinr laterals nineteen to fortyfive, posterior lateralis tweaty-one to thirty; micropores arranged in a semicircle caudod of the anus; first and second rows of dorsal pores absent; anterior group of thira row with four to six pores, posterior group with five to nine, located cephalo-laterad of the tinird pair of plates; fourth rom with five to seven in the anterior. six to eleven in the posterior group, located near the cephalolateral margin of the pJgidium; a group of tubularia for each row of dorsal pores, and located cephalad of the corresponding rovs of pores; a small tubularia cephalo-mesad of each plate vith a small tubule extending to an orifice at the tip of the plate; an elongated marginal pore between the median and second pair of lobes, two laterad of the second pair of lobes; a short, wide duct or tubule extends into the Jygidium cephalo-mesad of each marginal pore.

Hosts.- UImus americana, and Camperdown elm.

specimens collected at Champaign, Chicago, onarga, and Urbana were studied.

This species is generally distributed throughout the state. In many cases the infestation becomes serious enough to endanger the life of the host, this is especially true when nevly transplanted trees are infested. 



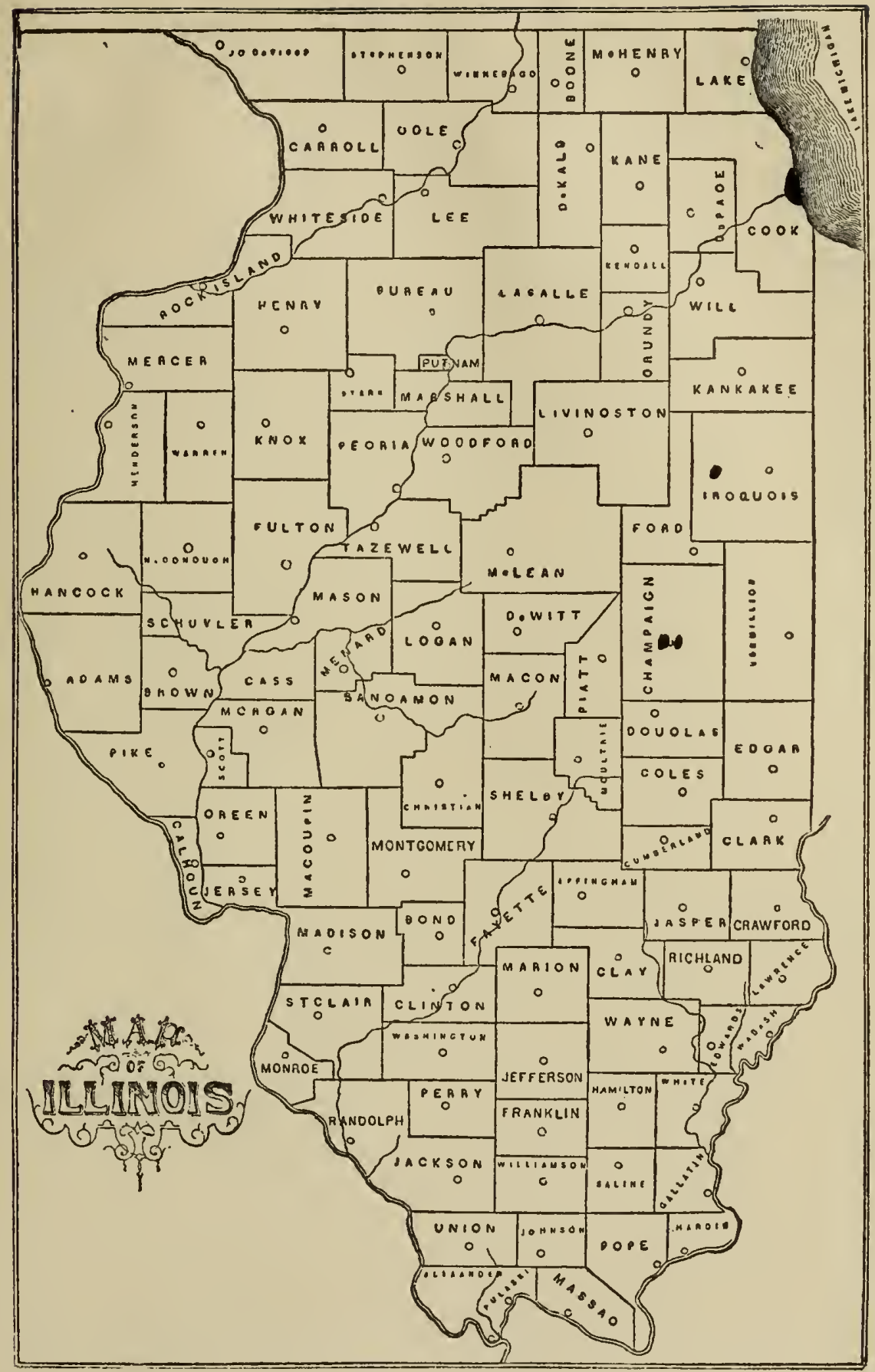





\section{Chionaspis corni.}

corni, Cooley, special Bull. Mass. Exp. station, 1899, 15. corni, King, Can. Entom.,34, 1902, 62.

corni, sanders, Ohio state Uni. Bull. (8) 17, 1904, 45.

scale of iemale.- scale irregularly horn-shaped, broadest near the posterior portions, convex, 1.50 to $2.10 \mathrm{~mm}$ in diameter; delicate; snowy-mhite; exuvia Incated anteriorly and orange to light yellow in color.

Femele.- Body color light yellow in living individurls; widest posteriorly, elongated; oygidium with three pairs of lobes; median lobes well developed, mesal margins fused for about one-holf their length, widely divergent, apex rounded, and margins entire; second pair of lobes rell developed, incised; mesal lobule longer than the lateral, margins entire; lateral lobule pyramidial, and margins not serrated; third pair of lobes broad and flat, incised; mesal lobule larger than the lateral, margins entire; lateral lobule srall; a chitinous process between the median oair of lobes, an indistinct process between the median and second and one between the second and tinird pairs of lobes; a short spine-like plate between the median and second pairs of lobes, another between the second and third pair of lobes, two one-third and one two-thirds the distance to the cephalic margin of the pygidium; a group of five plates on the cephalo-lateral margin of the pygidium; a dorsal seta at the lateral base of the median lobe, one at the lateral base of the mesal lobule of the second pair of lobes, one one-half the distance to the cephalic rgin of the pygidium, and one in the last group of plates; ventral setae located on the ventral surface slightly meso- 

caudad of the corresponding dorsall ones; five groups of circumgenital pores; the median grcup with fourteen to sixteen oores, anterior laterals twenty to twonty-eight, posterior laterals ten to eighteen; micropores arranged in a subtranverse row across the pygidium caudad of the anus; the first row and the posterior group of the second row of dorsal pores wanting; anterior group of the second row with five to seven pores located laterad of the anterior lateral group of circungenital pores; the third row located cephalomesad of the third plate with four to six pores in the posterior and five to eight in the anterior group.; the fourth row located cephalo-mesad of the fourth plate with seven to nine pores in the posterior and seven to ten in the anterior group; tubularia with wide short ducts located slightly cephalad of their corresponding groups of pores; an elongated marginal pore between tine median and the second pairs of lobes; a pair between the second and the third pairs of lobes; and a pair slightly laterad of the third pair of lobes; tubules of the marginal pores short and wide; plates with a tubrle extending mesad from the orifice in the plate to the mouth./ glanu; a series of small tubularia arranged promiscuously around the margin of the pygidium.

Hosts.- Cornus paniculata, Cornus alteronifolis, and Cornus (s) specimens collected at Chicago and Joliet were studied.

This species has beer found only in the northern part of the state. The infestation seems to be wholly local and the pest is not considered as being serious. 



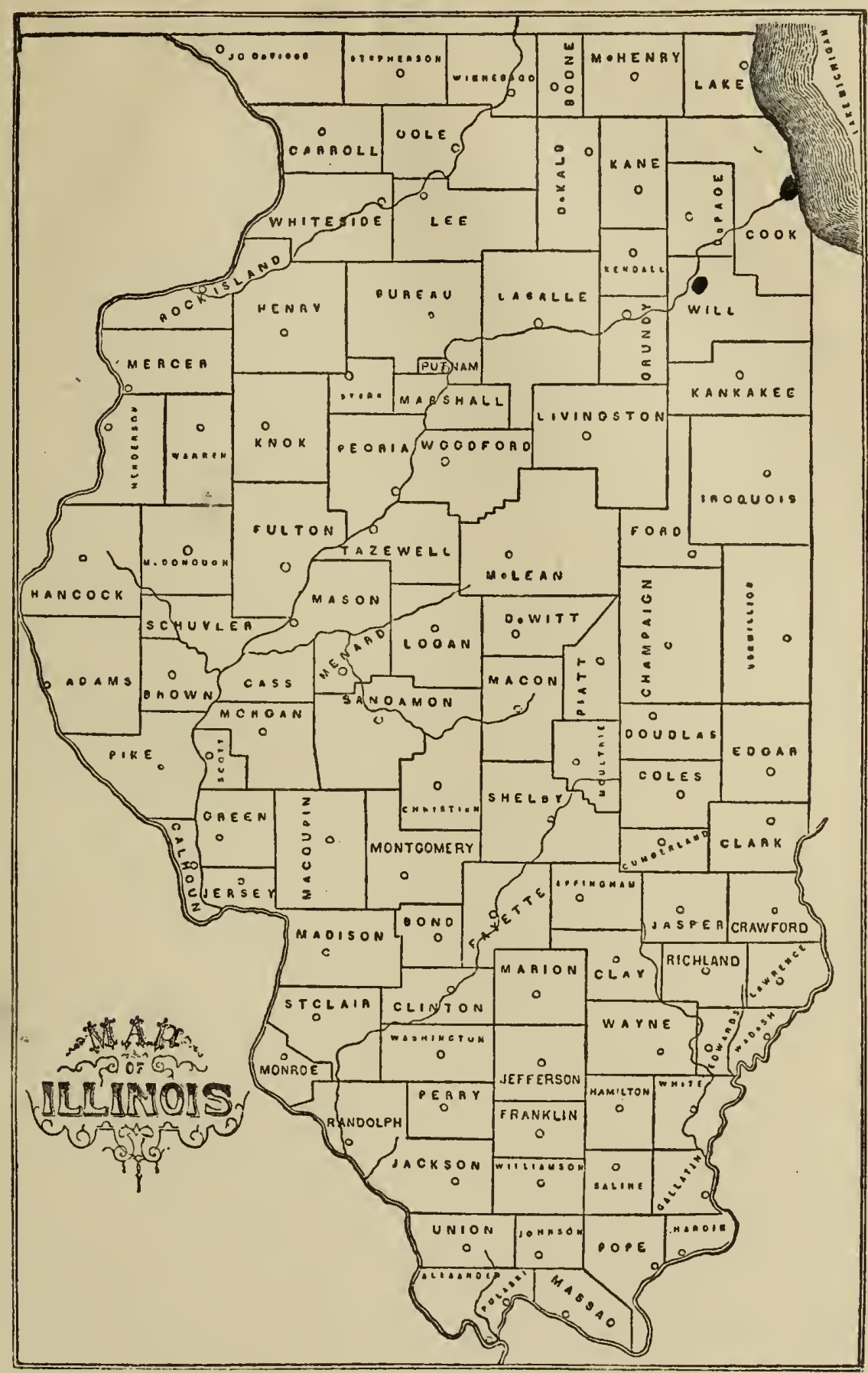

Locations where Chionaspis corni was collected. 

Chionaspis furfura.

Aspidiotus furfure, Fitch, 3rd Rep. Ins. N.Y.,1856, 352.

Chionaspis furfura, Comst., Rep. U.S. Dept. Agri., 1880, 315.

Chionaspis furfura, Cooley, spec. Bull. liass. Exp. st., 1899, 23.

Chionaspis furfura, Newstead, Lono. Br. Coccidae, 1, 1902, 186.

scale of Female.- scale elongate, pyriform, flat, thin, 2.00

to $2.50 \mathrm{~mm}$ in length, snow-white to light yellow; exuvia located in anterior portion, yellowish brom, and covered; ventral scale delicate.

Female.- Bndy color pink to orange in living individuals, elongate, pyriform, broadest near middle portions; pygidium not broady rounded, and with three pairs of lobes; median pair of lobes well developed, short, broadly rounded, mesal margins parallel, and the lateral margins entire; second pair of lobes vell developed, incised, mesal lobule as large as the median lobe, and the ojlique lateral margin finely serrated; lateral lobule small and rounded at apex; third pair of lobes small, broad, and flat; a single plete between the median and the second pair of lobes, one between the second and third pair of lobes, one one-tirira and one two-thirds the aistance to the cephalic margin of the pygidium; a group of four to seven plates on the cephalo-lateral margin of the pygidium; a dorsal seta on the lateral base of the median lobes, one on the lateral base of the mesal lobule of the second lobes, one on the third lobes, one one-third the distance to the cephalic margin of the pygidium, and one in the last group of plates; the ventral setae are on the ventral surface slightly mesad of the corresponding dorsal setae; five groups of circumgenital pores; the median group with seven to 

twelve pores, anterior laterals twelve to sixteen, posterior laterals sixteen to twenty-three; micropores arranged in a transverse row cephalad of the anus; first and second rows of dorial pores wanting; third row with two pores in the posterior and two or three in the anterior growo; fourth row with four pores in the posterior and one or two in the anterior groups; a groun of tubularia located cephalad of each group of pores; tubules short and wide; a marginal pore between the median and the second pair of lobes, two between the second and third pair of lobes, two between the third nair of lobes and the fourth dorsal setae; tuuularia wide and short.

Hosts.- Apple, Cornus alba siberica, Cornus paniculata, iloes (sp.), pear, sorous quercifolia.

specimens collected at Bloomington, Champaign, Chicago, llount Pulaski, and Normal were studied.

This species is more or less common throughout the state. It rarely becomes a serious pest because of its many enemies. 



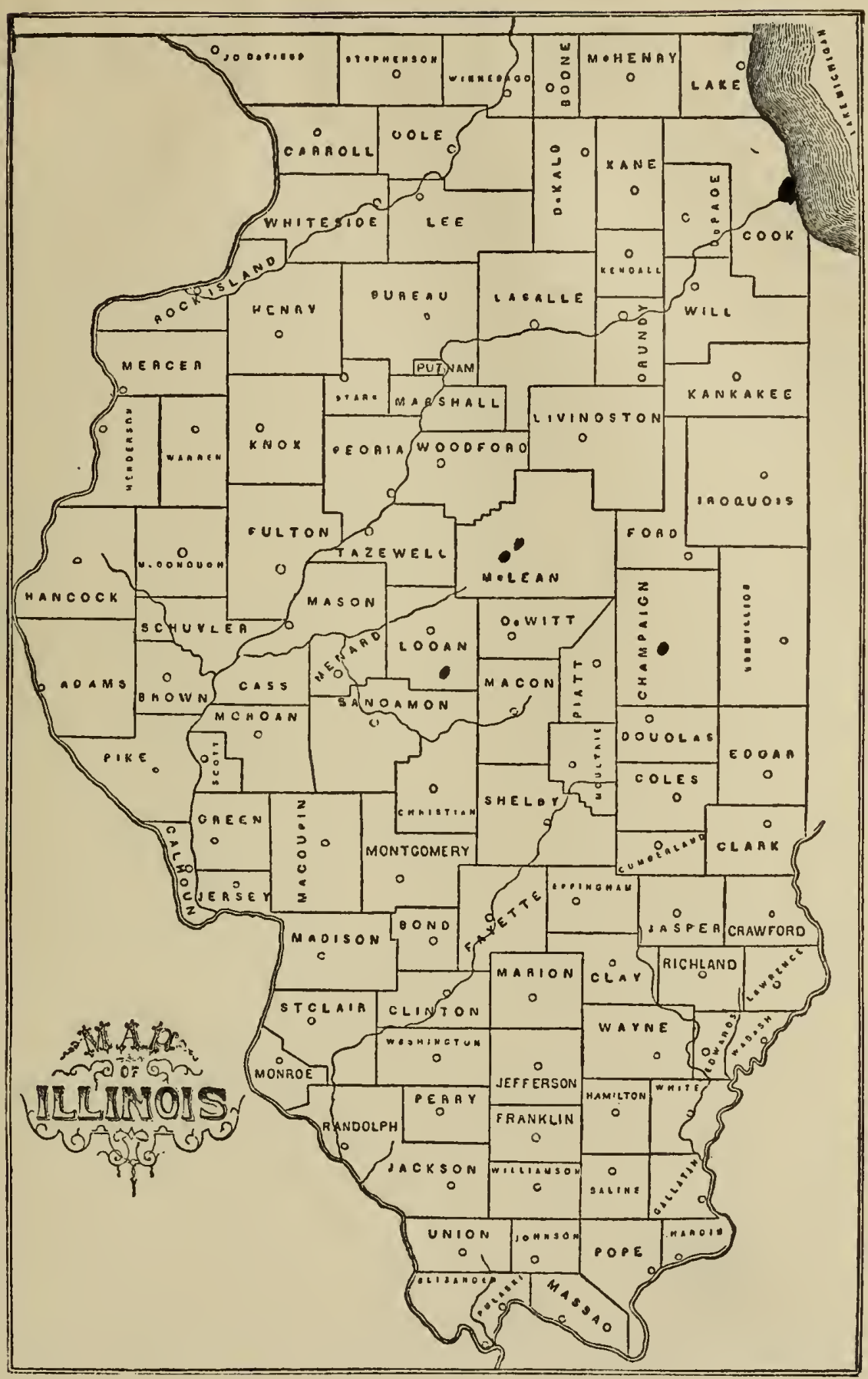



Chionaspis gleditsiae.

Chionaspis gleditsiae, sands..,Oh. st. Uni. Bull. (8) 17,1904,46.

scale of Female.- scale horn-shaped, posterior portions wider than anterior, convex, 1.40 to $2.10 \mathrm{~mm}$ in length; white or dark gray, not easily detected on the host; exuvia located anteriorly, light or dark orange yellow; ventral scile winte and delicate.

Female.- Body color light yellow in living individuals, pygidium one or two shades darker; sogmentation distinct; midest near posterior portions; pygidium vith three pairs of lobes; median lobes large, well developed, longer than wide, mesal margins fused about one-half of their length, widely divergent at apex, sharply rounded, latero-distal margins finely serrated; secrnd pair of lobes well developed, incised, mesal lobule long and narrow, apex rounded, latero-distal margin finely serrated, lateral lobule small, angular, and pointed at the apex; third pair of lobes rudimentary, oroad, flat, and finely serrated on the margin; a small inconspicuous plate between the median and the second pair of lobes, one between the second and the third pair of lobes, one one-third and another two-thiras the distance to the cephalic margin of the pygidium; a group of three or four vlates on the cephalo-lateral margin of the pygidium; dorsal setae small; one on the lateral base of the median pair of lobes, one on the lateral base of the mosal lobule of the second pair of lobes, ne on the base of the third lobe, and one two-thirds the distance to the cephalic margin of the pygidium; the ventral setae on the ventral surface shorter than the dorsal setae and located slightly laterad of the corresponding dorsal setae; five distinct groups of circumgenital pores; median group with five to 

ten pores, anterior laterals twelve to nineteen, posterior laterals eight to fourteen; micropores arranged in a subtranverse row caudo_ laterad of the anus; first and second rowis of dorsal pores wanting; third row with three to five/in the anterior and three to six in the posterinr group. located cephalo-mesad of the third orir of plates; fourth roin Bith one to four in the anterinr and three to six in the posterior group; Incated caudo-mesad of the group of plates on the cephalo-lateral margin of the pygidium; a group of tubularia for each group of pores, tubules short and wide; an elongated marginal pore between the median and the second pair of lobes, one between the second and the third, and one cephalo-laterad of the third pair of lobes; tuularia wide and short; a small slender tubule extends to the orifice in the tio of each of the plates. Host.- Gleditsia tricanthos.

specimens collected at Bloomington, Quincy, and Urbana were studied.

This species is probably not midely distributed throughout the state and it does not seem to be a serious pest. 



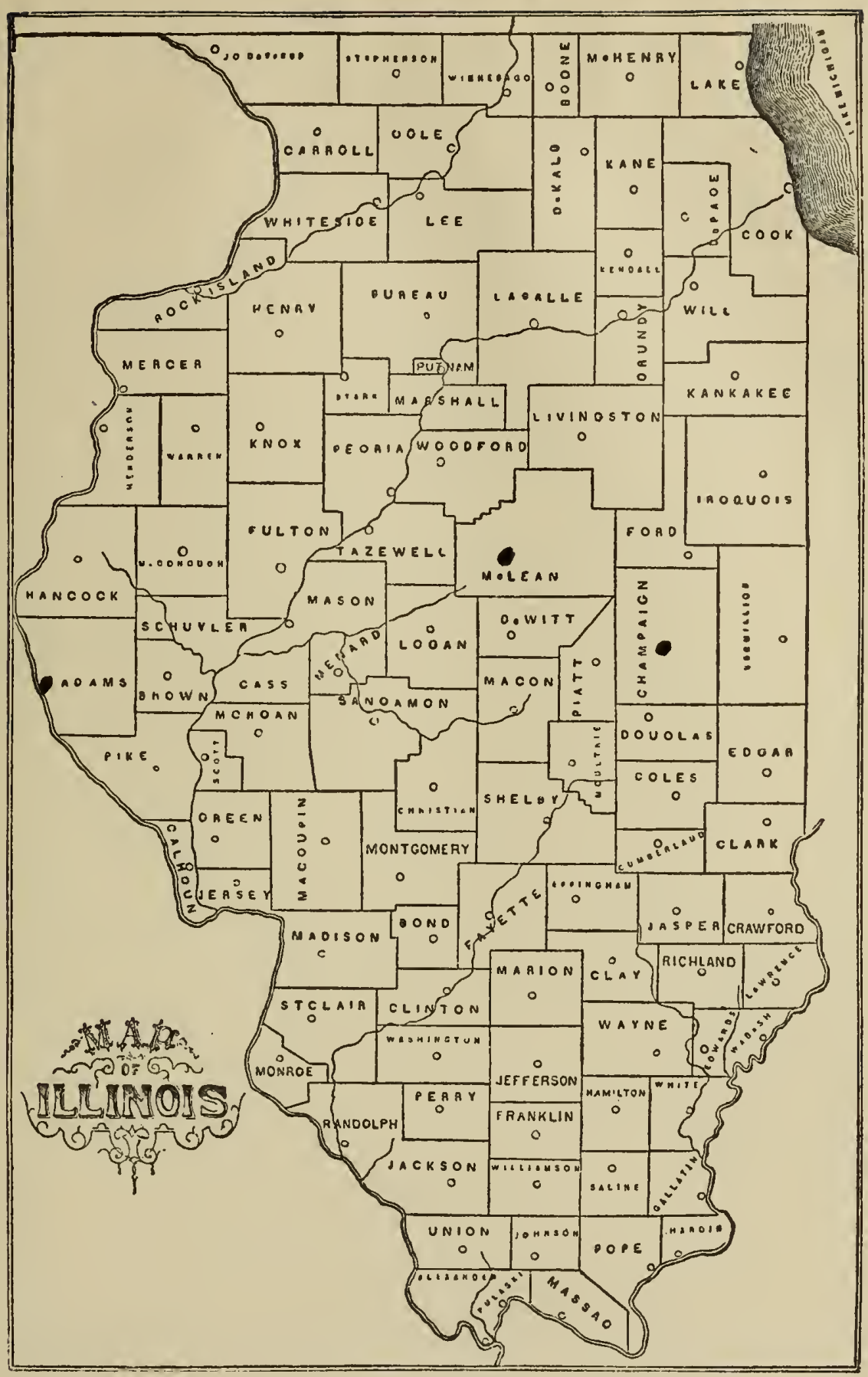

Locations whe:e Chionaspis gleditsiae was collected. 

Chionaspis pinifolia.

pinifolia, sig.,Ann. soc. Int. Fr., 1876, (5) 6, 604. pinifolia, Comstock, Rep. U.s.. Dept. Agri., 1880-81, 318. pinifolia, Conley, special Bull. Hass. Ixp. st., 1899, 30.

scale of Female.- scale elongated, broadest in the posterior region, convex, 2.90 to $3.80 \mathrm{~mm}$ in length; snow-mitite to dirty gray color; exuvia near the anterior margin, orange red to light brown.

Female.- Body color light yellow in living individuals, segmentation indistinct; pygidium broaly rounded and mith three pairs of lobes; median lobes widely separated, mesal margins slightly divergent, apices broaly rounded, and margins entire; second and thirj pairs of libes incised, mesal lobules much larger than the lateral ones, broady rounded at their apices; lateral lobules triangular and small; a small plate between the meian and the second pairs of lobes; a larger one betwe nn the second and the third pairs, a large one laterad of the tinim pil of lobes, one one-fourth and one to three one-half the distance to the cephalic margir of the pygiaium, and a croup of three or four near the cephalo-lateral margin of the pygidium; dorsal setae small and inconspicuous; one on the lateral base of the median pair of lobes, one on the lateral base of the mesal lobule of the second pair of lobes, one on the lateral base of the mesal lobule of the third pair of lobes, and one betve $n$ the fifth and sixth groups of plates; the ventral setae smaller than the dorsal setae and located on the ventral surface slightly laterad of their corresponding dorsal ones; five groups of circumgenital pores; median 

group with seven to twelve pores, anterior laterals twelve to fifteen, onsterior laterals tmelve to sixteen; micropores arranged in a subtransverse row cephalad of the anus; the first rov and the posterior group of the second row of dorsal pore wanting; the anterior group of the second row with two to four pores Incated laterad of the lateral groups of circumgenital nores; the third rom with three to five pores in the anterior and four to six in the posterior group : enurth row with four to seven in the anterzor end five to eight in tise posterirr grouc; tubularia wide and short, Incated cephalad of their corresponding groups of pores; marginal pores distinct, arranged singly around the margin of the pygidium, tubules extending to them wide and short.

Hosts.- Thite pine, jellow pine, scotch pine, and jack pine. sipecimens collected at Champaign, Dundee, and Urbana mere studied.

This species is found generally distributed over the state. The infestation in most cases is not serious to the life of the host The insect is found only on the leaves of the rost plant. 



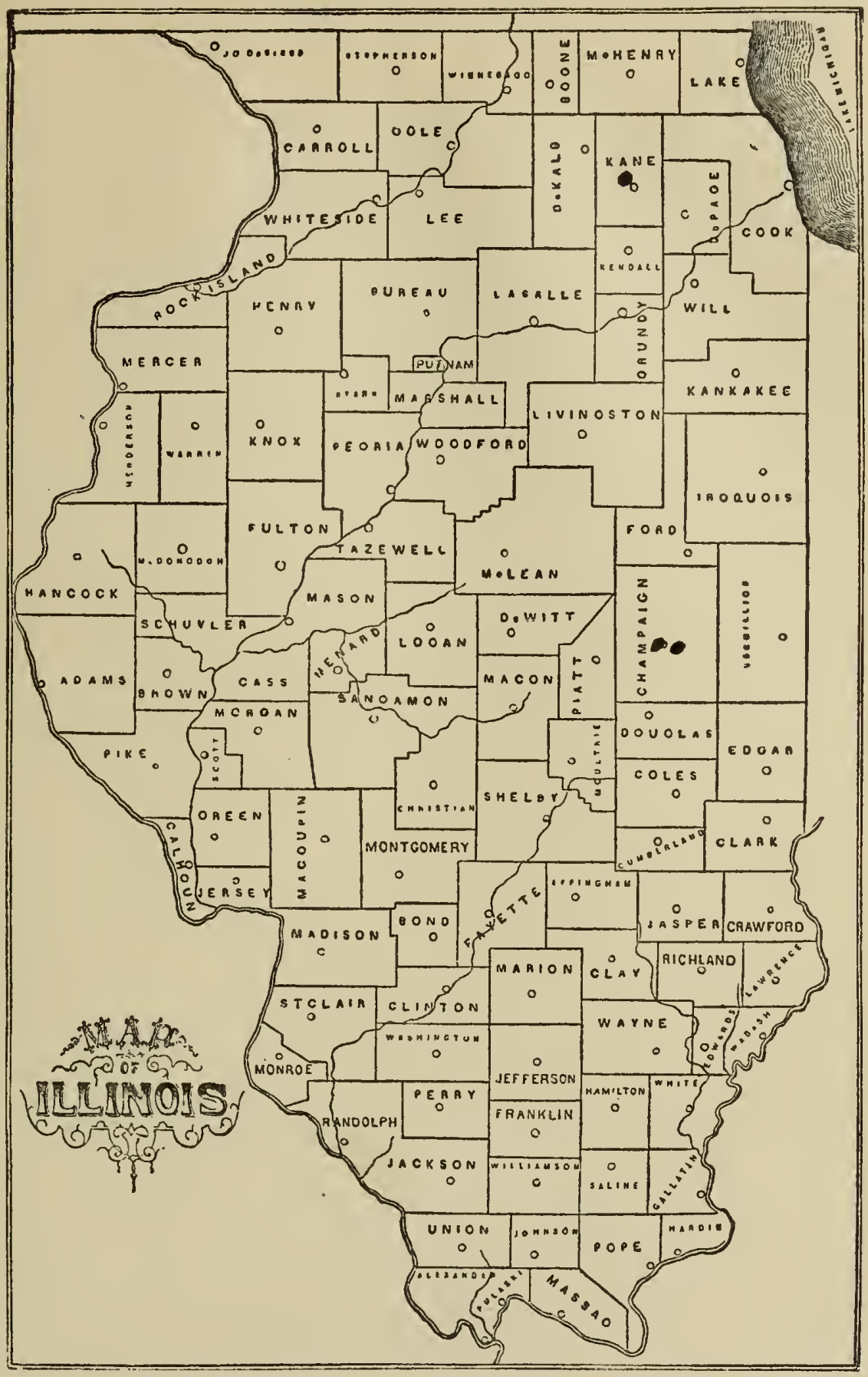

Locations where chinnaspis pinifolia was collected. 

prres in the anterior and six to nine in the posterior group; fourth row cepholo-mesad of the fourth group of plates, anterior group with five to seven and the posterior group with seven to eleven pores; a group of circular dorsal pores immediately laterad of the anterior lateral group of circumgenital pores, with nine to trelve openings; a second group with nine to seventeen pores between the anterior groups of the third and fourth rows of dorsal pores; a third group with seven to thirteen pores cephalad of the fourth row of dorsal onres; an elongated marginal pore between the median and the secoid oair of Inbes; two between the second and the third pairs of lobes; tubularia of mareinal pores vide and short; tubularia of the oval aorsal pores wide and short; tubularia of the round dorsal pores long and slender.

Hosts.- salix americana and Popalus carolina.

specimens collected at Bloomington and Urbana were studied.

This species has not been found generally distributed over the state, the infestation in most cases being local and not sexious enough to endanger the host plant. 



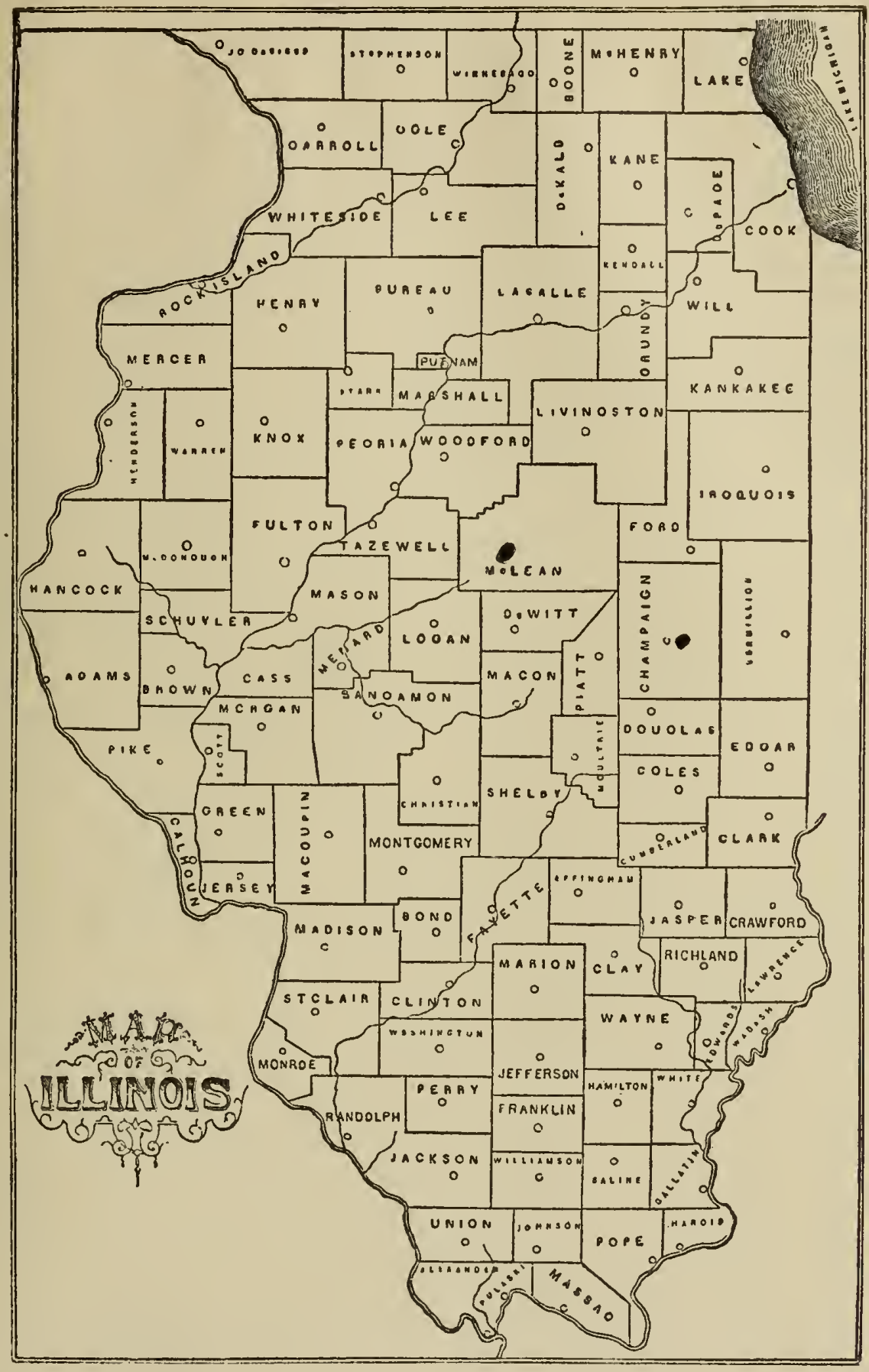

Locations where Chionaspis salicis nigrae was collected. 

Chojnaspis salicis-nigrae.

salicis nigrae, Comstock, Rep. U.j. Dept. Agri., 1880,320 . salicis, Packard, 5th Rep. U.j. Ent. Comm., 1890, 593. salicis nigrae, Cooley, jpec. Bull. Mass. Exp. st. 1899, 19. scale of Female.- scale elongate, pyriform, broadest near the midale, convex; 2.50 to $3.80 \mathrm{~mm}$ long; snowy-thite; exuvia near anterior portions, Iight to brownish yellow.

Female.- 3ody color light orange in living individuals; elongated, broadest posteriorly; pygidium broady rounded and with three pairs of lobes; median lobes vide,short, broady rounded, mesal mar gins slightly divergent, and both margins entire; second bair of lobes subequal to the median wir, incisea, mesal lobule about twice as large as the leteral, margins entire or slightly serrated; the third pair may be vanting or ruaimentary; a short plate between the median and the second bair of lobes; two betreen the second and the third pairs of lobes; two immediately laterad of the third oair of lobes; two or three one-half the distance to the cephalic margin of the pygidium; and a group of five or eight on the cephalo-lateral margin of the pygidium; dorsal setae small, one on the lateral base af each pair of lobes, and one one-thira the distance to the cephalic margin; ventral setae slightly longer than the dorsal setie and situated on the ventral surface slightly mesad of the corresponding dorsal setae; five groups of circumgenital pores; median group with twelve to eighteen pores, anterior laterals twenty-six to thirtyeight, and posterior laterals twenty to thirty; micropores arranged in a transverse row cephalad of the anus; dorsal nores with oval and circular openings; first and second row of oval pores absent; third row extends cephalo-mesad of the third pair of lobes, five to seven 

Diaspis auranticolor.

Diaspis auranticolor, Cke11., Can. Intom., 31, 1899, 106.

Scale of Female.- Scale circular or oval, slightly convex, $1.3 n$ to $1.80 \mathrm{~mm}$ in diameter; dull white to gray: exuvia eccentric, lemon yellow, first sin nalked; ventral scale delicate and a jheres to the host after insect is removed.

Femele.- Body oval; 1.10 to $1.30 \mathrm{~mm}$ long and .75 to $1.1 \mathrm{~mm}$ wide; four nairs of well developed lobes ; median loves large somewhat pyramiatal, bluntly rounded at apex, both margins distinctly notched and crenated, proximal ends meeting but divergent tomard the tips so that there is about the width of a lobe between them; second peir of lobes daubly incised with tiree lobules; the mesal one small and rudimentary; secend looule long and narror, rounded at the apex; thira lobule about as wide as the second but low and about one-third as long as the second; the third pair of lobes broad ana low deeply incised, appear saw-tooth-shaped, ana the latero-distal ends distinctly pointed; fourts pair of lobes doubly but not deeply incised, lobules saw-tooth-shaped, low and broad, and with their apices pointed mesn-caudad; a single vectinae between the meaian and the second pair of loves; a wingle larger one one between tine second and the third pairs; one betmeen the third and the fourth pair; and about twelve long plates on the margin laterad of the fourth pair of lobes; a pair of small setae between the median pair of lobes; dorsal setae large and prominent; one on the lateral base of the median pair of lobes; one on the lateral base of the third lobule of the second nair of lobes; on cephalolaterad of the lateral base of the second lobule of the third pair 

of lobes; one cephalo-laterad of the fourth pair of lobes; one one-third and one two-thirds the distance to the cephalic margin of the pygidium; ventral seta shorter than the dorsal and located on the ventral surface slightly cephalo-laterad of their corresponding dorsal setae; five groups of circumgenital pores; nedian group with nine to fifteen pores, anterinr laterals with twentyfive to thirty, posterior laterals with sixteen to twenty-five; micropores arranged in a subtransverse row cephalad of the anus; first and second row of dorsal pores wanting; third fow with four to five pores in the anterior and five to seven in the posterior group, located caudo-latere cf the circungenital pores; fourth row witn four to five in "trie atorior and four to six in the posterior group, ncated latcrad of the third row; tubularia extending to the dorwal nores short and wide; marginal poreo arranged singly around the margin of the pygidium with tubularia longer than those of the dorsal pores and about one-half as wide; tubularia extending to orifices in the glates small, huir-like, ond located caudo-mesad of the origin of the platas.

Hosts.- Imported Japanese shrub probanly osinanthus illicifolis specimens studied were collected at llount Greenwood. specimen taken from the collection of locuilae in the III. itate Iaboratory of Natural istory. 



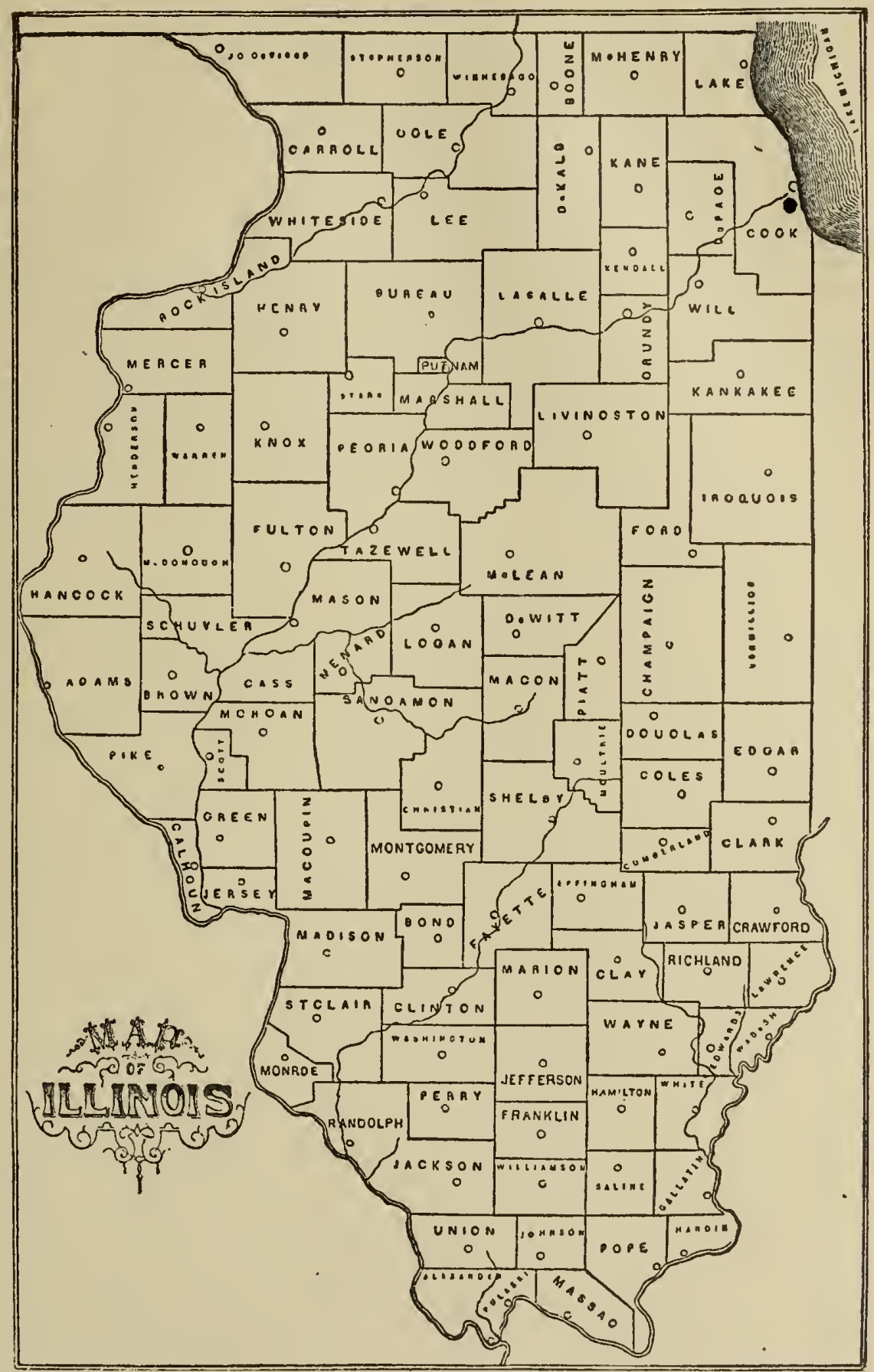



Lepidosaphes ulmi.

Hytalaspis pomorum, Comst., Rep. U.s. Dept. Agri., 1880-81, 325. Nytálaspis pomorum, Howard, Can. Entom., 26, 1894, 353. Lytálaspis ulmi, cockerell, Pr. Ac. N. Nci. Ph., 1899, 275. Mytalaspis pomorum, Iing and CkI1., Can. Intom., 33, 1901, 200. Lepidosaphes ulmi, jancers, ch. st. Uni. Bull. (8) 17, 1904, 74. scale of Female.- scale elongeted, horn-shaped, widens postericrly, convex, 2.40 to $3.10 \mathrm{~mm}$ in length, sniny black to brom; exuvia in the anterior portion, brom to brownish yellow; ventral scale dirty-white to gray.

Female.- Body color usually white or yellow, pygidium a few shades darker; pygidium with two pairs of lobes; median lobes large, prominent, mesal margins parallel for about one-half the length of the lobe, mesal and lateral markins distinctly notched near the apex; second pair of lobes broader than long, incised, lobules broaly rounded at apex, mesal one about three times as large as the lateral one; two spine-like plates between the median lobes; two unequal plates between the median and the second pair of lobes; two immediately laterad of the second peir of lobes; two one-third and two two-thirds the distance to the cephalic margin of the pJgidium; a strongly chitinized mareinal pore between the lateral base of the median and tre mesal base of the second pair of lobes: two elongated narginal pores laverad of the sevomi pair of lobes; a pair cephalo-laterad of the fourth pair os plates; and a pair laterad of the fifth pair of plates; dorsal setae long, promident, and dark; one on the base of each margin of the median pair of lobes; one immediately laterad of the second pair of lobes; one one-half the distance between the third and fourth pair of plates; 

and one one-half the distance between the fourth and iifth pair of plates; ventral setae located on the ventral surface of the pygidium; ne near the base on each margin of the median pair of Iobes; one on the lateral base of the mesal lobule of the second pair of lobes; one one-half the distance between the fourth and fifth pairs of plates; four or five stiff spine-f near the cephalic margin of the pygidium; five groups of circumgenital pores; median group with twelve to eigiteen pores; anterior laterals fourteen to twentythree; and posterior laterals sixteen to twenty-eight; four rows of dorsal pores; first row absent; second row with fifteen to twentyone small orifices located caud-mesad of the second pair of marginal pores; third row with ten to sixteen pores extends caudo-mesad of the fourth pair of plates; the fourth row with six to eight pores extends caudo-mesad of the fifth peir of plates; and tie fifth row with six to eight pores extends mesad from the margin cephalad of the fifth pair of plates; tuivlaria of the marginal pores short, as wide as the pores, and/extends caudo-mesed of each pore; four distinct rows of tubularia; a row for each row of jorsal pores, tubules located cephalo-mesad of their corresponding rows of dorsal pores; numerous smell tubularia arrangea promiscusly around the margin of the pygidium.

Hosts.- Apple, Cornus alba siberica, Cornus paniculata, Cydonid japonica, Fraxinus albe, Populus caroline, Rosa rugosa, Rosa (sp.), syringa vulgaris, jyringa $(s p$.$) , symphorecarphus vulgaris, and$ UImus americana.

specimens collected at Arlington Heights, Champaign, Chicago, Glenview, Kankakee, Iincoln, Naywood, Penria, Texico, and Urbana 

were studied.

This species is found to be generally distributed over the state. Very often the degree of infestation becornes so serious that the life of the host plant is threatened. 



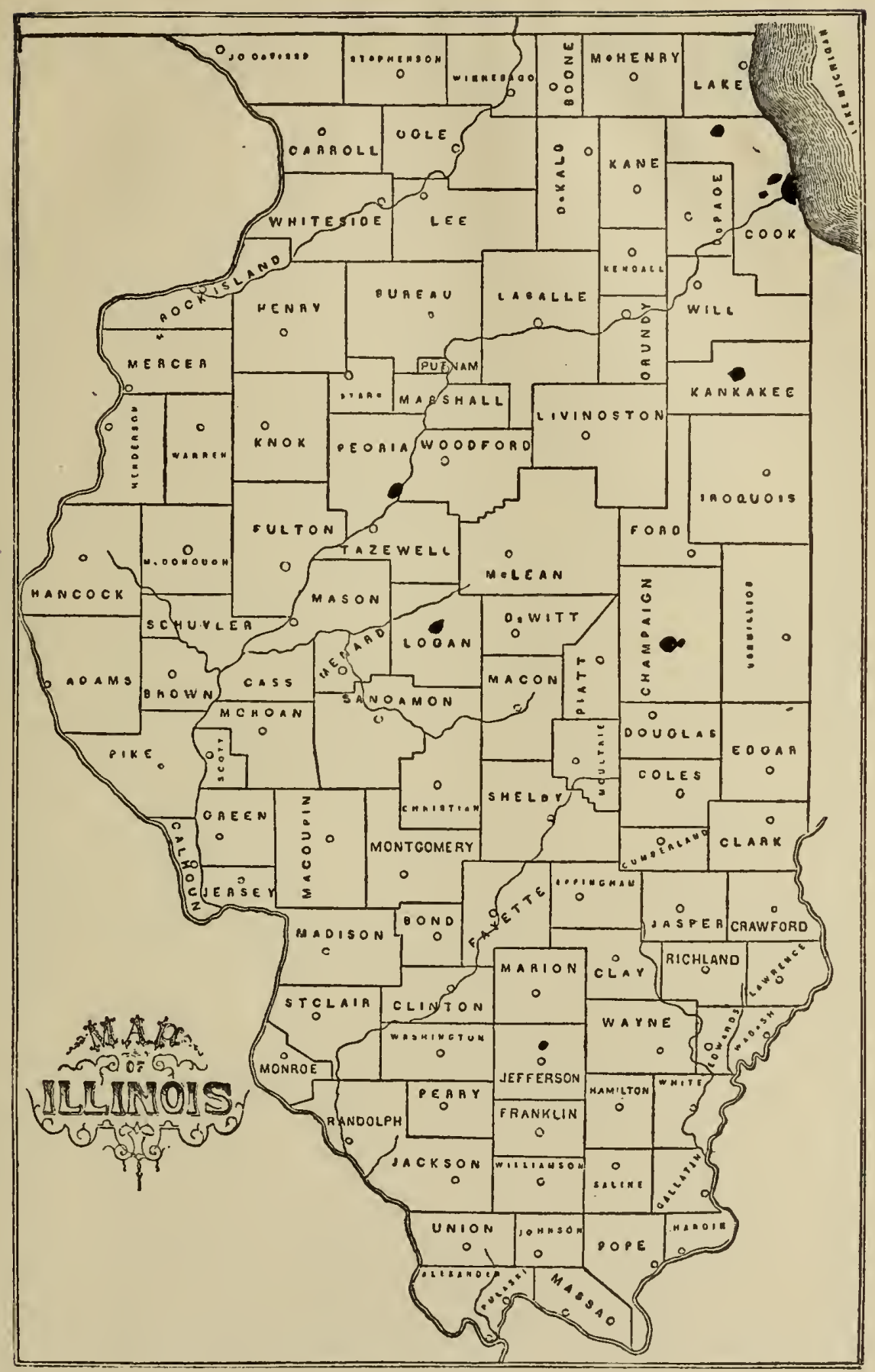

Locatlons where Lepijosaphes ulmi was collected. 



\section{Aspidiotus ancylus.}

ancylus, Comstock, Rept. U.'. Dept. Agri.,I880-8I, 292.

ancylus, Cockerel1, Can. Entom., 26, 1084, 191.

ancylus, Cockerell, Can. Entom., 27,1885, 261.

ancylus, sanders, Ohio Uni. Bull. (8) 17, 1904, 57.

icale of Female.- scale circular or nearly so, convex, 1.00

to $1.50 \mathrm{~mm}$ in diameter, body dark grey, periphery light gray; exuvia eccentric, covered, bricir-red; ventral scale whtte and delicate.

Female.- Body reddish Jellow in living individuals, oval to circular, segmentation indistinct; only median lobes present, well developed, distincty notchea near the midale of the distal margin, frequently with a sma.l notch near the middle of the caudo-mesal angle of eacn lobe,mesal margins distinctly separated and varallel for about one-half their length; incision between the nedian pair of lobes small, second incision wiảe and shallow; thirä incision two-third as wide as and equally as doep as the second; mesal margins of the medien peir of lobes with chitinous thickenings; a pair in the second and third incisions, the lateral thickening of each pair about two-thirảs as wiae as the lateral one; a pair of pectinae between the median pair of lobes; two pectinae in the second incision, dorsal setae at the lateral base of the median lobes, a pair laterad of the second and the third incisions; the ventral setae are on the ventral surface slightly laterad the corresponding dorsal setae; five groups of circumgenital glend orifices; the median group with zero to six pores; antericr laterals with six to fourteen; and the posterior laterals with five to eight; basal thickenings with the anterolr plates wide, short, and located mesad the anterior group of circumgenital glanas; posterior plates wide, long, mesad the 

posterior circumgenital pores, cephalic ends extenaing silghtly laterad between the anterior and the posterior groups of circumgenital pores; calli witn mesal plotes oeprate, lateral plates subequal in length and width to the median peir; four rows of dorsal pores; first row cephalo-laterad of the median pair of lobeg. two to Iour pores; second row cephalo-leterad ot the first and contains eight to ten pores; third row with six to nine pores located laterad of the second row; and the fourti row with two or four pores located laterad of the third and varallel to the margin of the pygidium; four groups of tusularia; first group situated caudad of the anus, ducts short, and extend to the first rom of dorsal pores; second and third groups with long ducts which extend to the second and third groups of dowsal pores respectively; and the fourth group with long slender tubules extends to the fourth row of dorsal pores.

Hosts.- Apple, Acer (sp.), chestnut oak, Cornus alba siberica, Cornus (sp.), Fraxinus alba, Gleditsia tricanthos, Juglans nigrae. osage orange, Populus carolina, Ribes flor., sorbus querquifoliz Ulmus americana, and jalix americana.

specimens collected at Belleville, Bloomington, Uhampaign, Uhicago, Cleyton, Galesburg, Joliet, Iormal, Juincy, springfield, and Urbana were studied.

This species is found generally distributed throughout the stato; homever, it is not of any great economic importance. This species is very often mistaken for aspidiotus forbesi. The tendency of tinis insect. to collect in groups on the host plent is often considered as characteristic of the species. 



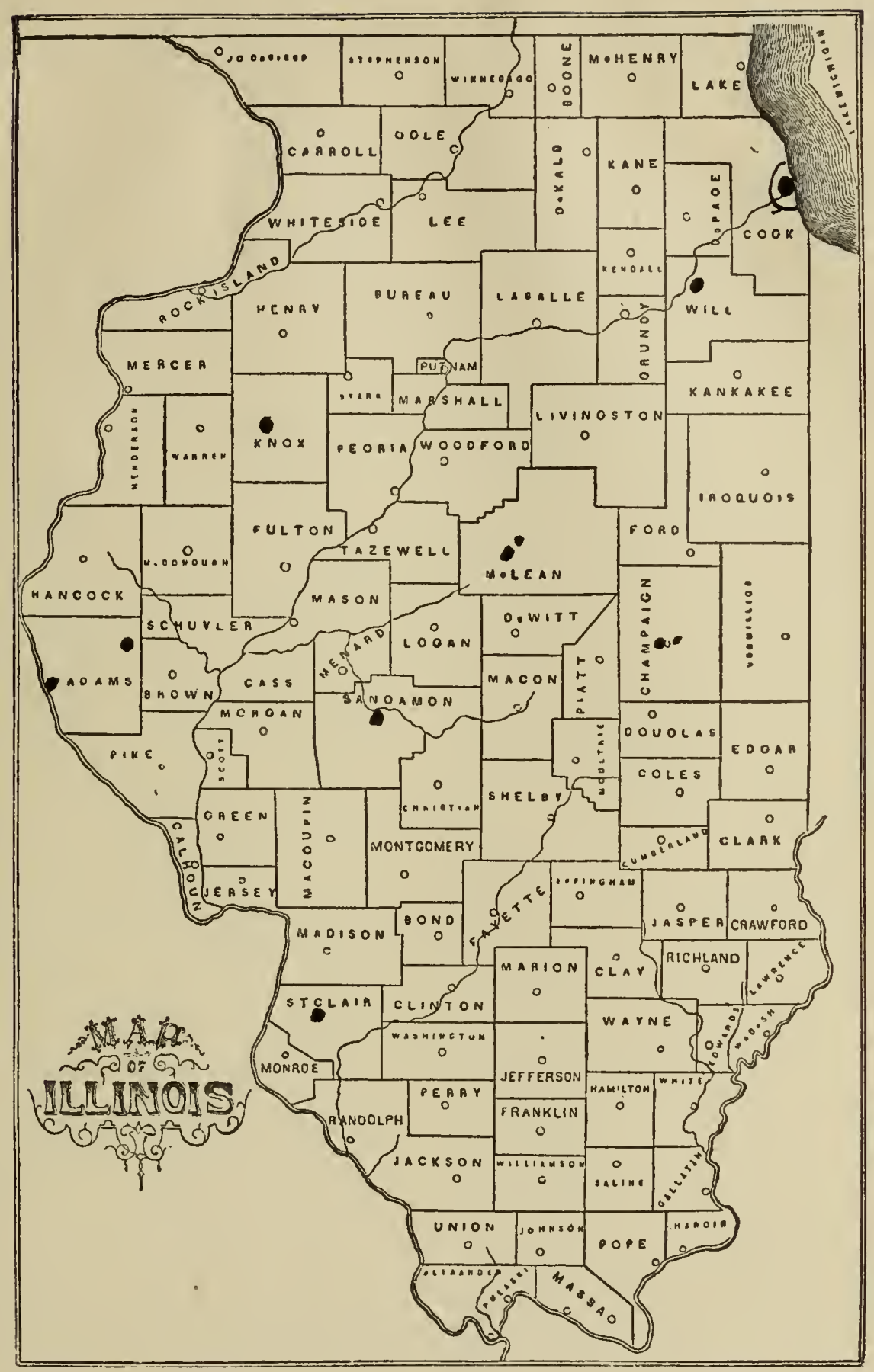

- Locations where Aspidiotus ancylus mas collected. 

Aspidiotus forbesi.

forbesi, johnson, int. News, 7, 1896, 151.

forbesi, Bull. Ill. St. Iab. N.H., 4, 1896, 380 .

forbesi, Forbes, 20 Report Ins, Ill, 1898, 16.

forbesi, Felt, Bull. 46, IT.Y. itt. Mus., 19n1, 330_-341.

forbesi, Sanders, nh. st. Uni. BuIl., (8) 17, 1904, 60 .

scale of female.- scale circular, convex, airty gray, a few shades lighter than Asvidiotus ancylus, delicate; 1.50 to $2.40 \mathrm{~mm}$ in diameter; exuvia cestral or nearly so, coverea with a delicate film; ventral scale very delicate.

Female.- Body colored orange red in living individuals, segmentation indistinct, pygidium slightly prolonged; pygidium with two pairs of lobes; median lobes large, well developed, prominent, converging near the apex, rounded, and distinctly notched on their latero-distal margins; second oair of lobes one-half to two-thirds as wiae as the median lobes, distal margin slightly rounded or pointed, oblique lateral margin with two or four distinct notches;

a pair of club-shaped chitinous processes betmeen the median lobes, a pair in the incision between the median and the second pair of lobes, the mesal one twice as large as the lateral one, somewhat gourdshaded, a third pair in tile incision laterad of the second paim of lobes, the mesal process distinctly larger than the lateral; incision between the median lobes narrow and shallow, incision between the median and the second pair of lobes narrow, and an incision laterad of the second pair of lobes as long as the median incision and slightly wider; plates or pectinae manting between the median lobes, a pair of inconspicuous plates in the third incision; 

pectinae absent; dorsal setae located only at the lateral base of the second pair of lobes, one near the third incision, and one near the middle of the pygidial marcin; ventral setae located on the ventral suriace slightly mesad their corresponding dorsal setae, seta on lateral base of the median lobes present; five groups of circurngenital pores; median group with one to four pores, anterior laterals three to six. posterior laterals three to 1ive; basal thickenings present, posterior pair large, long, subparallel to the meson, located mesad the postexior lateral grouo of circumgenital pores; anterior pair short, not parallel with the meson anà located mesad the anterior lateral group of circumgenital pores; calli with mesal plates fused on the meson forming a low $V$, lateral plates narrower than the mesal, aistinctly separated, and parallel with the cephalic margin of the pygidium; three rows of dorsal pores; first row consists of three or four pores located cephalad of the second incision, second row of five to ten located caudad of the third incision, and the third row of seven to twelve pores located slighty cephalad of the third incision; three distinct groups of tubularia; first group located cephalo-laterad of the anus and extend to the first row of dorsal pores, second group cephalo-laterad of the first and extend to the second rov of dorsal pores, and a third group lies parallel to and laterad of the second group and extends to the third row of dorsal pores.

Hosts.- Apple, cherry, Cornus alba siberica, flowering almond, osage orange, nlum, Prunus pissardi, peach, Ribes (sp), Syringa vulgaris, syringa (sp.), Ulmus americana. 

Specimens from Decatur, Glenviev, Joliet, Mount Pulaski, Wount sterling, Texico, and Urbana were studied.

Protassor Johnson gave this scale the namel" Cherry scale" and says that it is one of the most dangerous scale insects of Illinois. Bven though the species reprodoces very rapidly, its progress is held in check by its parasitic enernies and the indbility of the insect to withstand the winters in the northern part of the state. However, this insect causes a great deal of damage and it should be rated as one of the chief scale pests of this region. It is generally distributed from the northern to the southern parts of the state; the greatest damage, however, is done by it in the southern parts. 



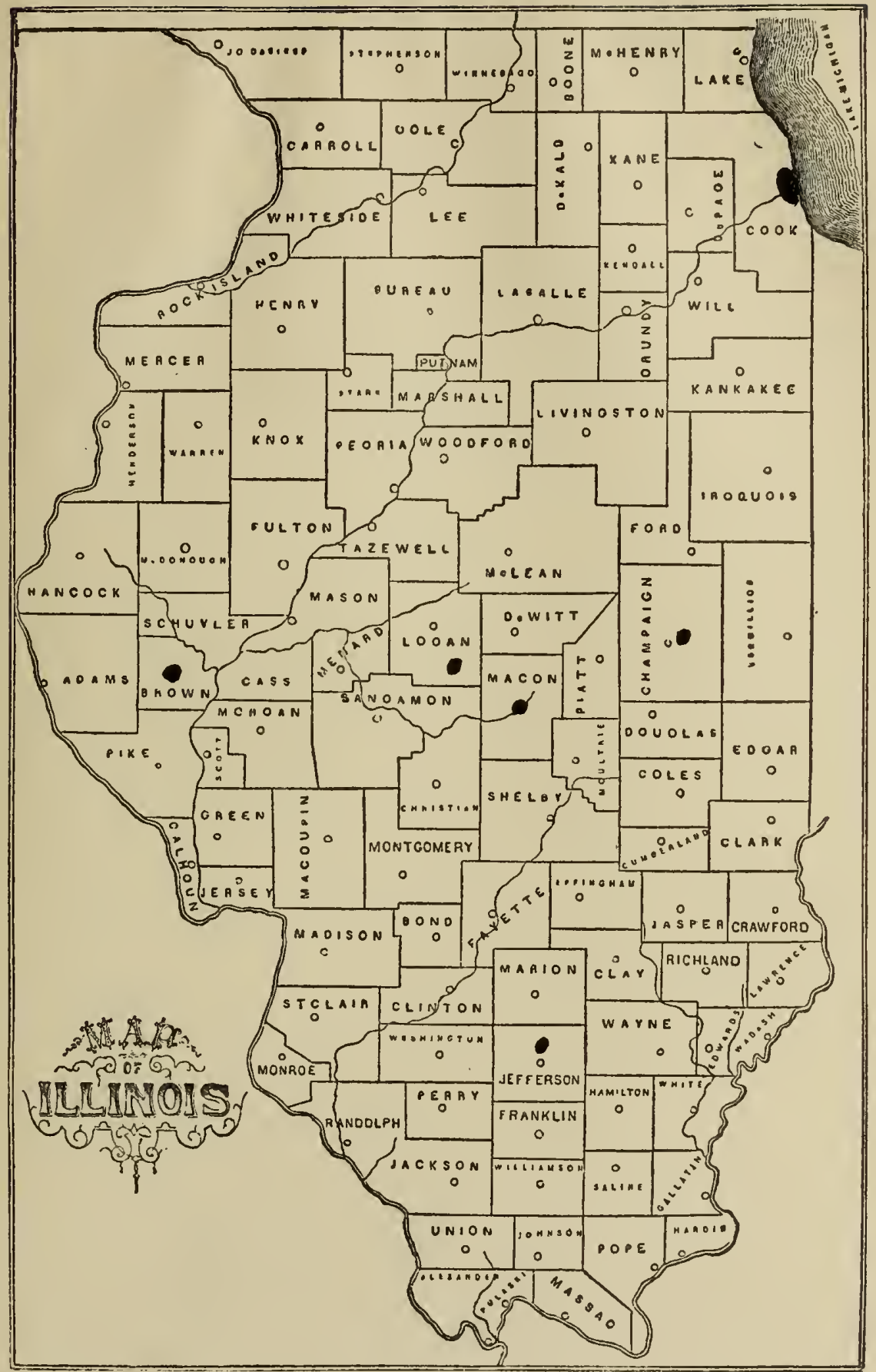

Locations where Aspidiotus forbesi was collected. 



\section{Aspidiotus fernaldi.}

fernaldi, Cockerell, Ann. Mag. Iat. Hist. (7) 2, 1898, 323. fernaldi, Iing, Can. Entom. , 31, 1894, 226.

fernaldi, Parrot, Can. Entom.,31,1894, 10.

fernaldi, Newell, Contr. Ia. Agri. Coll., 3, 1899.

scale of female.- Scale circular, slightly convex, 1.80 to

$2.10 \mathrm{~mm}$ in diameter, dark gray; exuviae orange red, slightly eccentric; ventral scale white, delicate, adheres to the host after the insect is remored.

Female.- Body color light yellow in living individuals, oval, segmentation indicsted ing the margin of the body; pygidium with two pairs of well developed lobes; median pair large, inner margins not parallel, distal margins not broady rounded, and the laterodistal margin distinctly notched; second pair of lobes triangular, distinctly inclined caudo-mesad, and the oblique latero-distal margin with four or five notches; incision between the median pair of lobes with thickened edges; second and third incisions with paraphyses-like thickenings, the mesal ones twice as long as and slightly wider than tine lateral ones; a pair of plates between the median lobes; a bifurcated or trifurcated pectinae between the median and the second parr of lobes; a small, inconspicuous pectinae laterad of the second pair of lobes; dorsal setae large, prominent, a pair at the lateral base of each lobe, one nne-third and one onehalfe distance to the cephalic margin of the pygidium; ventral setae shorter than the dorsal setae, located on the ventral surface slightly laterad of their corresponding dorsal setae; five groups of circumgenital pores; median gromp with two to seven pores, anterior laterals. with eight to fourteen, posterior laterals with 

Pive to seven pores; basal thickenings with the anterior pair of plates small, located mesad of the anterior lateral group of circumgenital pores; posterior plates wide, long, J-shaped, lncated mesad of the posterior lateral group of circumgenital pores, and with the cophalic end extending laterad between the anterior and the posterior lateral grouns of pores; calli with median plates fused at meson forming a low $V$; lateral plates thread-like and not parallel with the cephalic margin of the pygidium; four rows of dorsal pores; first row cephalad of the incision between the median and the second pairs of lobes with two to four pores; second row located laterad of the first and cephalad of the incision laterad of the second pair of lobes; third row lncated latero-cephalad of the second; and the fourth row latero-ce ohalad of the thira; four distinct groups of tubularis; first row caudad of the qnus, ducts short, tubules extend to first row of dorsal pores; second group located laterad of the anus, tubules long,slender and extend to the second row of dorsal pores and the third incision; third row located cephalo-laterad of the second, tubules long, slender, and extend to the third row of dorsal pores; the fourth row cephalad of the third and parallel with the margin of the pygidium, tuoules long, slender, and extend to the fourth row of dorsal pores.

Hosts.-Acer (sp.), black locust, cataloa, Fraxinus excelsus, jorbus, symphorecarphus vulgaris, and Tilia ameriaana.

specimens studied were collected at Bloomington. Champaign, Chicago, ana Glenview.

This species is more abundant in the northern than in the southern part of the state. There is a tendency to collect in masses on the trunk and larger limbs of the host. Scale not a serious pest. 



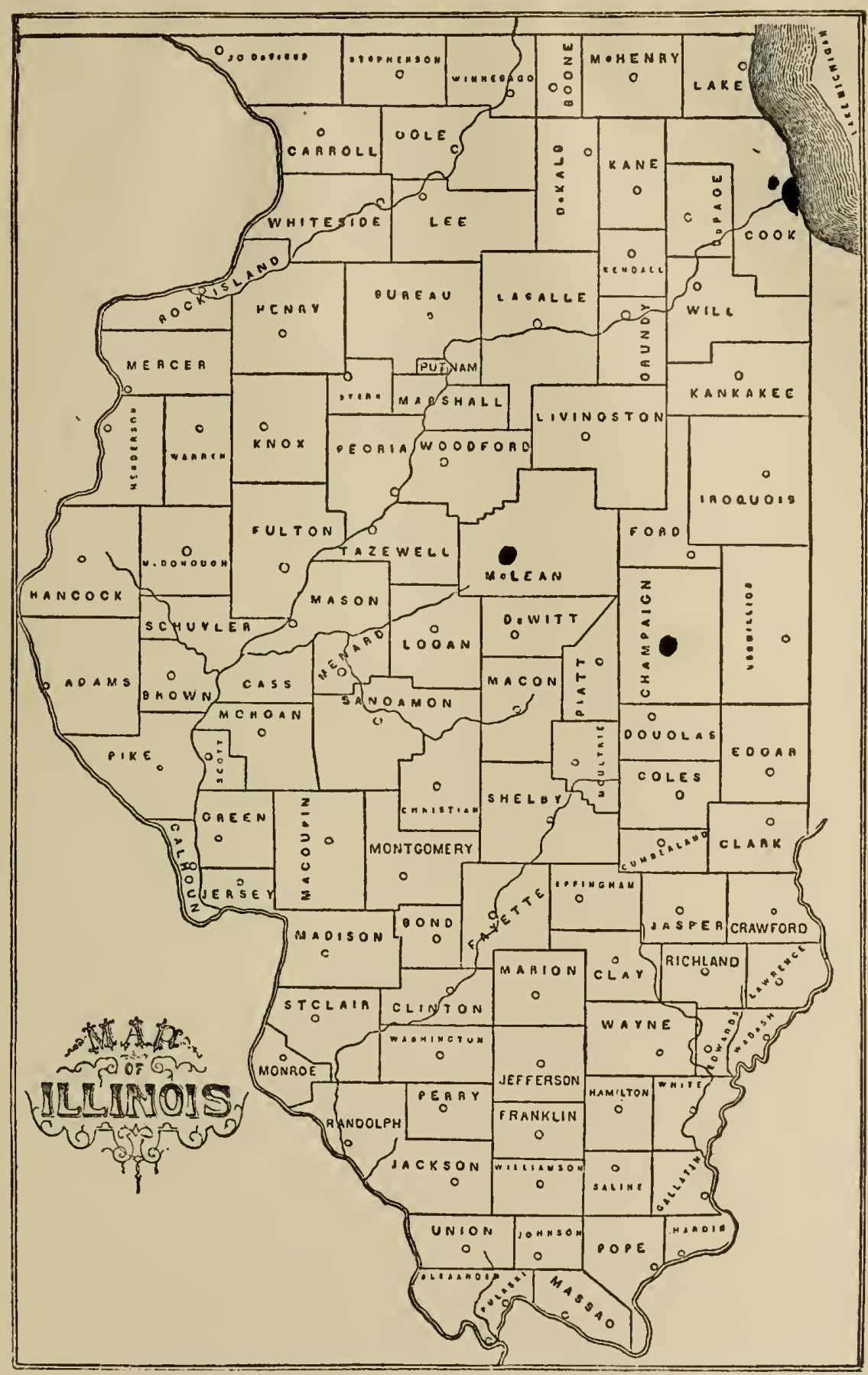

Locations where Aspidiotus fernaldi was collected. 

Aspidiotus hederae.

hederae, liaskel1, New Zea. Trans., 11, 1878, 197.

nerii, Comstoci, Rep. U.s. Dept, Agri., 1880-81, 301.

hederae, Irewstead, Hono. Br. Coccidae, I, 1901, 120.

hederae, King, Can. Entom., 31, 1899, 225.

hedera, janders, Oh. st. Uni. Bull. (8) 17, 1904, 62.

Scale of Female.- scale oval or irregularly circular, flat,

1.50 to $2.00 \mathrm{~mm}$ in diameter, dirty wite to light yellom; exuvia

ligint yellow, slightly eccentric, and exposed.

Female.- Body color light yellow in living individuals, oval; pygidium with three paixs of lobes; median pair elnngate, well develoned, distinctly notched near the distal extremity on both mesal and lateral margins; second pair of lnbes elongate, well developed, distinctly notched near the lateral margin of the anex; third pair small and pointed; incisinns and chitinous thickenings wanting; pectinae extend beyond distal margin of loves; two distinct pectinae jetween the median lobes; two between the median and second pair of lobes; three between the second and third pair of lobes; and six laterad of the third pair; three blates laterad of the last group of pectinae; dorsal setae located at the lateral base: of each lobe, one one-third and one one-half the distance to the cephalic margin of the pygidium; ventral setae on the ventral surface located slightly laterad of their corresponding dorsal setae; four groups of circumgenital pores; anterinr laterals with eight to twelve openings; posterior laterals with six to ten; basal thickenings present, narrow, generally curving laterad at their cephalic ends; calli with four distinct plates, arranged in 

a subtransverse row across the cephalic portion of the pygidium, parallel with the cephalic margin; dorsal pores arranged in four irregular rows or groups; first group consists of three to five openings cephalad of the median lobes;second group consists of six or seven pores cephalo-laterad of the first group; third group with Iive to seven pores Iocated parallel to but slightly laterad of the second group; and the fourth row of a varying nurber of ovenings laterad of the tinird and near the lateral margin of the pygidium; four groups of tubularia; a group located cephalad of each group of dorsal pores; tubules short and wide.

Hosts.- Citrus trees, and most. of the common greenhouse plants.

specimens from Gampaign, Saybrook, and Tuscola were studied.

This species is more or less common over the state, but it is found only in greenhouses, and, therefore, it is confined largely to the northern part of the state where the florist industry is pursued 'with greater vigor. 



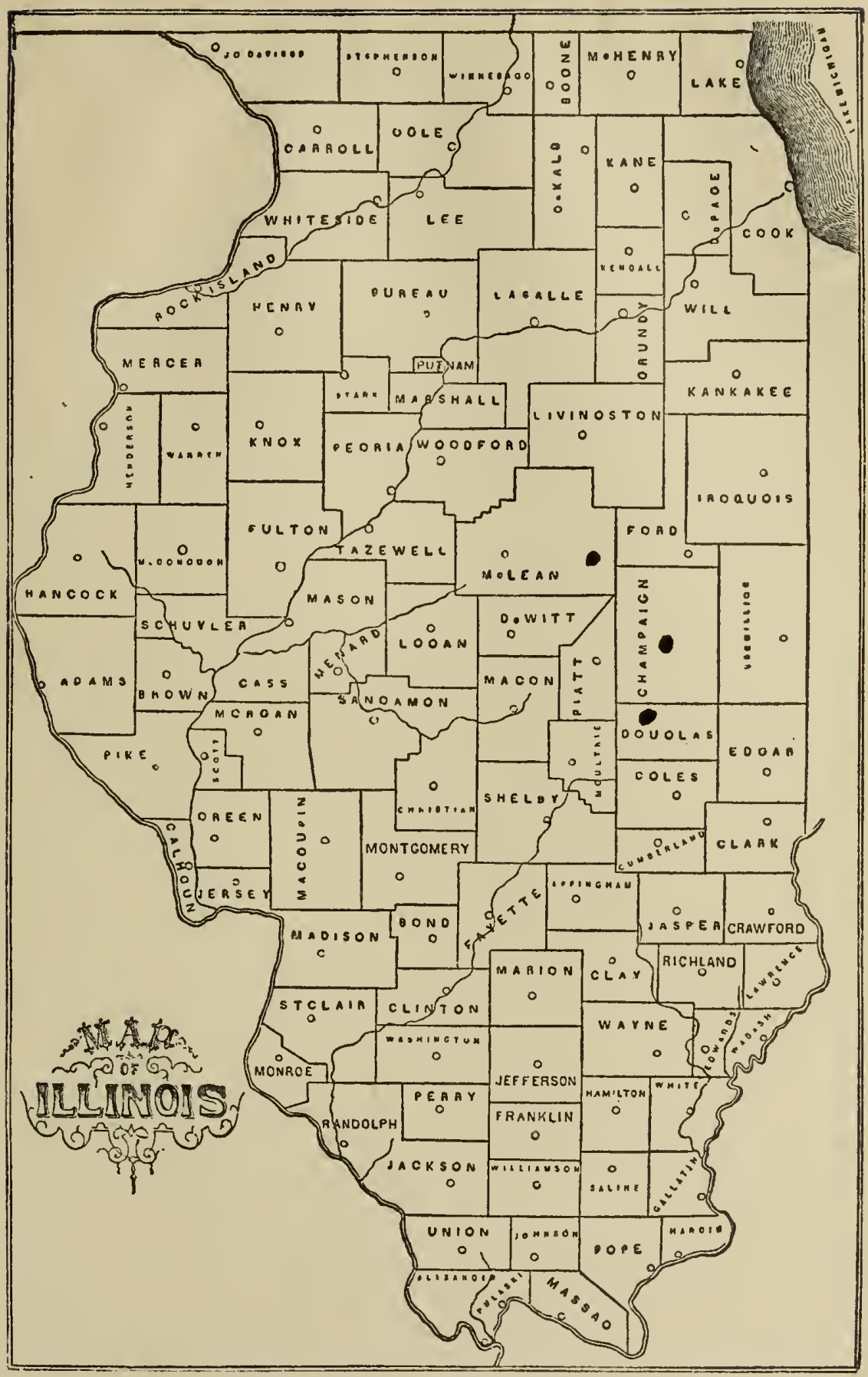

Iocations where Aupidiotus hederae was collected. 

Aspidintus juglans-regiae.

juglans-regiae, Comstock, Rep. U.S. Dept. Agri., 1880-81,300. juglans-regiae, Cockerel1, Can. Entom.,26, 1894, 131, 394. juglans-regiae, Sanders, Oh. Uni. Bull. (8) 17, 1904, 62. Scale of female.- scale circular, flat, 2.80 to $3.00 \mathrm{~mm}$ in diameter, reddish to redaish-brown, exuvia slightly eccentric, covered with a thin waxy secretion; ventral scale thin, delicate, film-like, and adheres to the bark after the scale is removed.

Female.- Body color pale yellov in living individuals, slightly oval, segmentation indicated along body margin; pygidium with three pairs of lobes; median lobes ed, set close together, mesal margins converging at apex, and with a distinct notch on the latero-distal margin; second pair of lobes abnut two-thirds as long as and one-half as wide as the median pair of lobes, lateral margins oblique with three or four distinct notches; third pair of lobes rudimentary, little more than a pushed out point in the body margin;a pair of small chitinous thickenings between the inner bases of the median pair of lobes, a pair in the margins of each of the incisions, the mesal thickenings of each pair are distinctly larger than the lateral ones; a pair of short inconspicuous plates between the median lobes; a pair of pectinae in the second incision, the mesal one about two-thiras as wide as the lateral one which is distinctly furcated; three or four furcated pectinae in the third incision; dorsal setee are large and proninent, one in the lateral base of each lobe, one about one-third and another about two-thirds the distance to the cephalic margin of the pygidium; ventral setae situated on the ventral surface sightly 

laterad their corresponding dorsal setae; five groups of circumgenital pores; median group of zero to ten pores; anterior laterals oight to sixteen; posterior laterals four to eight; calli with median plates fused; lateral platos small and parallel with the cephalic margin of the pygidium; basal thickenings with the anterior plates small and located laterad the anterior group of circumgenital pores; posterior group Inng, slender, mesad of the posterinr group of circumgenital, pores; five grouns of dorsal giland orifides; first group latera of the median lobes, contains three to five pores; second group laterad of the second lobes, contains twelve to twentyfour pores; third group laterad of the third lobes contains eighteen to twenty pores; fourth group located immediately laterad of the third group contains six to ten openings;and the fifth group is a miscellaneous group laterad of the fourth group and near the margin of tine body; five groups of tubularia; the first group caudac and laterad of the anus witin short tubules extending to the first incision and the first group of dorsal pores; the second group laterad the first and caudad of the anus with tubules longer than those of the first group extending to second incision and second group of dorsal pores; third group cephalo-laterad of the anus with long slent der tubules which extend to the third groun of dorsal pores; fourth group cephaln-laterad of tine thira, tubules short and extend to the fourth group of dorsal pores; fifti group laterad of the fourth, tubules short and extend to the lifth group of anrsal pores.

Hosts.- Juglans nigra), Acer (sp), Papulus carolina, valix americana, jymphorecarphus vulgaris.

specimens collected at Bloomington, Bowmanville, dairo, Chicago, Glenview, and ilorgan Park were studied. 

This scale was first described by Professor Comstocis in 1880 . It was discovered on English walnut, but since its aiscovery, it has been found on various other host plants. This species is not generally distributed throughout Illinois; the heaviest infestation is near Chicago and from this place the infestation becomes lesis and less towar $\mathrm{u}$ the south. The species is not of anz great economic importance $\pm n$ IIlinois. 



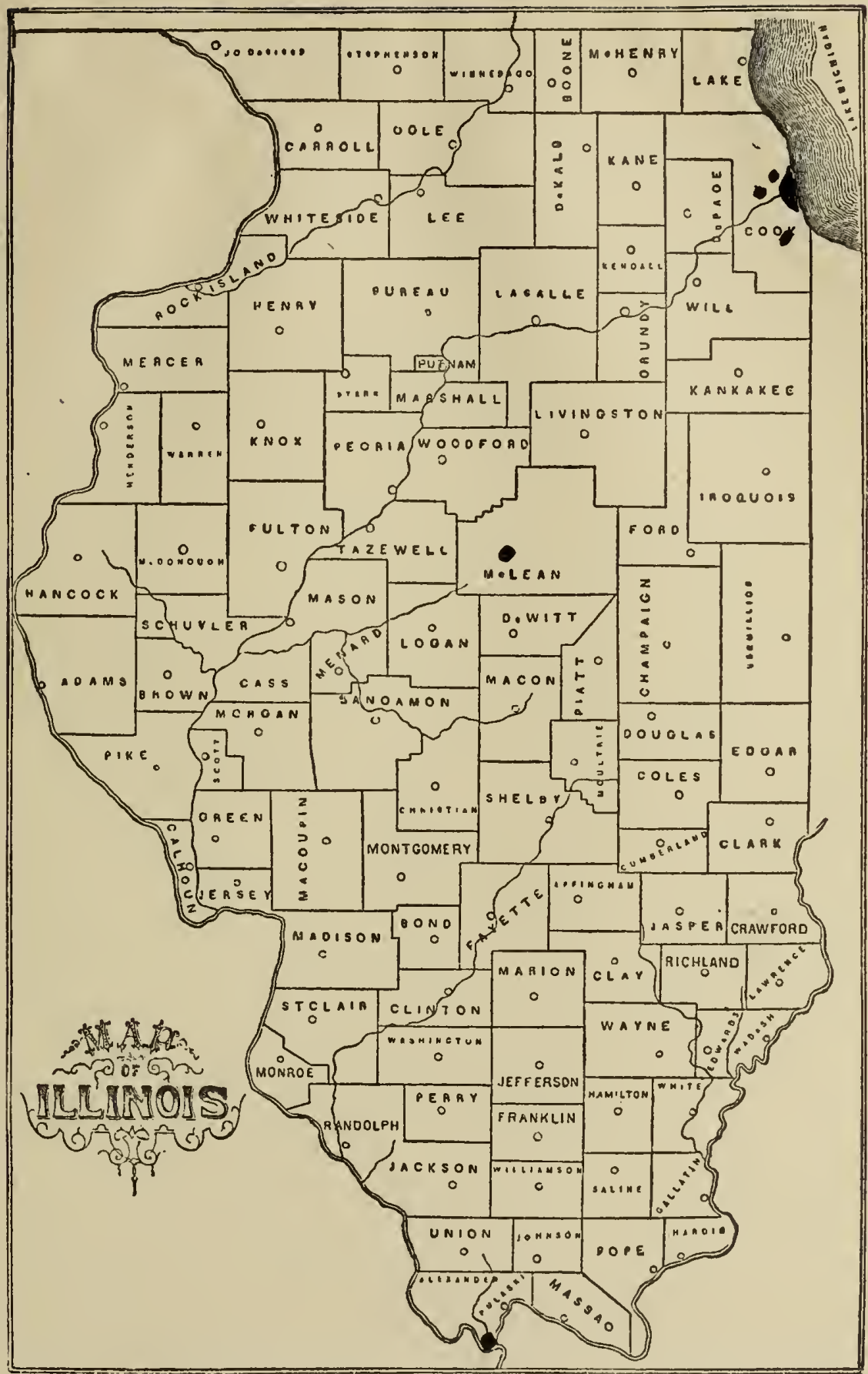

Locations where Aspidiotus juglans-regiae was collected. 

Aspidiotus ostraeformis.

Diaspis ostra eformis, Comst., Rep. U.S. Dept. Agri. 1880-81, 311. Aspidiotus ostraeformis, Newst.,Mono. Br. Coccidae, 1, 99. Aspidiotus ostraeformis, San.,Oh. Uni. Bull. (8) 17, 1904, 64. Diaspis ostraeformis, sig., Essai sur le Coc., Ann. soc. Ent. Fr.

scale of İemale.- s̀cale circular or oval, flat, l.00 to 1.55 $\mathrm{mm}$ in diameter; body of scale generally ashy-gray, periphery somewhat lighter color; exuvia large, dark-brown, slightly eccentric; ventral scale white and delicate.

Female.- Body color light yellow in living individuals, circular, segmentation indistinct; pygidium with two pairs of lobes; median lobes large, well developed, lateral margins broadly rounded, mesal margins parallel, and latero-distal margins distinctly notched; second pair of lobes as wide as and one-nalf as long as the median pair of lobes, bluntly pointed, and distinctly notched nn the oblique latero-distal margins; incision between the median lobes with thickened edges; a pair of paraphyses-like thickenings in the incision between the median and the second pair of lobes, the mesal process larger than the lateral; a subequal pair in the incision laterad of the second pair of lobes; a pair of short pointed plates in the incision between the median lobes; a plate and a pectinae between the median and the second pair of lobes, the plate located mesad of the pectinae; two coarsely furcated pectinae laterad of the second pair of lobes; dorsal setae large, long, prominent, situatel at the lateral base of each lobe, one one-half the distance to the cephalic margin of the pygidium; ventral setae situated on the ventral surface slightly laterad their corresponding dorsal ones; five groups 

of circumgenital pores; median group with four to eight orifices; anterior laterals with ten to fourteen; posterior laterals with eight to twelve; basal thickenings with anterior plates wide, heavy, and prominent, situated mesad of the anterior lateral group of circumgenital pores; posterior plates long, narrow, and situated mesad of the posterior group of circumgenital pores; calli with median plates at the meson forming an are of -a circle; lateral plates long, narrow, extending beyond the lateral extremity of the meirian plates, and parallel with the cephalic margin of the pygidium; four rows of dorsal oores; first row with two or three pores situated cephalad of the incision between the median and second pair of lobes; second row with eight to fourteen pores situated cephalad of the incision laterad of the third pair of lobes; third row with six to twelve pores situated one-third tine distance to the cephalic margin of the pygidium; and the fourth row with four to five pores situated tmo-thirds the distance to the cephalic margin of the pygidium; four groups of tubularia; first group with short ducts extending to the first row of dorsal pores and the second incision; second group laterad of the first, ducts long, extend to the second group of dorsal pores and the third incision; third group laterad of the second, tubules of two kinds, long, coarse, and short, fine ones, extend to the third group of dorsal pores; and the fourth group lies laterad of the third with two kinds of tubules, and extends to the fourth group of dorsal pores. Hosts.- Acer olanefolia, Fraxinus alba, Ribes (sp.), osage orange, Tilia americana, Tilic europes, and Viburnum opulus sterilis jpecimens studied were collected at Chicago, Glenview, Maywood, and Urbana.

This species is common around Chicagn, and in northern Illinnis. 



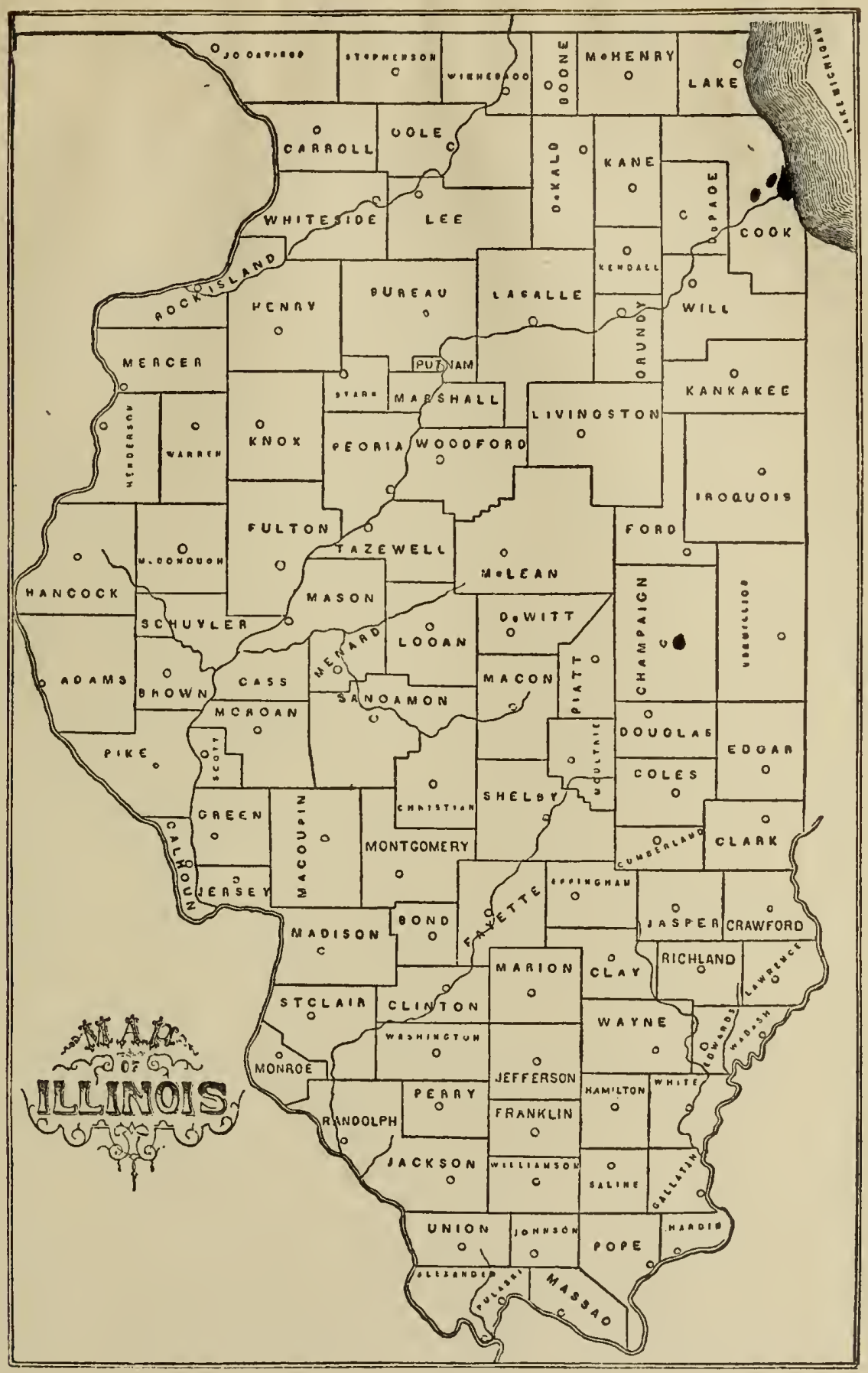

- Locations where Aspidintus ostraeformis was collected. 

Aspidiotus pernicosus.

pernicosus, Comstock, Report U.S. Dept. Agri., 1880-81, 304. pernicosus, Comstock, 2 Rep. Ent. Cornell Uni., 1883, 65. pernicosus, Howard, Can. Entom., 26,1094, 353. pernicosus, Felt, Bull. 46, IJ.Y. St. Mus., 1901, 004. pernicosus, Hebster, Bull. 73, Oh. Exp. St., 1896, 217. pernicasus, janders, Oh. St. Uni. Bull. (8) 17, 1904, 65. Scale of female.- scale circular, slightly convex, 1.10 to 2.00 $\mathrm{mm}$ in diameter, in great part gray or dark gray, with a central reddish, covered nipple-shaped exuvia surrounded by a depressed ring. The depression surrounding the exuvia is characteristic of this species.

Female.- Body color light orange or yellow in living individuals circular in outline, segmentation indicated along margin by slight indentations: pygidium with two pairs of well developed lobes, median lobes large, prominent, broady rounded, notched at each comer, and convergent at the apex; second pair of lobes one-third to onehalf as wide as and two-thirds as long as the median lobes, located adjacent to the median pair, distinctly notcheì near the middle of the oblique distal margin, caudo-mesal angles pointed and converging toward the median lobes; mesal margins of the median lobes with club-shaped thickenings; incisions with margins with thickened edges lateral thickening one-half to two-thirass the size of the mesal one; median incision with two plates or pectinae; second incision with two pectinae, third incision with three pectinae; a peg-shaped projection of the body-wall immediately laterad of the third incision; three wide flat extensions of the body-wall cne-third the distance to the cephalic margin of the pygidium, the caudal one trifurcate, 

cephalic ones bifurcate; dorsal setae situated at the lateral base of each lobe, one one-third and one twe-thirds the distance to the cephal. ic margin of the pygidium; ventral setae on the ventral surface located slightly laterad the corresponding dorsal setae; anterior and posterior basal thickenings of each side fused forming an S-shaped process; calli with the transverse median plates fused with the meson; lateral plates smaller and narrower than the median plates; circumgenital pores wanting; two rows dorsal pores; first row contains three to five pores, second row two to five; three paired groups of tubularia; median group of six tubules located cephalad of the anus with ducts leading to the incising betreen the median lobes; second group laterad of the anus, ducts lead to the second incision and the first row of dorsal pores; thirả group laterad of the second, ducts Inng and lead to the third incision and the second row nf dorsal pores Hnsts.- Apple, canoe birch, Cydonia japonica, Camperdown elm, Cornus alba siberica, Cornus (sp.), grape, juneberry, nsage orange, peach, pear, plum, Prunus pissardi, Rosa rugosa, Ribes (sp.), Rhamnus frangula, Rhamnus (sp.t, mountain ash, sweet cherry, Ulmus americana, sumac, Wheatleii elm, and Tilia americana.

specimenis from Astoria, Belleville, Bloomington, Champaign, Chicago, Dalton, Danvers, Jecatur, Dix, Glenviev, Hopedale, Joliet, Kankakee, Ia salle, Kell, Moline, Hount Pulaski, Mount sterling, Iashville, Nauvoo, Nebo, Normal, Palmyra, Quincy, Roseland, Springfield, Texico, Virginia, Waverly, and Vestern springs were studied.

This species is very destructive to the host plant and is of great economic importance. The species is generally distributed throughout the state, however, it is most serious in the southern one-half. 



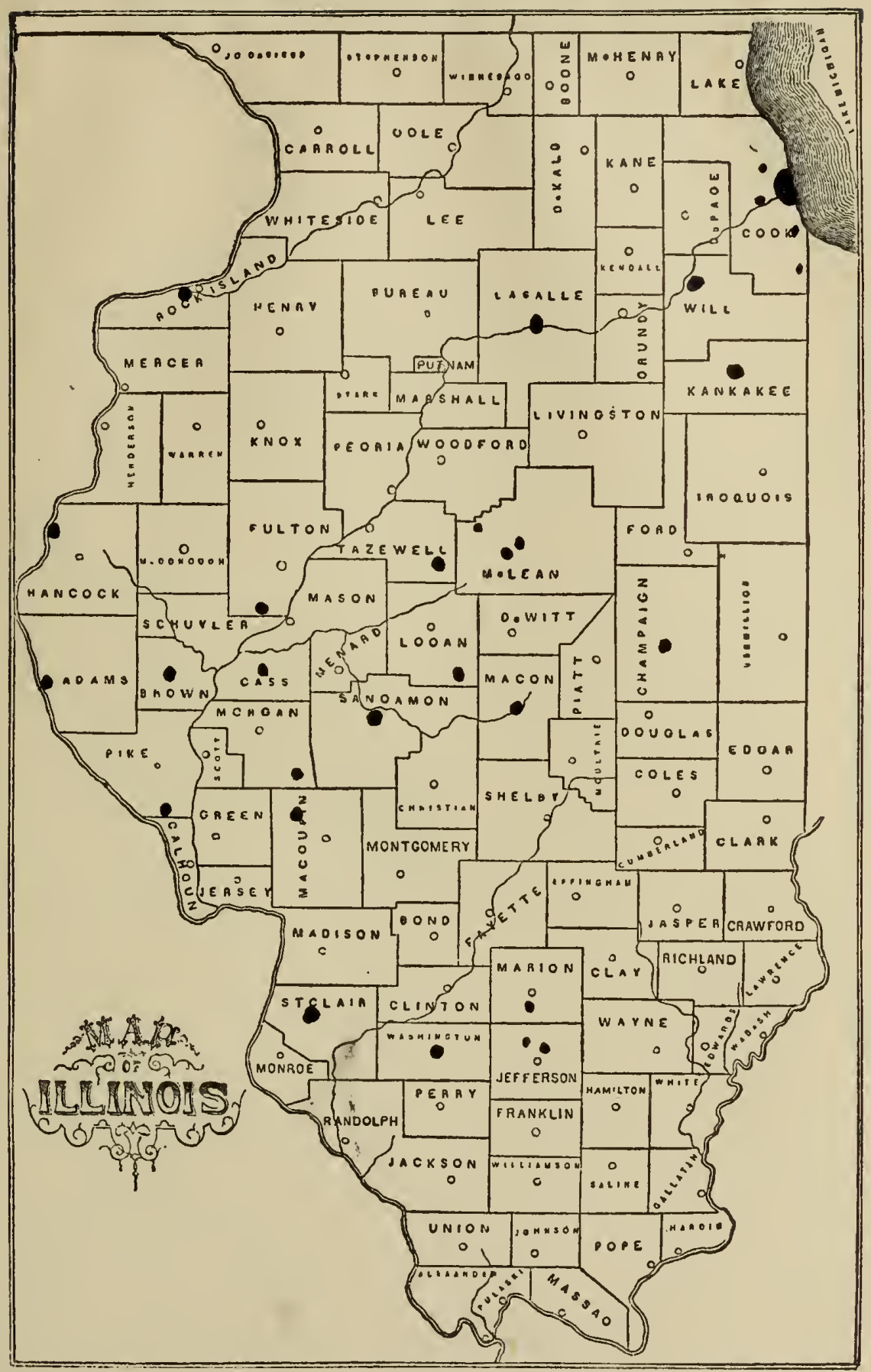

Locations where Aspidintus peraicosus was collected. 

Aspidiotus ulmi, Johns., Bull. Ill. St. Lab. N.H., 4, 1896,388. Aspidiotus ulmi, jenders, Oh. st. Uni. Bull. (8) 17, 1904, 67. Aonidella ulmi, Leonardi, Gen, e ispec. Jiaspiti, Asp., 1900, 10. Scale of Female.- Scale circular or nearly so, slightiy convex, 1.30 to $1.60 \mathrm{~mm}$ in diameter, light gray to tan color; tanned only winen found under an overhanging fragment of bark; exuvia orange red, dirty gray in old specimens, slightly eccentric, covered; ventral scale well developed, snow-white; adheres to bark after insect has insects

been removed making presence of scald quite conspicuous.

Female.- Body color light yellow in living individuals, in very old specimens the bodyl few shades darker, circular to oval; pygidium with two pairs of lobes; median lobes large, well developed, prominent, about as wide as long, mesal margins parallel for almost the entire length of the lobe, lateral margin distinctly notched; second pair of lobes small or rudimentary; incision between the median lobes small; second incision laterad the median lobes deep and narrow; third incision cephalo-laterad of the second, as wide as but much more shallow than the second; a pair of small chitinous thickenings in the incisicn jetween the median pair of lobes; a pair of paraphyses-like thickenings in the second incision, the mesal one about three times as large as the lateral, and balloon-shaped; a pair in the third incision, mesal one distinctly curved at its mesocephalic end, and much loner and wider than the lateral one; plates and pectinae absent between the median pair of lobes; a pair of plates extenaing/caudad of the second incision; and four plates cephalo-laterad of the third incision; dorsal setae large, prominent, 

one at the lateral base of the median lobes, one between the second and the third incision, and two laterad of the third incision; the ventral setae located on the ventral surface slightly laterad of the corresponding dorsal setae, except the one on the median pair of lobes; circumgenital pores wanting; basal thickenings with the anterior and posterior plates of each side fused, the caudaI portion with a distinct arm extending caudo-laterad; calli with median plates separate, arranged in a subtransverse row parallel with the cephalic margin of the pygidium; three rows dorsal pores; first row with three or four pores located cephalad of the second incision; second with five to eight pores located cephalad of the third incision; and the tilid row with four to six pores loceted caudo-mesad of the fourth dorsal setae; three distinct groups of tubularia; first group situated caudo-mesad of the basal thickenings, tubules long, slender and extend to the first row of dorsal pores;second group laterad of the basal thickenings, trbules long, slender, and extent to the second row of dorsal pores; third group cephalo-laterad of the second tubules long, slender, and extend to the third row of dorsal pores. Hosts.- joft maple, catalpa, Ulmus americana.

specimens collected at Champaign and Urbana were studied.

This species was found in Uhampaign and Urbena near the University campus heavily infesting the trunk of the host. The presence of the scale is made very conspicuous by the presence of the white ventral scale which adheres to the bark of the host after the insect has been removed. The species is probably not generally distributed over the state, and is not of any great economic importance. 



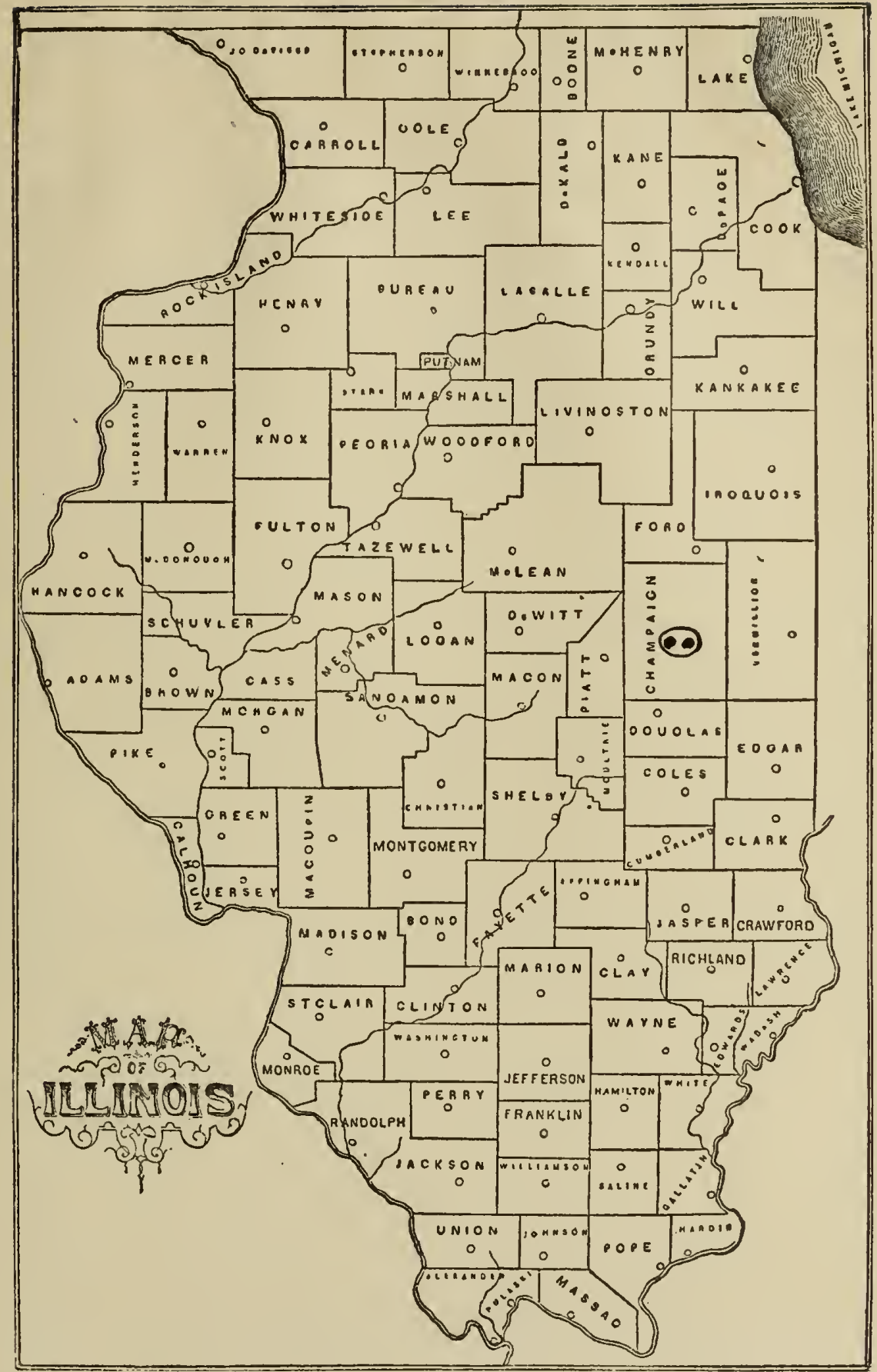

Locations where Aspidintus ulmi was collected. 

Chrysomphalus obscurus.

Aspidiotus obscurus, Comst., Rep. U.s. Dept. Ag., 1880, 303. Aspidiotus obscurus, Hunter, Kans. Uni. Quarterly, 8, 1899, 7. Asnidiotus obscurus, Eunter, Eans. Uni. Quarterly, 9, 19r0,107. Chrysomphalus obscurus, san., Oh. Uni. Bul1. (80 17, 19n4, 72. scale of female.- scale circular, slightly convex, 2.75 to $3.00 \mathrm{~mm}$ in diameter, dark gray in color, exuvia siligtly eccentric, nipple-like and surraunded by a rather indistinct ring, ventral scele àistinct.

Female.- Body reddisin brom in living individuals, 2.50 to $2.80 \mathrm{~mm}$ long, 2.60 to $2.30 \mathrm{~mm}$ mide, segmentation ot ine body indistinct, distinct aivision between the pygidium and the remainder of the body; pygidium with three vairs of well developed lobes; median Inbes large, broady rounded at the apex, mesal margins fused for about two-thirds their length, aistal margin witi a silgnt lateral notch; second pair of looes subequal to the median pair, distal margin bluntly pointed, lateral margin oblique and with four or fivo distinct notcheg; third pair of lobes as Inng as but slightly narrower than the second pair, distal margin bluntly pointod, lateral margin oblique witi tiree small indistinct notches: pygiaial margin with a thickened dentate lobe-like projecticn laterad nf the thira pair of lobes; pygidium with seven paraphyses on each side; two jetween the median and the second pair nf lobes, the mesal one twice as long as the lateral, three between the second and the third pair of lobes, the luteral and mesal about one-half as long as the middle one, and a pair of subequal ones latered nf the third pair of lobes; a pair of thickened. paraphyses-like prooesses between 

the bases of the median lobes; a single bifurcated or trifurcated pectinae jetween the median lobes, one between the median and the second pair of lobes, two between the second and thira pair, and two coarsely furcated ones laterad of the third pair of lobes; a dorsal seta at the lateral base of the nedian lobe, one at the base of the second lobe, one laterad the third incision, and one near the midale oI the pygidial margin; ventral setae located on the ventral surface laterad of their corresponding dorsal setae; five grovos nf circumgenital pores; median groun of three to six orifices, anterior laterals eight to twelve, postorior laterals five to seven; three rows of dorsal pores, anterior group of the first row wanting, posterior group consists of four to vix orifices, second row consistw of twelve to thirty-four orifices, divided into two groups, pores in the posterior group are round and those in the anterior group are oval, thira row contains four to eight orifices divided in to two groups; three oaired groups of tacularia, the median group with short ducts which extend to the first group of dorsal pores, ducts of the second group are long and extend to the secona group of ârsal pores and the second incision, and the thira group consists of about one-half as many tubules as the second, ducts similar in form to tirose in the second group and extend to the third grcup of dorsal pores and the third incisinn; basal trickenings indistinct and in two groups; calli with median plates lone, straight, and transverse, lateral plates sinuate, subequal in length to the median and oblique to them.

Hosts.- Chestnut nak, hickory, white oak, black oak, nak (sp.) 


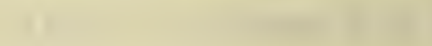


specimens from ilacomb, Millstadt, Hormal, Riehl, Starved Rock, and Texico were studied.

This species is found generally throughout the state and occurs abundantly in the forests. It does not appear to do a great deal of damage or even to seriously retard the growth of the host plant. 



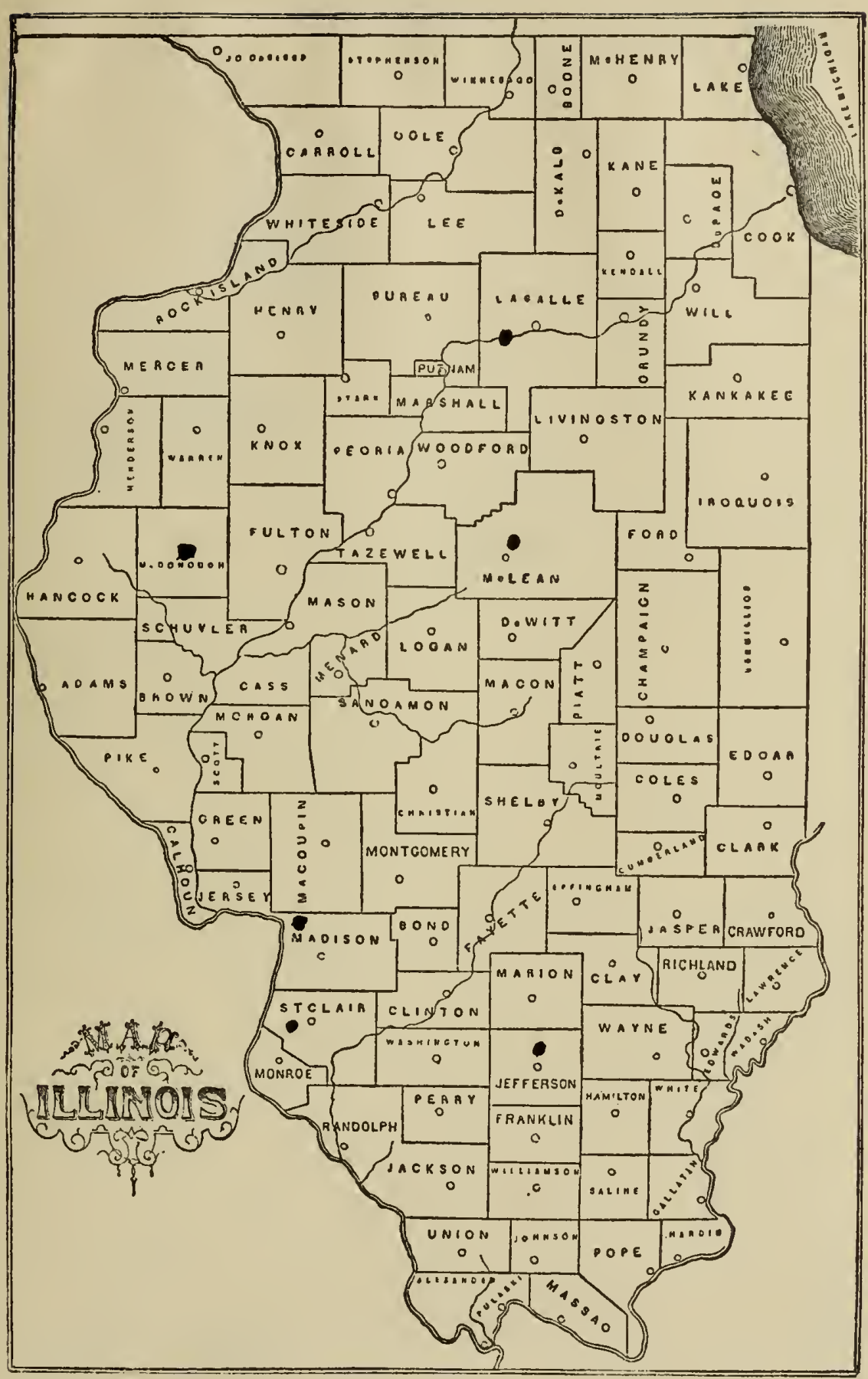

Locations where Chrysomphalus obscurus was collected. 



\section{ACKIN HLEDGEMENTS.}

This investigation was carried on under the direction of Dr. A.D. Mackillivray and to him I am indebted for many valuable suggestions and the unlimited use of his unpublished table for the classification of the Coccidae. To Dr. J.T. Folsom I orre many thanks for the sosistance he has at times given me. I am especially indebted to Dr. S.A. Forbes for the free access to the collection of Coccidae in the Illinois state jaboratory of Natural History. I am also indebted to $\mathrm{Nr}$. P.A. Glenn for specimens of the Coccidae which he has given me. 

116 
Explanation of Plate No. 1. (Aspidiotus so.)

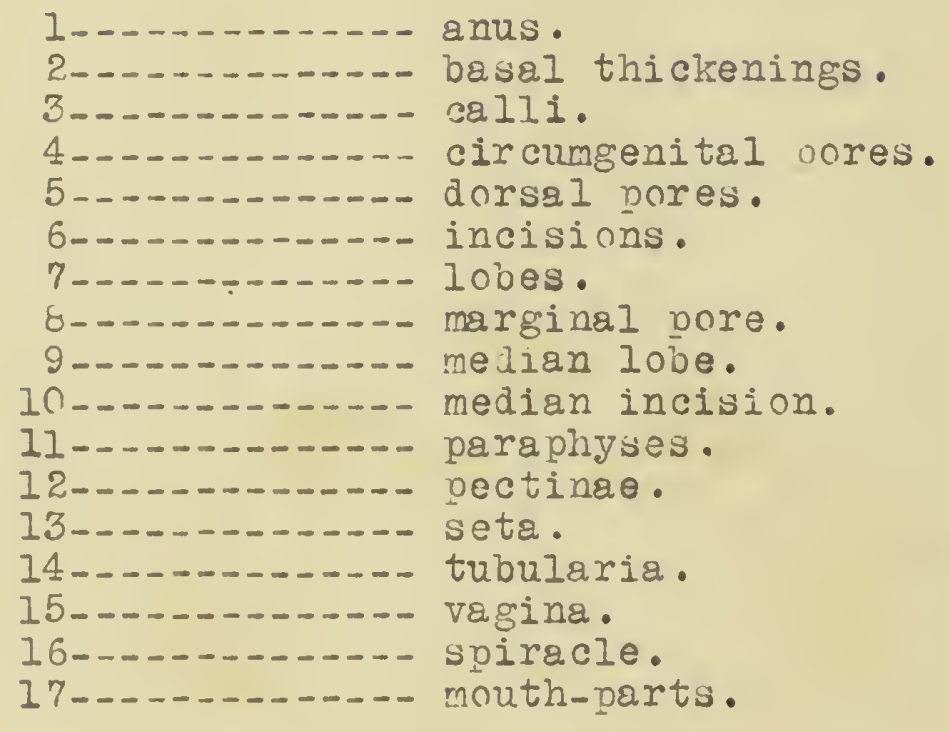



\begin{tabular}{rr}
117 & 17 \\
\hline
\end{tabular}

(1)


Explanation of Plate Io. 2. (Chionaspis sp.)

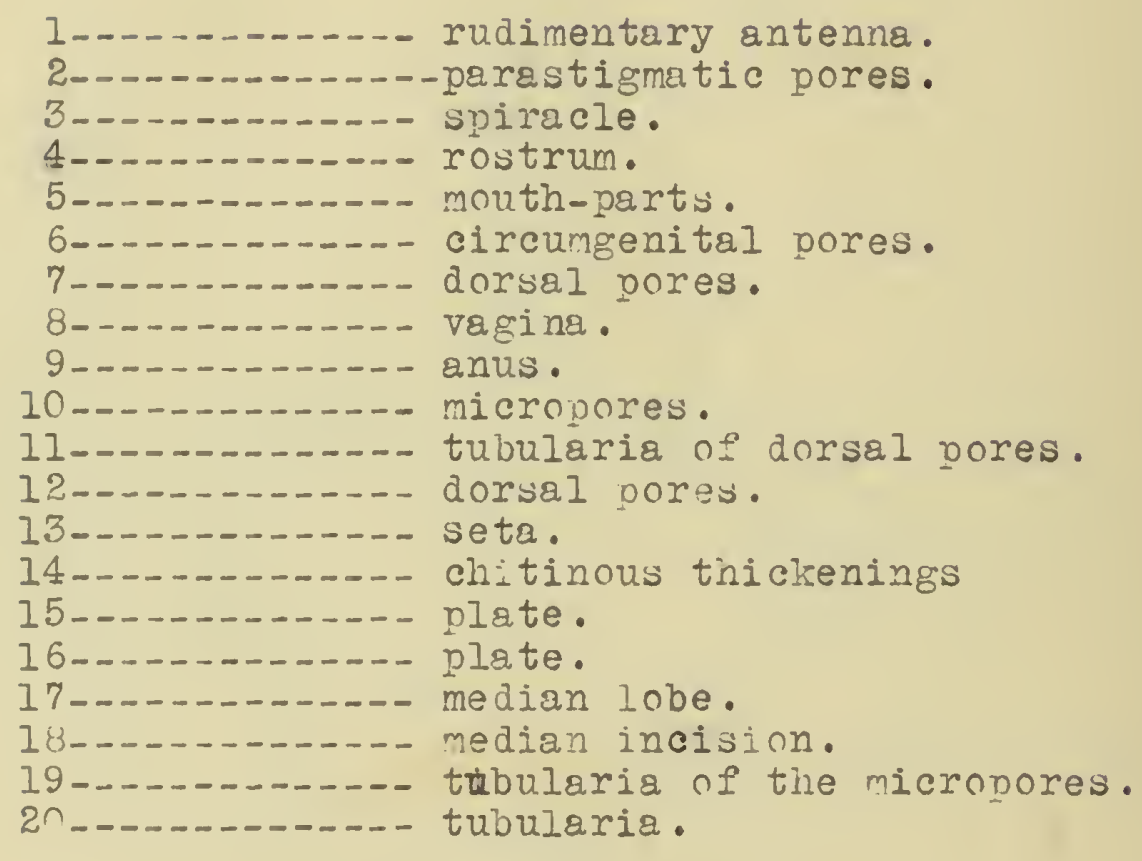




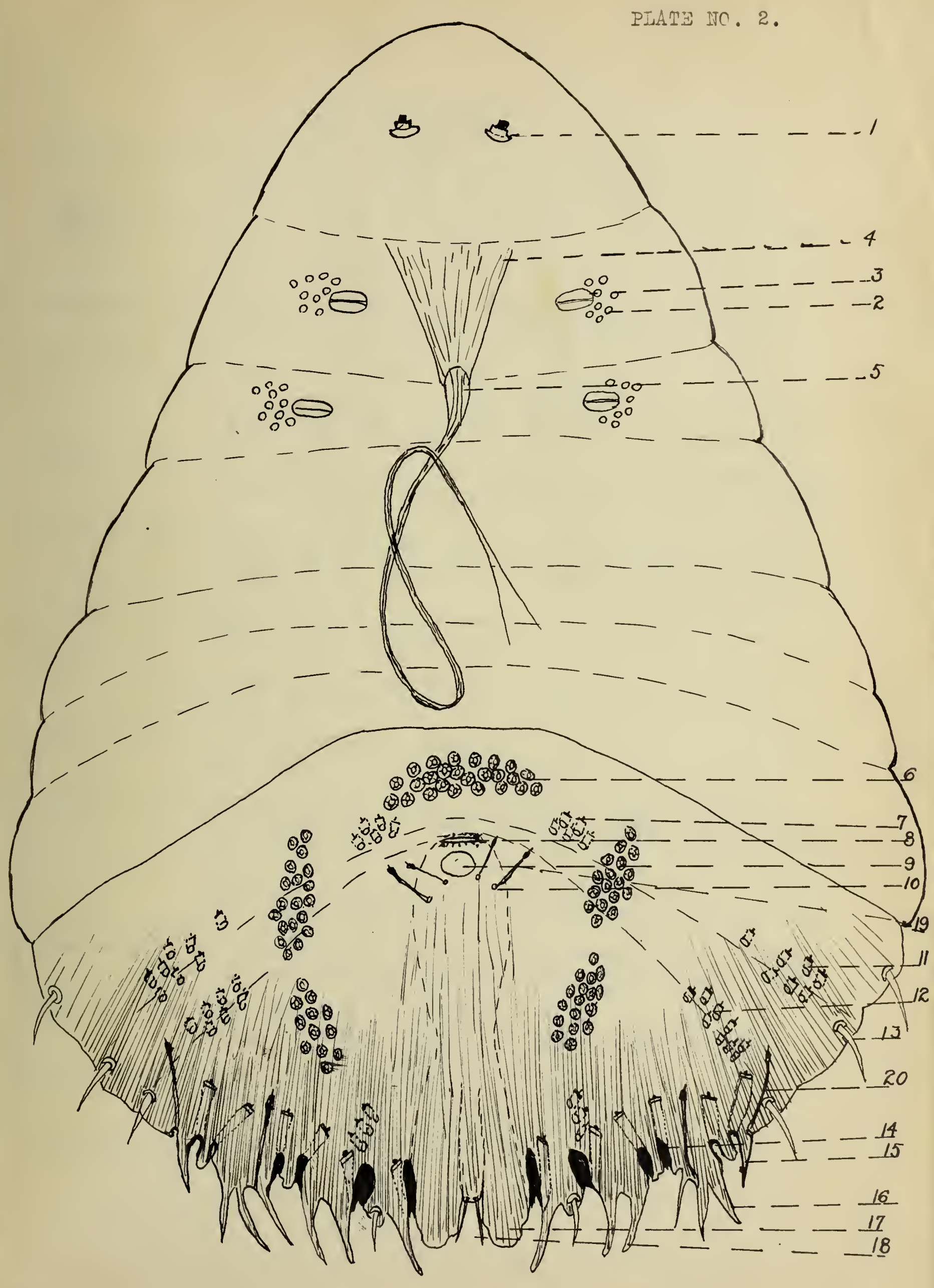



IX. BIBIIOGRAPHY.

Ashmead, $\mathbb{V} \cdot$ H.,- A Generic Jynopsis of the Cnccidae.

Trans. Am. Entom. Soc.,18, 1891, 92---102.

Cockerell, T.D.A.,- Tables for the Determination of the Coccidae. Can. Entom., 31, 273.

Comstock, J.H. and A.B.,- A Manual for the study of Insects. Ithaca N.Y., 7tin Ed. 1907, 80, 148--174.

Comitock, J.H.-Rept. U.S. Dept. Agri., 188C_-81, 276_-349.

Second Report of scale Insects.

Rept. Cornel1 Uni. Exp. St., II, 1883, 47--147.

Cooley, R.A.-The Coccid Genera Chionaspis and Hemichionaspis. Hatch Exp. st. Hass. Agri. Coll., 1899. Spec. Bull.

Fernald, Mrs. H.P., A Catalog of the Cnccidae of the lorld. ipec. Bull. Hatch Exp. ist., 88, 1903, 1--360. Authors a.., same title, Amherst, Ilass., 1903.

Green, R.E.,- The coccidae of Ceylon.

Pts. I-_-IV, Inndon, 1896 --1904.

Hunter, S.J.,- Coccidae of Kansas.

Kans. Uni. Quart., 8, 1, 1899.

Kuwana, s..I.,- The Coccidae of Japan.

3ro. Cal. Ac. śc., (E) 3, 1902.

Narlatt, C.I.,- New Jpecies of the Diaspinae scale Insects.

U.S. Dept. Agri.., Bur. Fntom., Tech. ser., 16 pt. $2--4,1908$.

National collection of Cocciade.

U.s. Dept. Agri., Bur. Entom., Tech. ser., 16, pt. 1,1908 .

Newstead,R., - A Mnograph of the Coccidae of the British Isles. Ray soe, London, London, 2 Vols. $8^{\circ}, 1900--1902$.

Maskell, W.M.,- Intes on the Coccidae.

Trans. Nev Zea. Ins., 28 and following volumins.

sanders, J.G.,- Coccidae of Chio?

Ohio state Uni. Bull., (8) 17, 1904,

Signoret, V.,- Essei sur les Cochinelles.

Ann. Soc. Ent. Fr. , 1868-.-1876. 


UNIVERSTTY OF ILLINOIS-URBANA

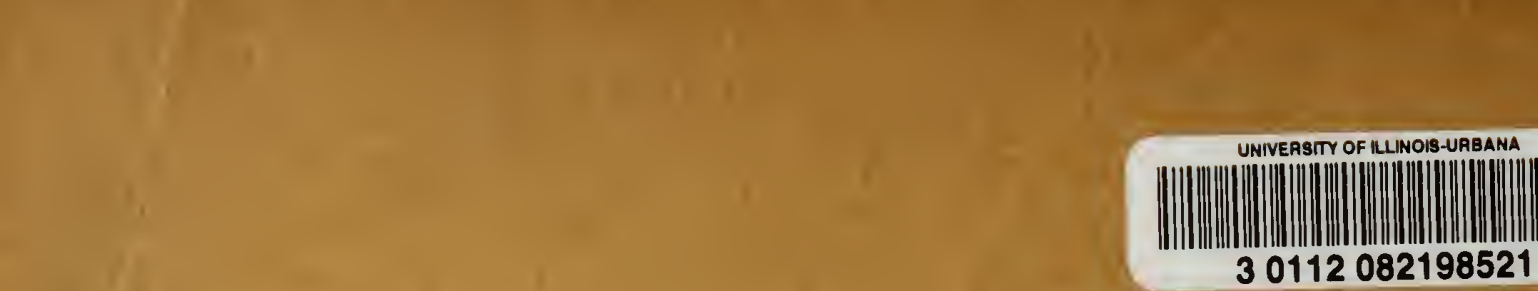

